\title{
A Review on the Chemistry of Eremanthine: A Sesquiterpene Lactone with Relevant Biological Activity
}

\author{
José C. F. Alves \\ Departamento de Química, Instituto de Ciências Exatas, Universidade Federal Rural do Rio de Janeiro, \\ 23890-970 Seropédica, RJ, Brazil \\ Correspondence should be addressed to José C. F. Alves, alvesjcf@yahoo.com.br
}

Received 10 December 2010; Accepted 2 February 2011

Academic Editor: Bill Baker

Copyright ( $\odot 2011$ José C. F. Alves. This is an open access article distributed under the Creative Commons Attribution License, which permits unrestricted use, distribution, and reproduction in any medium, provided the original work is properly cited.

The several aspects on the chemistry of eremanthine such as isolation, structural classification, biological activity, synthesis, and chemical transformations in other sesquiterpene lactones are described in this review. The main publications on this sesquiterpenolide, from its isolation of natural sources in 1972 to the current days, are included.

\section{Introduction}

Eremanthine (1) (Figure 1) is a sesquiterpene lactone abundantly found in the Brazilian Compositae (Asteracea) Eremanthus elaeagnus [1] and Vanillosmopsis erythropappa [2] (Eremanthus erythropappus) [3]. This compound is a target for studies because of its biological properties, structural complexity due to the presence of a flexible seven-membered ring in its skeleton, as well as for the possibility to transform it in other potentially bioactive sesquiterpene lactones.

This review is composed by five items which include the isolation, structural classification, biological activity, synthesis, and chemical transformations of eremanthine. The main publications on this sesquiterpenolide from its isolation of natural sources in 1972 to the current days are described in the present review. Special attention is given to the synthetic studies that were developed aiming at the preparation of potentially bioactive sesquiterpene lactones.

\section{Isolation of Eremanthine}

The search, here in Brazil, for plant-derived inhibitors against infections by cercariae of Schistosoma mansoni led to the isolation and characterization of eremanthine (1) from the oil of the Compositae Eremanthus elaeagnus and Vanillosmopsis erythropappa in 1972 [1,2]. The extraction of crude oil from these vegetable species was made through the classic method of infusion of the pulverized trunk wood in organic solvent, at room temperature, followed by the evaporation stage of the extractor solvent under reduced pressure. Therefore, after evaporation of hexane that was used to extract the oil of Eremanthus elaeagnus and subsequent stage of crystallization of the crude oil with the same solvent, eremanthine (1) was obtained as colorless needles with melting point $73-74^{\circ} \mathrm{C}$ and $[\alpha]_{D}^{29}-59^{\circ}$ (c 1.0 in $\mathrm{CHCl}_{3}$ ) [1]. This value of specific optical rotation was later corrected as it is going to be described soon afterwards in this review. In the case of the hexane concentrated extract obtained from the extraction of the Vanillosmopsis erythropappa oil, eremanthine (1) was obtained after elution over column chromatography of silica gel [2]. The physical data of eremanthine obtained from Vanillosmopsis erythropappa were identical to the ones of eremanthine obtained from Eremanthus elaeagnus. The only structural feature not determined in those works published in 1972 was the absolute configuration at the carbon C-1.

It was demonstrated in 1974 that vanillosmin, isolated from Vanillosmopsis erythropappa by a research group in Italy [4], also had the same structure of eremanthine (1). In this case, the oil of that vegetable species was obtained from the acetone concentrated extract of the pulverized trunk wood in infusion, followed by the subsequent stages of treatment with a mixture of $\mathrm{MeOH}-\mathrm{H}_{2} \mathrm{O}$ and extraction with petroleum ether. The concentrated oil obtained after 


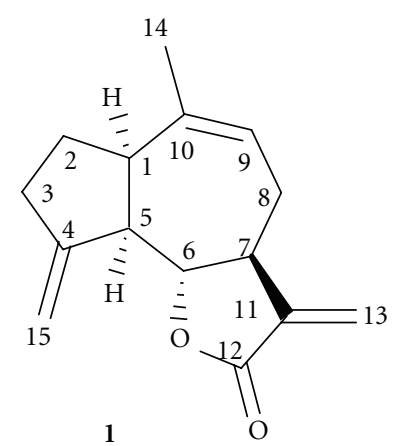

FIGURE 1: Structure of eremanthine (1).

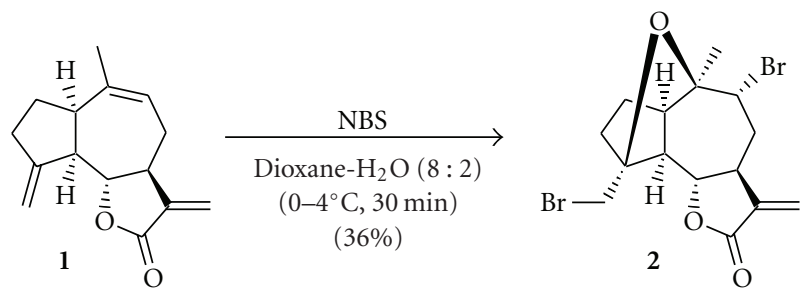

Scheme 1: Synthesis of the dibromoether 2.

these stages was eluted over column chromatography of silica gel impregnated with $\mathrm{AgNO}_{3}$ to furnish vanillosmin that was crystallized in hexane as long needles with melting point $62-62.5^{\circ} \mathrm{C}$, boiling point $175-180^{\circ} \mathrm{C} / 0.2 \mathrm{~mm}$, and $[\alpha]_{D}^{20}-110^{\circ}$. There were elucidated in that work the absolute configurations at $\mathrm{C}-1$ and $\mathrm{C}-5$ as being both $R$, on the basis of a series of chemical reactions.

The 1,5-cis-fused bicyclo[5.3.0] decane skeleton for $\mathbf{1}$ was confirmed by Garcia et al. [5] through the formation of dibromoether 2 when eremanthine (1) was treated with $N$-bromosuccinimide in dioxane containing $20 \%$ of water (Scheme 1). There was demonstrated through threedimensional analysis of $\mathbf{1}$ that the formation of an ether linkage between the $\mathrm{C}-4$ and $\mathrm{C}-10$ positions was possible only if the five- and seven-membered rings were cis-fused. As the name eremanthine for $\mathbf{1}$ has historical precedence over vanillosmin the latter name passed no longer to be used. It was demonstrated in that work published by Rabi et al. [5] that the value of specific optical rotation previously calculated $[\alpha]_{D}^{29}-59^{\circ}\left(\right.$ c $\left.1.0, \mathrm{CHCl}_{3}\right)$ [1] was incorrect. A new determination was made and it was obtained $[\alpha]_{D}^{23}-111.7^{\circ}$ (c 1.0, $\mathrm{CHCl}_{3}$ ) being, therefore, in agreement with the value of $[\alpha]_{D}^{20}-110^{\circ}$ described in [4].

In 1985 Lima et al. [6] published a selective method for extraction of $\alpha$-methylene- $\gamma$-lactones from Vanillosmopsis erythropappa. The oil of that vegetable species was obtained by the procedure of infusion of the pulverized trunk wood left in contact with hexane and then in ethanol. After evaporation of the extractor solvents, it was obtained an oil resultant from the hexane extract and another of the ethanol extract. The ethanolic extract furnished a dark oil that was exhaustively extracted with hexane to afford an oil.
The aliquots of each oil were soon afterwards submitted to the separation procedure of $\alpha$-methylene- $\gamma$-lactones from the other chemical substances of the crude extracts. Such procedure used the property of the unsaturated $\gamma$-lactones undergo facile 1,4-addition with nucleophilic substances. The sequence of reactions that was used to obtain eremanthine (1) for this procedure is outlined in Scheme 2. For this procedure the crude extract from Vanillosmopsis erythropappa, containing $\alpha$-methylene- $\gamma$-lactones (3) in mixture with other substances, was dissolved in EtOAc and then submitted to reaction with aqueous solution of dimethylamine. The obtained mixture, containing the adducts of dimethylamine (4) together with other substances, was diluted with EtOAc and then washed with water. The separated and concentrated organic layer was submitted to reaction with acetic acid to furnish the acetates 5 in mixture with other substances. The acetates were extracted with water and the aqueous phase was washed with EtOAc, neutralized with saturated solution of sodium carbonate, and then reextracted with EtOAc. The mixture of the adducts of dimethylamine (4) was submitted, soon afterwards, to reaction with MeI to generate a mixture of iodides (6). Saturated solution of sodium carbonate was added and let to react at room temperature for 1 hour to the elimination reaction of the quaternary adducts of trimethylamine. There was obtained, after extraction of the last reaction, an exclusive mixture of $\alpha$-methylene$\gamma$-lactones (3). Filtration of this mixture of $\gamma$-lactones over column chromatography of silica gel, followed by crystallizations, furnished eremanthine (1) as majority product as well as the minority $\alpha$-methylene- $\gamma$-lactones shown in Figure 2.

Due to the importance of bioactive chemical substances present in the crude extract from Vanillosmopsis erythropappa (Eremanthus erythropappus), tree popularly known by the name of candeia, nowadays a plan to conserve this forest species is being developed [7, 8]. The wood obtained in the forests of candeia is mainly sold for the industries of essential oils [9] that extract the crude oil through the steam distillation process. For that process, the pulverized trunk wood of Eremanthus erythropappus is put inside chemical reactors of high pressure and then it is heated at high temperature with water. The steam generated in the reactors passes, soon afterwards, for industrial condensers where it is cooled and then a mixture of oil and water is collected. The densest substance (water) is removed from the mixture to furnish the concentrated oil of Eremanthus erythropappus which is mainly sold for the industry of cosmetics that uses another important chemical substance found in that oil, the $\alpha$-bisabolol (20) [10] (Figure 3). The use of the concentrated oil from Eremanthus erythropappus, extracted for the modern industrial method, certainly gives good results for isolation of eremanthine (1). Another recent method to extract the oil from Eremanthus erythropappus, using the supercritical extraction process and phase equilibrium of candeia oil with supercritical carbon dioxide, was reported by de Souza et al. [11].

2.1. Determination of the Absolute Stereochemistry of Eremanthine. The absolute stereochemistry of eremanthine (1) (vanillosmin) at the chiral carbons C-1, C-5, C-6, and C-7 


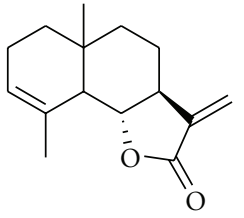

$\alpha$-Cyclocostunolide (7)<smiles>C=C1C(=O)O[C@@H](CC(C)=C/C=C\CC)[C@@H]1C</smiles>

Costunolide (11)

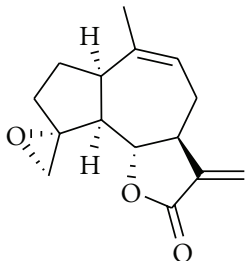

4,15- $\alpha$-Epoxieremanthine (8)

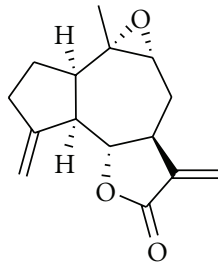

9,10- $\alpha$-Epoxieremanthine $(9)$

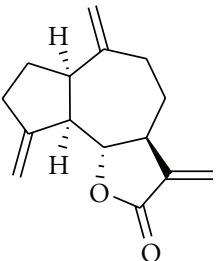

Dehydrocostus lactone (10)

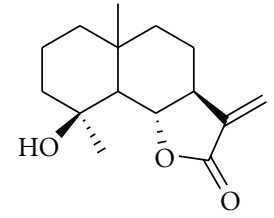

4-epi-Arbusculin A (16)

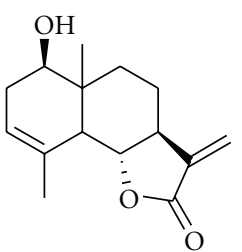

Reynosin (12)<smiles>C=C1C(=O)O[C@H]2C1CCC1(O)C(O)CCC(=C)C21</smiles>

Santamarin (13)<smiles>C=C1C(=O)O[C@@H]2C3=C(C)CCC(O)C3(O)CCC12</smiles>

Magnolialide (14)<smiles>C=C1C(=O)O[C@H]2C1[C@H]1CCC3(C)CCC[C@@](C)(O)C213</smiles>

Arbusculin A (15)

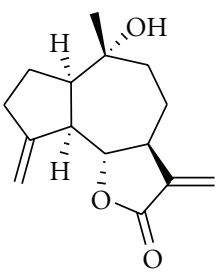

Trifloculoside (17)

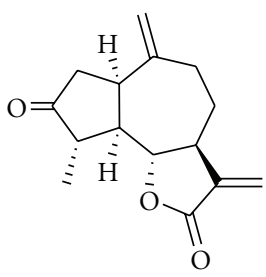

Estafiatone (18)

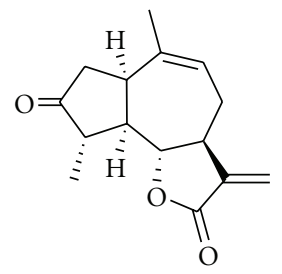

Eregoyazin (19)

FIgURE 2: Minority $\alpha$-methylene- $\gamma$-lactones isolated from Vanillosmopsis erythropappa.

was determined through the correlation of derivatives from the substance 1 with other lactones that possess known absolute stereochemistry in these positions. The sequences of reactions that were employed by Corbella et al. [4] to synthesize the substances used to determine the absolute stereochemistry of eremanthine are outlined in Schemes 3-8.

As the most guaianolides possess cis fusion in the fiveand seven-membered rings at the hydroazulene system, there was initially attributed the stereochemistry of eremanthine in those centers as shown in the chemical structure 1. Reaction of substance 1 with $\mathrm{NaBH}_{4}$ generated a single product characterized as the lactone $\mathbf{2 1}$ (Scheme 3 ). Reduction of this substance with hydrogen and soluble Wilkinson's catalyst furnished a product identified as the compound 22 . Hydrogenation of 22 in EtOAc with $\mathrm{H}_{2}$ and $\mathrm{Pd}$ resulted in isomerization of the double bond $\mathrm{C} 9-\mathrm{C} 10$ to the tetrasubstituted position C1-C10 to afford the compound $\mathbf{2 3}$ as the main product of that reaction. In the following stage, the compound $\mathbf{2 3}$ was synthesized starting from $O$-acetylisophoto- $\alpha$-santonic lactone (24) (Scheme 4).

Catalytic hydrogenation of lactone $\mathbf{2 4}$ furnished the compound 25 of known absolute stereochemistry. Reaction of substance 25 with 1,2-ethanedithiol and $\mathrm{BF}_{3} \cdot \mathrm{OEt}_{2}$ furnished thioacetal 26, resultant from the protection of carbonyl group at C-3 position and elimination of acetic acid.
Reductive removal of the thioacetal $\mathbf{2 6}$ with Raney-Nickel generated a compound identified as the substance 23, previously obtained from eremanthine (1).

To ensure that the acid treatment of the lactone 25 (Scheme 4) did not affect the configuration of the methyl at C-4, that is more stable in the alpha position than in the beta position, the C-4 epimer of compound 23 was prepared as described in Scheme 5. Alkaline treatment of the lactone $\mathbf{2 5}$ generated the compound $\mathbf{2 7}$ resultant from the hydrolysis of the acetate and epimerization at C-4 position. Thioacetalization of compound 27 furnished two products: one of them, the compound $\mathbf{2 8}$, stayed with the hydroxy group at C-10 and the other, the compound 29, resultant from elimination of water. Desulphurization of the thioacetal 29 generated the lactone 30, whose physical data were different from those of the lactone $\mathbf{2 3}$ obtained from eremanthine (1) (Scheme 3). This correlation confirmed the structure proposed for the compound 23 and established the absolute configuration at C-5, C-6, and C-7 positions of eremanthine as shown in the chemical structure $\mathbf{1}$.

To determine the absolute stereochemistry at C-1 position of eremanthine (1), the reactions outlined in Schemes 6-8 were performed. Starting from tetrahydroeremanthine (22), obtained from eremanthine (1) (Scheme 3), the oxymercuration-desmercuration reaction shown in 

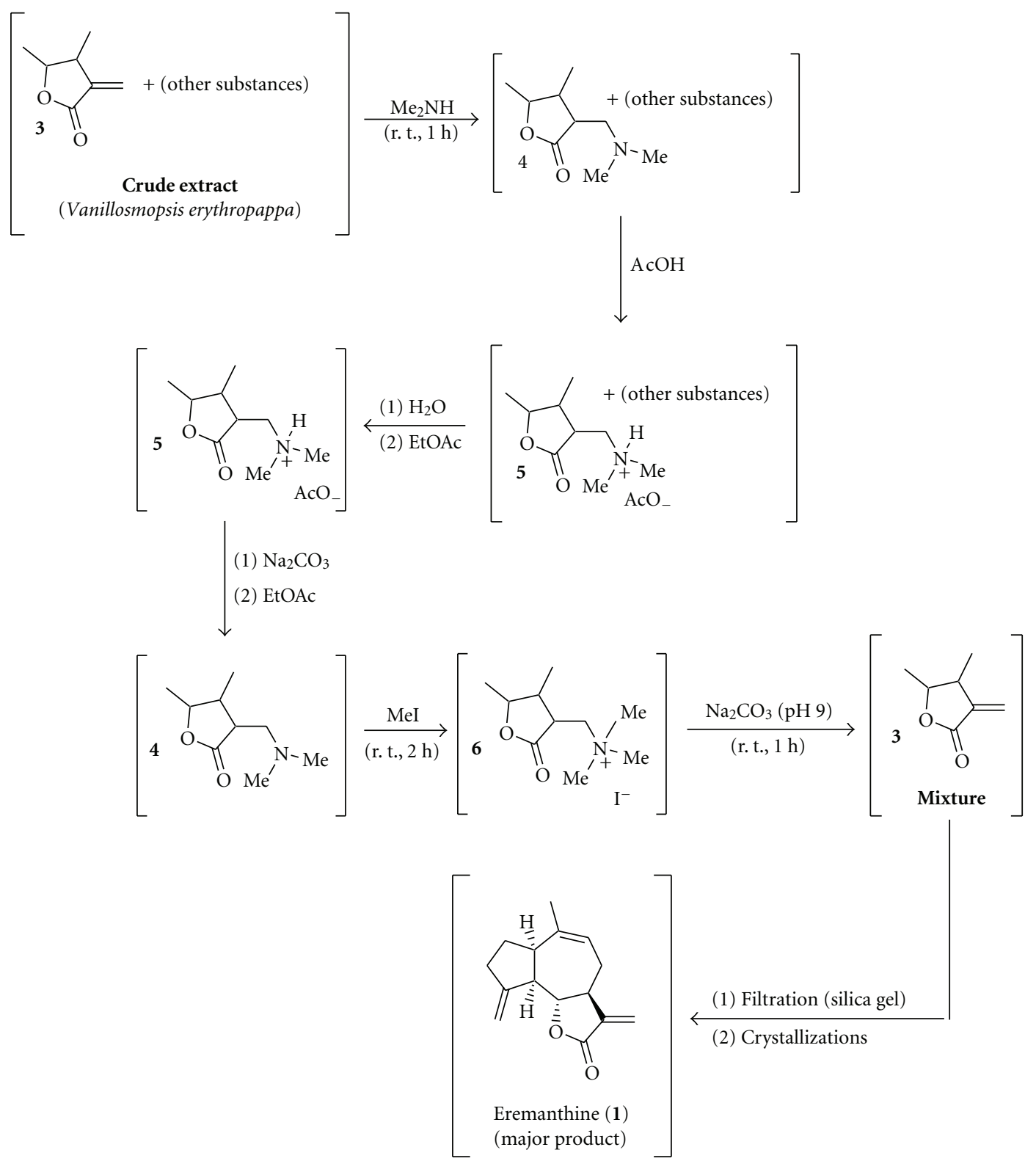

Scheme 2: Sequence of reactions used for the selective isolation of $\alpha$-methylene- $\gamma$-lactones from Vanillosmopsis erythropappa.

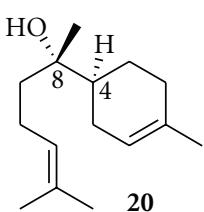

FIgURE 3: Structure of (-)- $\alpha$-bisabolol (20).

Scheme 6 was performed and two isomeric hydroxy-lactones 31 and 32 were obtained in the proportion of $(1: 12)$. The chemical structure of the substance $\mathbf{3 1}$ was confirmed through the synthesis depicted in Scheme 7.

Alkaline hydrolysis of the acetate $\mathbf{2 4}$ generated the lactone 33 (Scheme 7) that was submitted to catalytic hydrogenation to furnish the dihydroderivative 34. Treatment of this compound with etanedithiol and $\mathrm{BF}_{3} \cdot \mathrm{OEt}_{2}$, at low temperature, generated the thioacetal 35. This compound was reduced with Raney-Nickel to afford a product whose physical data were identical to those of the hydroxylactone $\mathbf{3 1}$ derived from tetrahydroeremanthine (22).

The most abundant product of the oxymercurationdesmercuration reaction on tetrahydroeremanthine (22) was the hydroxy-lactone 32 (Scheme 6), which is the C-10 epimer of substance 31 . To ensure that the configuration at C-10 was the only difference between the structures 31 and 32, the product 31 obtained from the conditions described in Scheme 7 was submitted to dehydration with thionyl chloride and pyridine at low temperature (Scheme 8). The anhydroderivative 36 obtained in that reaction was 


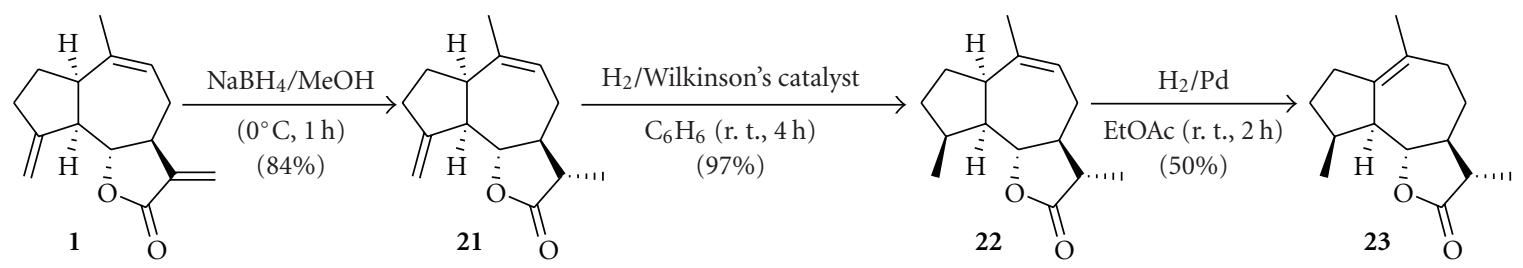

Scheme 3: Synthesis of the lactone 23 starting from eremanthine (1).

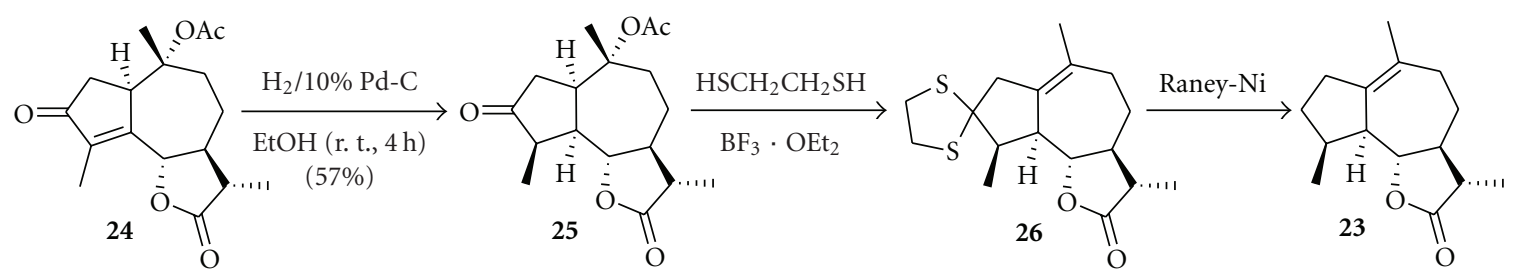

Scheme 4: Synthesis of the lactone 23 starting from $O$-acetyl-isophoto- $\alpha$-santonic lactone (24).

submitted to subsequent stage of oxymercuration-desmercuration to furnish a compound identical in all its physicochemical properties to the hydroxy-lactone 32 . These results demonstrated that the hydrogen at C-1 position of eremanthine (1) has alpha configuration and, consequently, the absolute stereochemistry of this substance is in agreement with the chemical structure shown in Figure 1.

The absolute configuration of eremanthine (1) was also confirmed in an article published in 1999 by Yuuya et al. [12]. In that publication the guaianolide $\mathbf{1}$ was synthesized starting from the natural product $\alpha$-santonin.

\section{Structural Classification of Eremanthine}

Eremanthine (1) belongs to the class of substances denominated guaianolides. These substances possess the basic skeleton of bicyclo[5.3.0]decane, characteristic of the guaiane sesquiterpenes, to which was inserted at positions C-6 and C-7 or C-7 and C-8 a $\gamma$-lactonic ring (Figure 4).

3.1. The Biogenesis of Sesquiterpene Lactones. Guaianolides are biogenetically derived from the farnesyl pyrophosphate (37) that passed by cyclization to generate the cyclodecadiene 38. This intermediate undergoes enzymatic oxydations to yield the germacranolide (39), a presumed precursor of the skeleton of guaianolides (Scheme 9) [13]. A detailed study on the biogenesis of sesquiterpene lactones was reported by Fischer et al. [14].

The skeletons of sesquiterpene lactones, with lactonic fusion at C-6 and C-7 positions, derived from germacranolides and the respective references were described in the works of Ferreira's M.S. [15] and Fantini's Ph.D. [16]. In Scheme 10 are outlined such biogenetical relationships reported in those works.
The biogenetical hypothesis of the guaianolides formation and their transformation into pseudoguaianolides reported by Fischer et al. [14] is outlined in Schemes 11-14. It was formulated that the skeleton of guaianolides is formed by the cyclization of a germacranolide-4,5-epoxide (40) in a chair-like transition state (Scheme 11). The intermediate cisfused guaianolide cation (41) undergoes reaction with water to furnish the guaianolide $\mathbf{4 2}$ with cis fusion between the fiveand seven-membered rings that is, with rare exceptions, the stereochemistry found in the most guaianolides.

The biogenesis for the few trans-fused guaianolides found as natural products was proposed to proceed via either the melampolide-4,5-epoxide (43) or germacranolide4,5-epoxide (44) pathways (Scheme 12). The cyclization of these compounds should furnish the trans-fused guaianolide cation (45) which after reaction with water would result in the formation of the skeleton $\mathbf{4 6}$ with trans fusion between the five- and seven-membered rings.

The biogenesis for the pseudoguaianolides-denominated ambrosanolides, with $\mathrm{C}-10 \beta$ methyl group and lactonic ring at C-6 and C-7 positions with the C-6 oxygen at $\beta$ orientation, is outlined in Scheme 13. The cyclization of the germacranolide-4,5-epoxide (47) would give the cation guaianolide (48) which upon double hydride and methyl shift, as indicated by the arrows, gives the ambrosanolide skeleton (49). As all ambrosanolides possess cis lactonic fusion at C-6 and C-7 positions, it was proposed that a C-6- $\beta$-oxygen would be assisting the rearrangement step of the carbocation 48 to compound 49 . The intramolecular frontside stabilization of the cationic center at $\mathrm{C}-10$ by the $\mathrm{C}-6$ oxygen at $\beta$ position would allow a $\mathrm{C}-1$ to $\mathrm{C}-10$ hydride shift to occur before the competing step of elimination or nucleophilic attack at C-10 to form a guaianolide.

The biogenesis of the pseudoguaianolides-denominated helenanolides, with C-10 $\alpha$ methyl group and lactonic ring at 


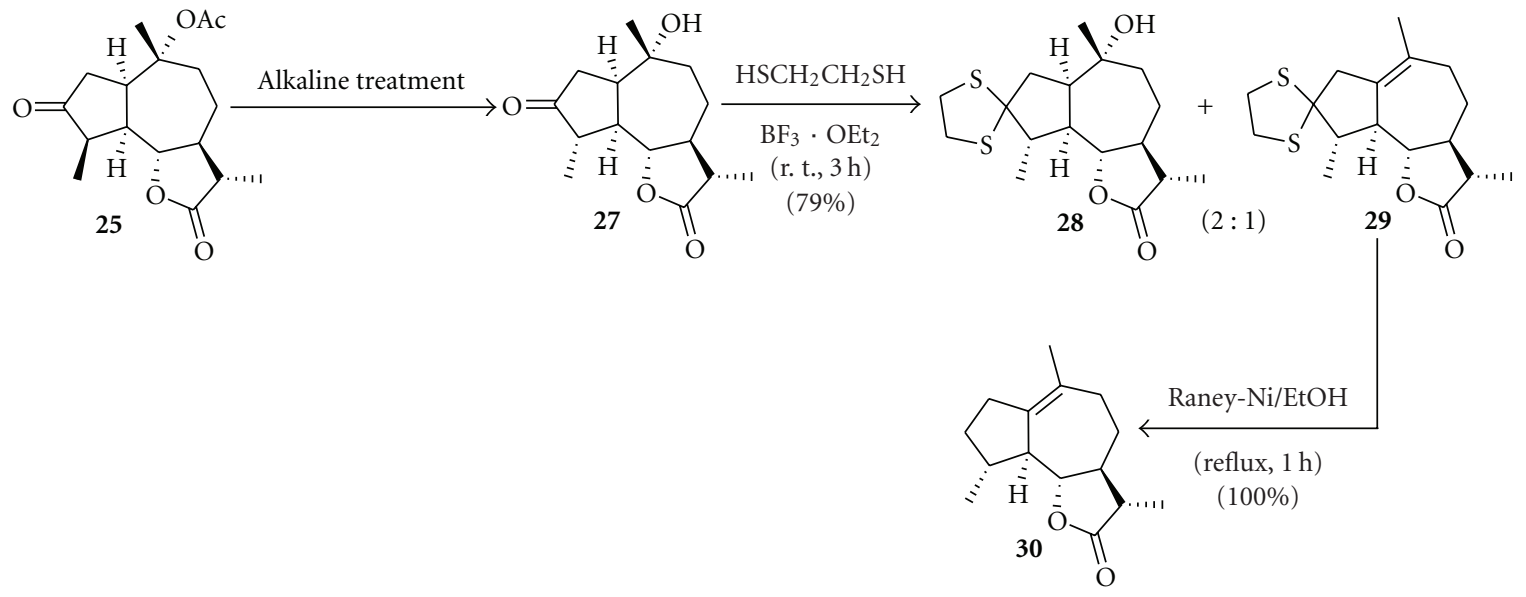

SCHEME 5: Synthesis of the lactone 30.
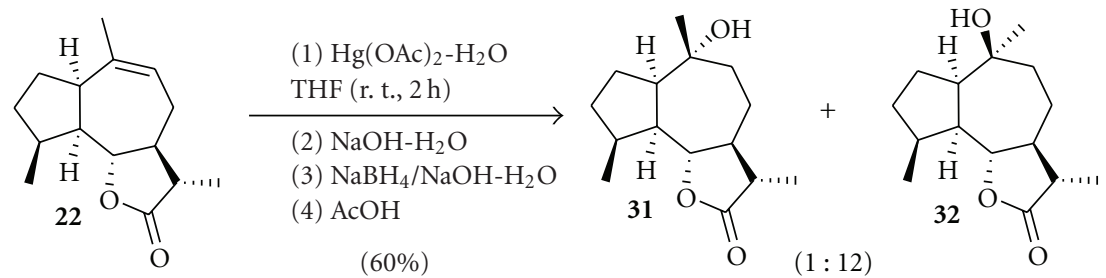

Scheme 6: Oxymercuration-desmercuration reaction performed on tetrahydroeremanthine (22).
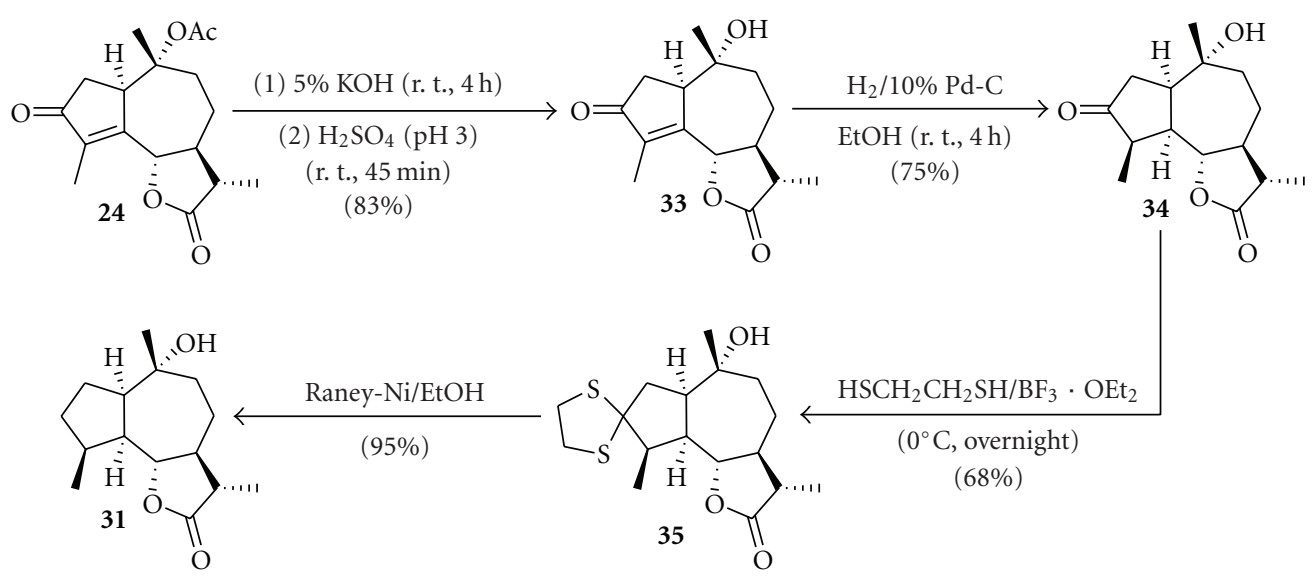

$\mathrm{HSCH}_{2} \mathrm{CH}_{2} \mathrm{SH} / \mathrm{BF}_{3} \cdot \mathrm{OEt}_{2}$

$\left(0^{\circ} \mathrm{C}\right.$, overnight $)$

$(68 \%)$

Scheme 7: Synthesis of the compound 31 starting from the lactone 24.
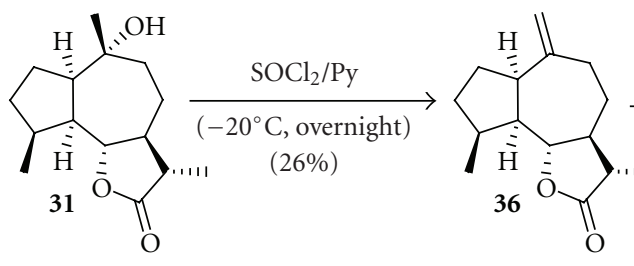

(1) $\mathrm{Hg}(\mathrm{OAc})_{2}-\mathrm{H}_{2} \mathrm{O}$ THF (r. t., 2h)

(2) $\mathrm{NaOH}-\mathrm{H}_{2} \mathrm{O}$

(3) $\mathrm{NaBH}_{4} / \mathrm{NaOH}-\mathrm{H}_{2} \mathrm{O}$

(4) $\mathrm{AcOH}$

(47\%)

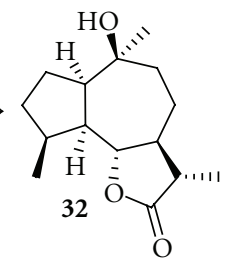

Scheme 8: Epimerization at C-10 position of the lactone 31. 


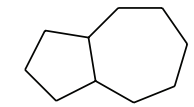

Bicyclo[5.3.0]decane

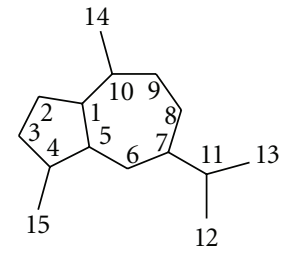

Guaiane<smiles></smiles>

Guaianolide
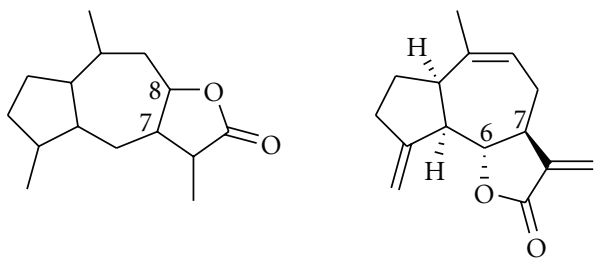

Eremanthine (1)

Figure 4: Bicyclo[5.3.0] decane, guaiane, guaianolide and eremanthine (1).

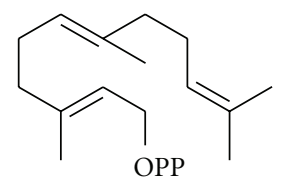

37

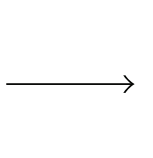<smiles>C/C=C(\C)CCC1CCC=C(C)C(C)C1C</smiles>

38
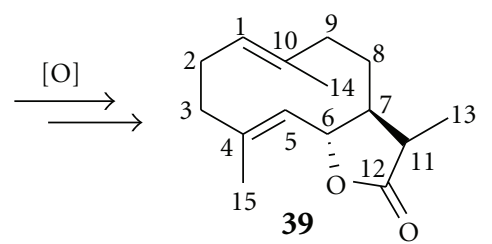

39

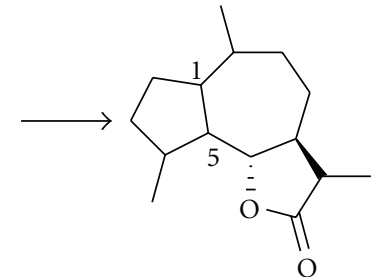

Guaianolide

Scheme 9: Biosynthesis of guaianolides.

C-7 and C-8 positions with the C- 8 oxygen oriented either $\alpha$ or $\beta$, is outlined in Scheme 14. Acid-induced cyclization of the melampolide-4,5-epoxide (43) would give the cation 45 from which by the indicated shifts, the skeleton of the helenanolides $(\mathbf{5 0})$ would be formed. An alternative route to the helenanolide intermediate $(45)$ could involve a germacranolide 4,5-epoxide precursor (44) which would provide the same cyclised skeleton (50) which is formed via the melampolide route.

In 1981 Fischer et al. [17] published an article on the biomimetic transformation of guaianolide into pseudoguaianolide. The conditions studied in that biogenetic type in vitro conversion are outlined in Scheme 15. The reaction of epoxide 51 with $\mathrm{BF}_{3} \cdot \mathrm{OEt}_{2}$ furnished the compounds 52 and 53 and not the desired product 54 with pseudoguaianolide skeleton. It was proposed that the minor product (52) resulted from the acid-catalysed opening of the ring epoxide of 51 and the major eudesmanolide 53 from the skeleton rearrangement of that substrate catalysed by $\mathrm{BF}_{3} \cdot \mathrm{OEt}_{2}$. The nonformation of substance $\mathbf{5 4}$ starting from the epoxide $\mathbf{5 1}$ reinforces the hypothesis that, to occur the rearrangements indicated by the arrows in Scheme 15, there is necessary a precursor guaianolide with a $\beta$-oxygenated function at C-6 position.

Other articles related to biomimetic transformation of guaianolide into pseudoguaianolide were reported in literature [18-20]. The study on the biomimetic transformation of eremanthine is going to be discussed in this text at the section on chemical transformations of this natural product.
3.2. Stereochemistry of Bicyclo[5.3.0]Decane. The bicyclo [5.3.0] decane (hydroazulene system) is a nucleus present in a great variety of natural products such as the guaiane and pseudoguaiane sesquiterpenoids [21] and the guaiane [2251], ingenane [52-67], daphnane [68-86], and asebotoxin [87-95] diterpenoids (Figure 5). Due to the chemical, biogenetical, and pharmacological interests that these classes of substances present, the literature reports a vast number of published works, with prominence for the reviews on sesquiterpenoids [21] and diterpenoids [96-101]. As eremanthine (1) belongs to the class of guaiane sesquiterpenoids (guaianolides), soon afterwards some considerations are going to be done on the stereochemistry of hydroazulene system present in its molecular structure.

The hydroazulene system is composed by a fivemembered ring (rigid system) fused with a seven-membered ring (flexible system). Due to the flexibility of the sevenmembered ring at the hydroazulene system, the study of conformational analysis of that system became necessary for a better understanding of stereoelectronic course of the reactions occured with the classes of substances that contain this nucleus in its hydrocarbon skeleton. The conformational analysis of hydroazulenes is also important for the interpretation of spectral data from nuclear magnetic resonance (NMR) of the substances that possess this system.

The study of conformational analysis applied to cyclic systems, including the hydroazulene, was initiated in the decade of 1960 with Hendrickson's works [102-109]. Subsequent studies, in that area, were published in the decade 


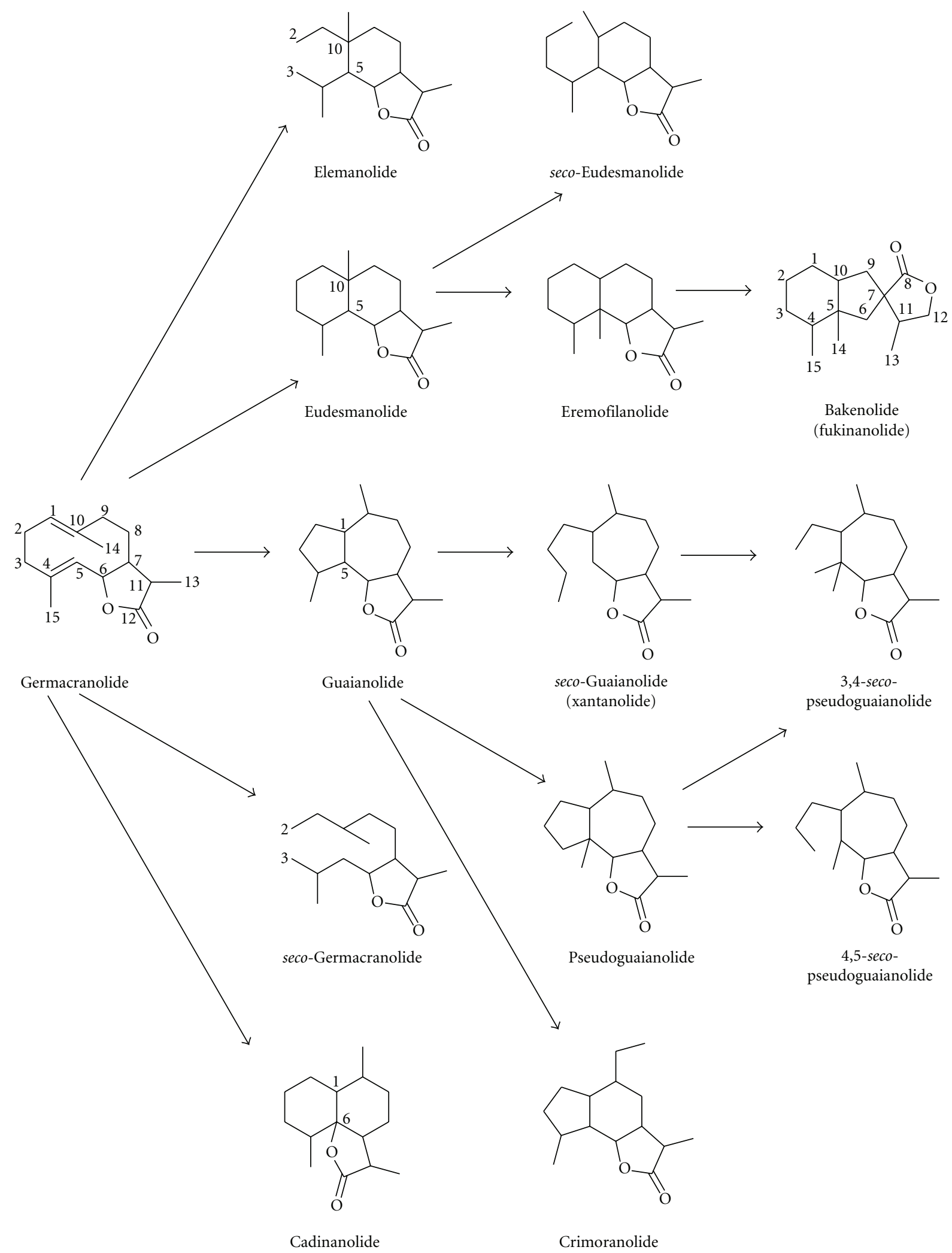

SCHEME 10: Biogenesis of sesquiterpene lactones. 


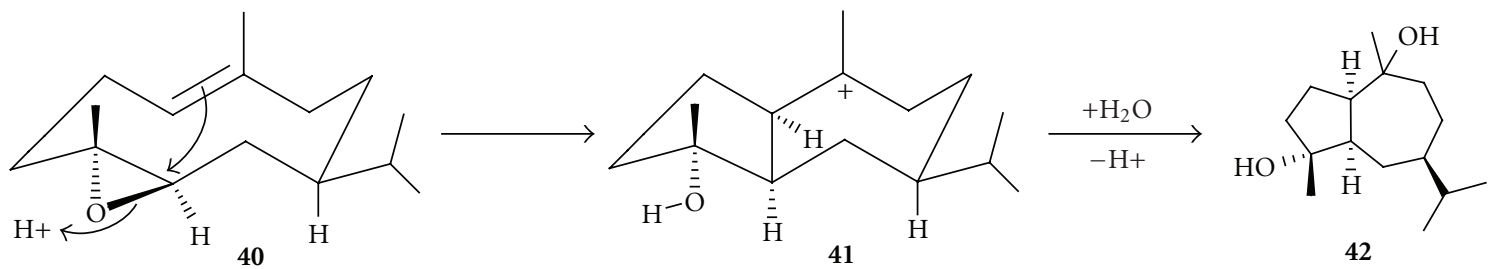

Scheme 11: Biogenesis of cis-fused guaianolides.
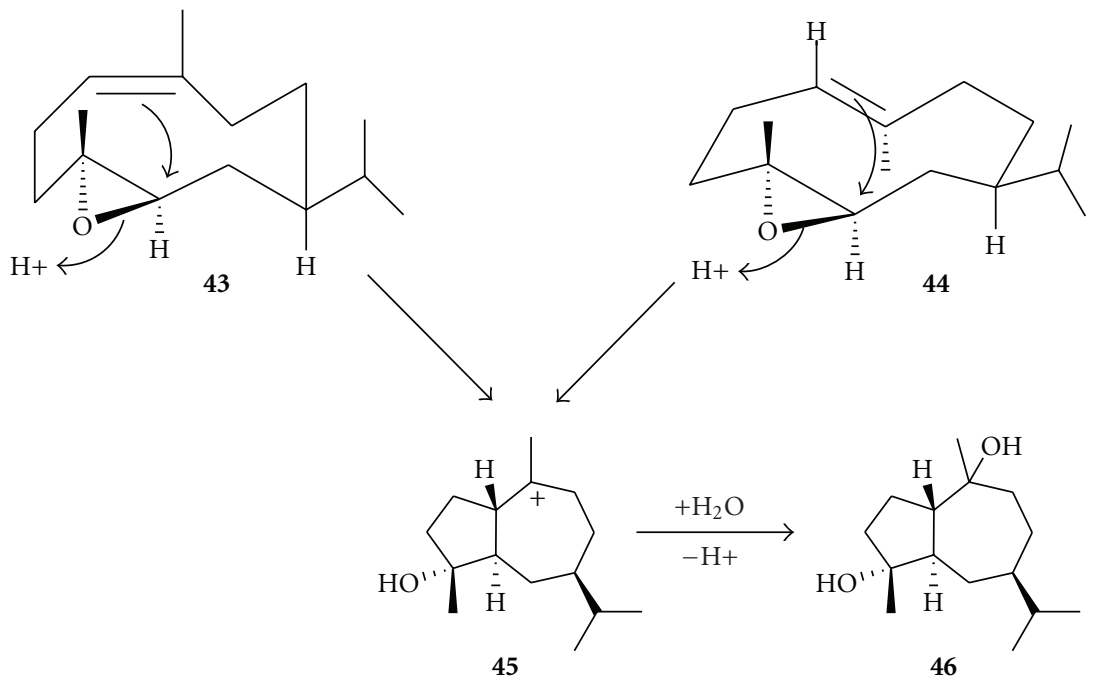

Scheme 12: Biogenesis of trans-fused guaianolides.

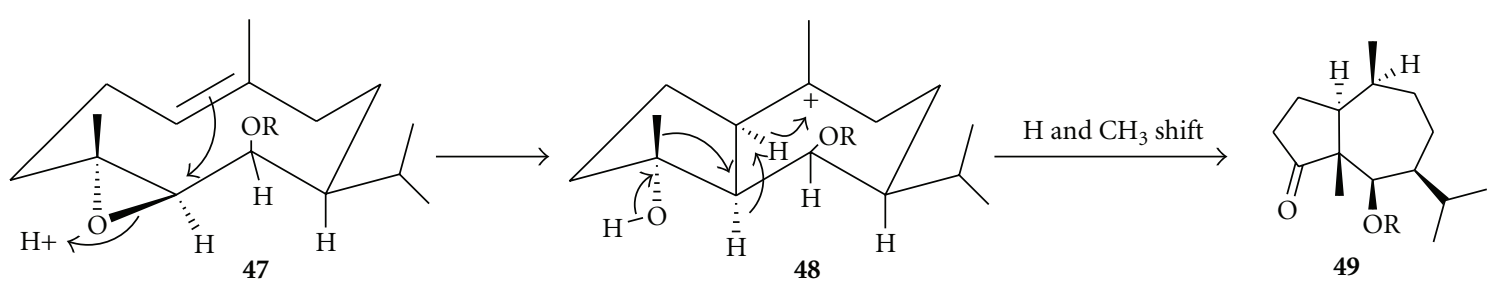

SCHeme 13: Biogenesis of ambrosanolides.
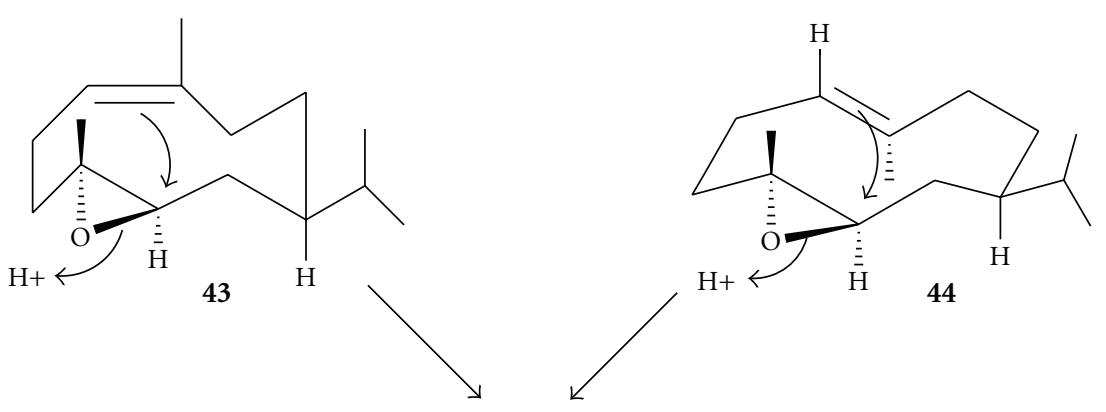

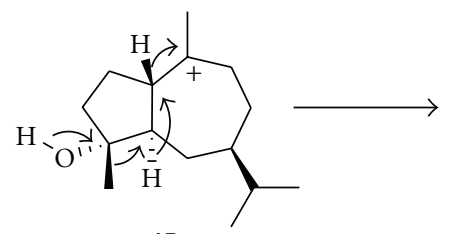

45

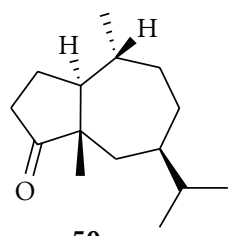

50

Scheme 14: Biogenesis of helenanolides. 

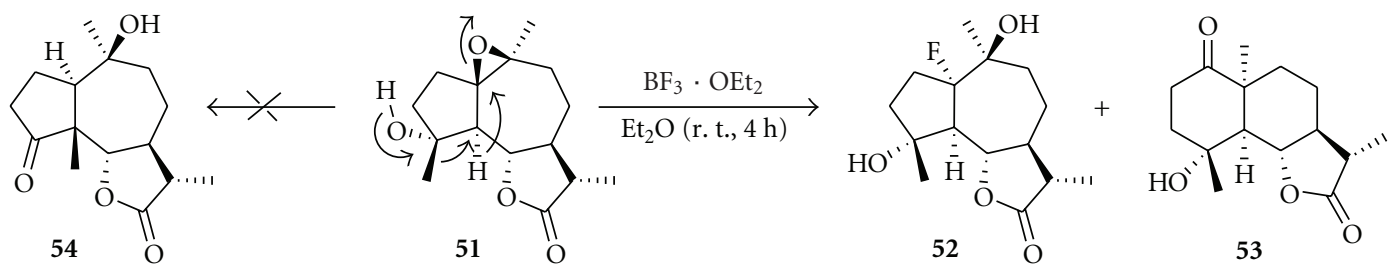

Scheme 15: Attempt of biogenetic in vitro conversion of the guaianolide 51 into pseudoguaianolide 54.

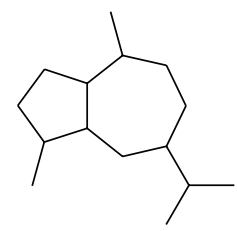

Guaiane sesquiterpene

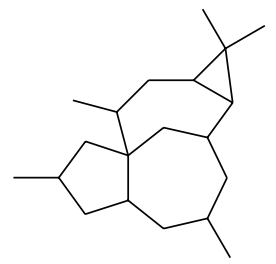

Ingenane diterpene

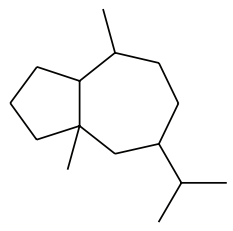

Pseudoguaiane sesquiterpene

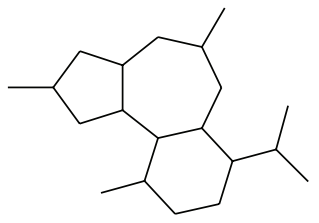

Daphnane diterpene

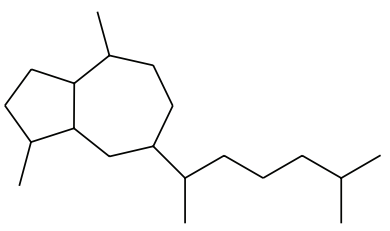

Guaiane diterpene

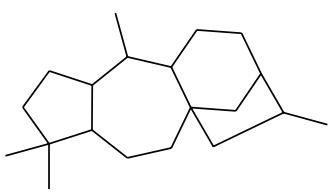

Asebotoxin diterpene

FIGURE 5: Hydrocarbon skeletons of guaiane and pseudoguaiane sesquiterpenes and guaiane, ingenane, daphnane and asebotoxin diterpenes.

of 1980 by Clercq [110-115]. Those works were focused on the conformational analysis of the seven-membered ring that commands the geometry of the hydroazulene system. According to the results of those published studies, the sevenmembered ring can present itself in the basic conformations shown in Figures 6-7.

In Figure 6 the subscript used to define a particular form (twist-chair TC, chair C, twist-boat TB, and boat B) indicates the atom sectioned by the symmetry element and the strain energies are given in parenthesis in kilojoules per mol. The same annotation was used in Figure 7, with the symbol $\sim C_{2}$ indicating a pseudo- $C_{2}$ axis of symmetry.

According to Clercq [110] the chair and boat conformations of cycloheptane are flexible and undergo pseudorotation. The twist forms (TC and $\mathrm{TB}$ ) with $C_{2}$-axis of symmetry are generally more stable than the chair $(\mathrm{C})$ and boat (B) forms with a $C_{S}$ plan of symmetry. In the case of cycloheptene, the chair form is generally the most stable conformation and the order of relative stability of conformers is the following: $C>\mathrm{TB}\left(C_{2}\right)>\mathrm{TB}\left(\sim C_{2}\right)>\mathrm{B}$. The method of de Clercq $[110,111]$, for systematic conformational analysis of hydroazulenes, was used in synthetic studies to explain the stereoselectivity of the reactions of sesquiterpene lactones that possess the hydroazulene skeleton in its molecular structure [115].

Nowadays, with the technological progresses, several research groups are using computation programs that were developed to aid in the visualization of the three-dimensional chemical structures of the molecules and to calculate their physical properties. It is possible to perform the conformational analyses of the studied substances, starting from the three-dimensional structures drawn by computation programs. Articles were published on the several modern techniques used to determine the conformations of the hydroazulene system from sesquiterpene lactones, including the analyses of X-ray diffraction, calculations of quantum mechanics, and molecular mechanics in combination with the NMR data [116-123].

\section{Biological Activity of Eremanthine}

Researchers verified that animals of laboratory (mice) were protected against infections caused by cercariae of Schistosoma mansoni, when the essential oils from Eremanthus elaeagnus and Vanillosmopsis erythropappa were applied on the skin of those guinea-pigs. That protective action was mainly attributed to the substance eremanthine (1), an abundant component found in those oils $[1,2]$. The biological activity of eremanthine was attributed to the presence of an $\alpha$-methylene- $\gamma$-lactone in its molecular structure [1]. That functional group was indicated as the main responsible for the biological activity in sesquiterpene lactones, due to its ability to react with the biological nucleophiles in a conjugate fashion [124-130]. The pharmacological results from the protective action of Eremanthus elaeagnus and Vanillosmopsis erythropappa oils were reported by Baker et al. [2]. 


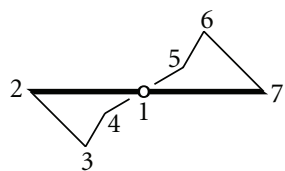

$\mathrm{TC}_{1}(0.0)$<smiles>C1CCCCCC1</smiles>

$\mathrm{C}_{2}$

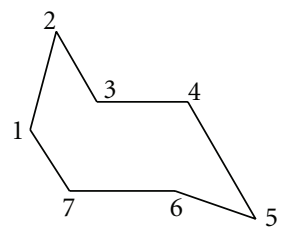

$\mathrm{C}_{5}(5.9)$<smiles>C1CCCCCC1</smiles>

$\mathrm{C}_{\mathrm{S}}$

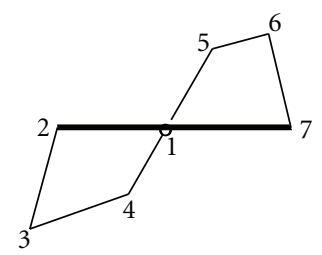

$\mathbf{T B}_{1}(10.0)$

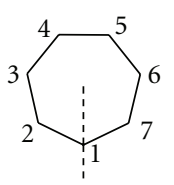

$\mathrm{C}_{2}$

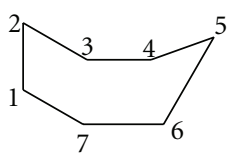

$\mathbf{B}_{5}(11.0)$

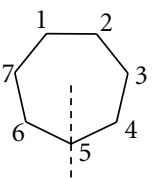

$\mathrm{C}_{\mathrm{S}}$

FIGURE 6: Conformational diagrams of the basic cycloheptane forms.

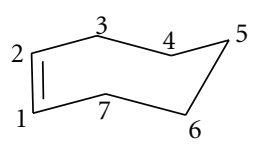

$\mathrm{C}_{5}$<smiles>CC12CCC=CCC1C2</smiles>

$\mathrm{C}_{\mathrm{S}}$

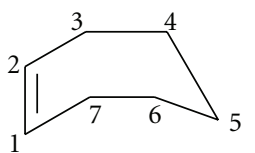

$\mathbf{B}_{5}$

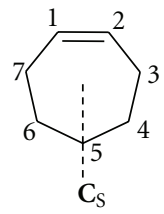

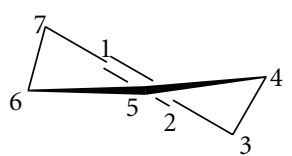

$\mathrm{TB}_{5}$<smiles>CC1(C)CCC=CCC1</smiles>

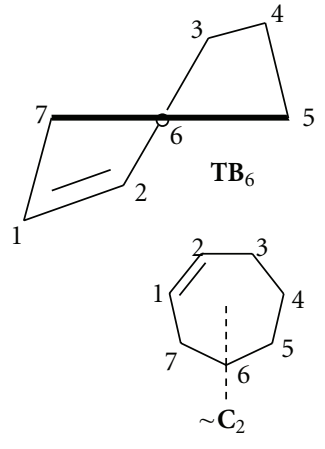

FIGURE 7: Conformational diagrams of the basic cycloheptene forms.<smiles>C=CC=CI</smiles>

60<smiles>C1CCC23CCCCC2CCC3C1</smiles>

56<smiles>C=CC</smiles><smiles>C1CCC2CCCCC2C1</smiles>

$\mathrm{O}$

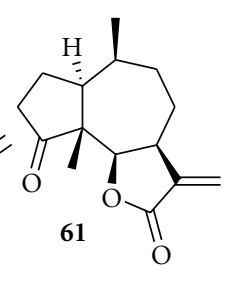

57<smiles>C1CCCCCC1</smiles>

59

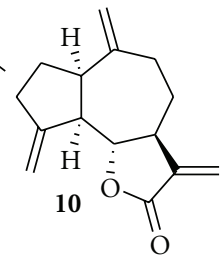

Scheme 16: Basic strategies to construction of the hydroazulene skeleton. 


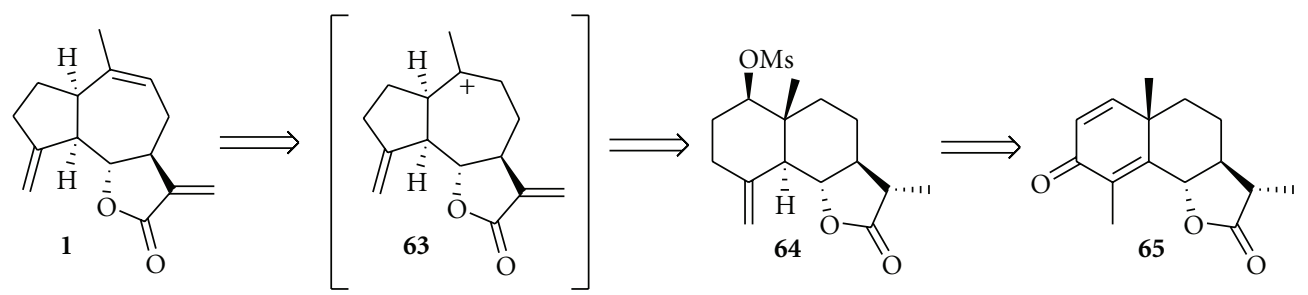

Scheme 17: Retroanalysis to the synthesis of eremanthine (1).<smiles>CC1=C2[C@H]3OC(=O)[C@@H](C)[C@H]3CC[C@@]2(C)C=CC1=O</smiles><smiles>C[C@@H]1C(=O)O[C@@H]2[C@H]1CCC1(C)CC=C[C@@H](C)[C@H]21</smiles>

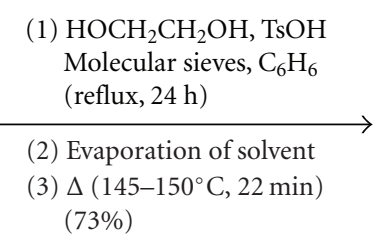<smiles>CC1=CCC2(OCCO2)[C@@]2(C)CC[C@H]3[C@H](C)C(=O)O[C@H]3[C@H]12</smiles>

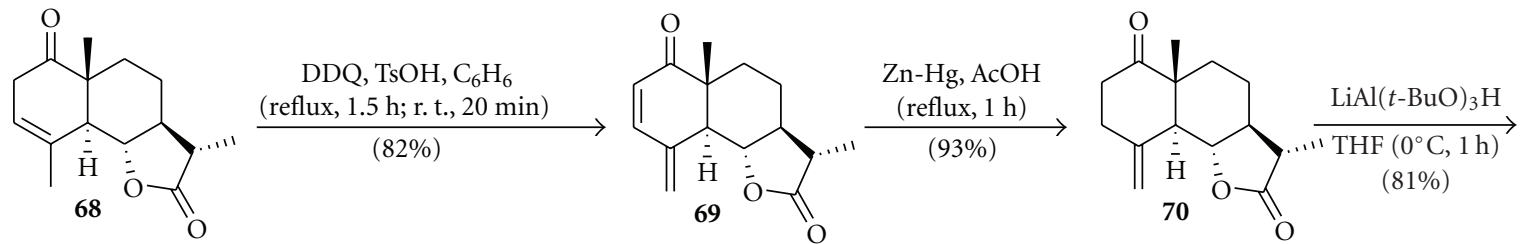

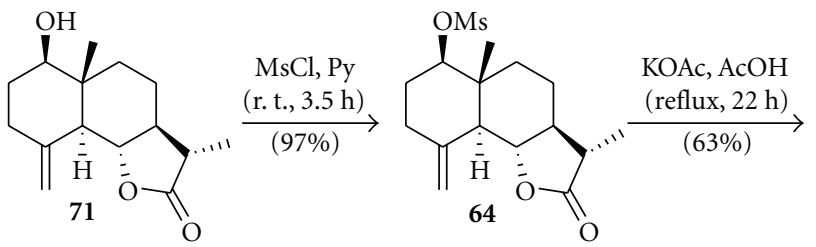<smiles>C=C1CCC2=C(C)CC[C@@H]3[C@H](C)C(=O)O[C@H]3[C@H]12</smiles><smiles>C=C1CC[C@H]2C(C)=CC[C@H]3[C@H](C)C(=O)O[C@H]3[C@H]12</smiles><smiles>C=C1CC[C@H]2C(C)C(=O)O[C@@H]2[C@H]1C</smiles>

$(2: 1: 2.4)$

$$
\begin{array}{cl}
\mathbf{7 2 + 2 1 + 7 3} & \stackrel{(1) \mathrm{LDA}, \mathrm{THF}\left(-76^{\circ} \mathrm{C}, 1 \mathrm{~h}\right)}{(1: 1.6: 4)} \\
& (2)(\mathrm{PhSe})_{2}, \mathrm{HMPA}, \mathrm{THF} \\
\left(-76^{\circ} \mathrm{C}, 30 \mathrm{~min} ;-40^{\circ} \mathrm{C}, 2 \mathrm{~h}\right)
\end{array}
$$
$(85 \%)$

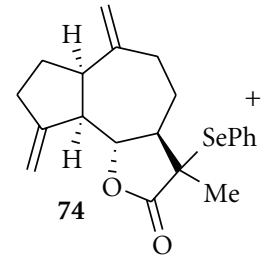

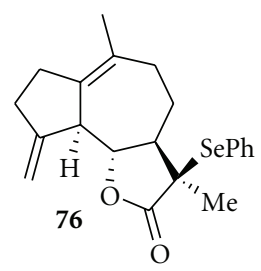

$(48: 25: 12)$

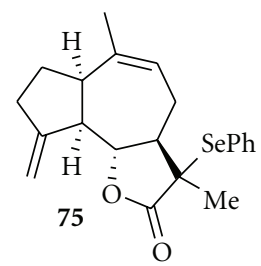

$$
\underset{(89 \%)}{\stackrel{\mathrm{H}_{2} \mathrm{O}_{2} / \mathrm{AcOH}}{\operatorname{THF}\left(0^{\circ} \mathrm{C}, 1 \mathrm{~h}\right)}}
$$<smiles>C=C1C(=C)[C@@H]2CCC(=C)[C@@H]3[C@@H]4OC(=O)C(C)=C4CC=C(C)[C@@H]3CC[C@H]12</smiles>

$(76: 13)$ 


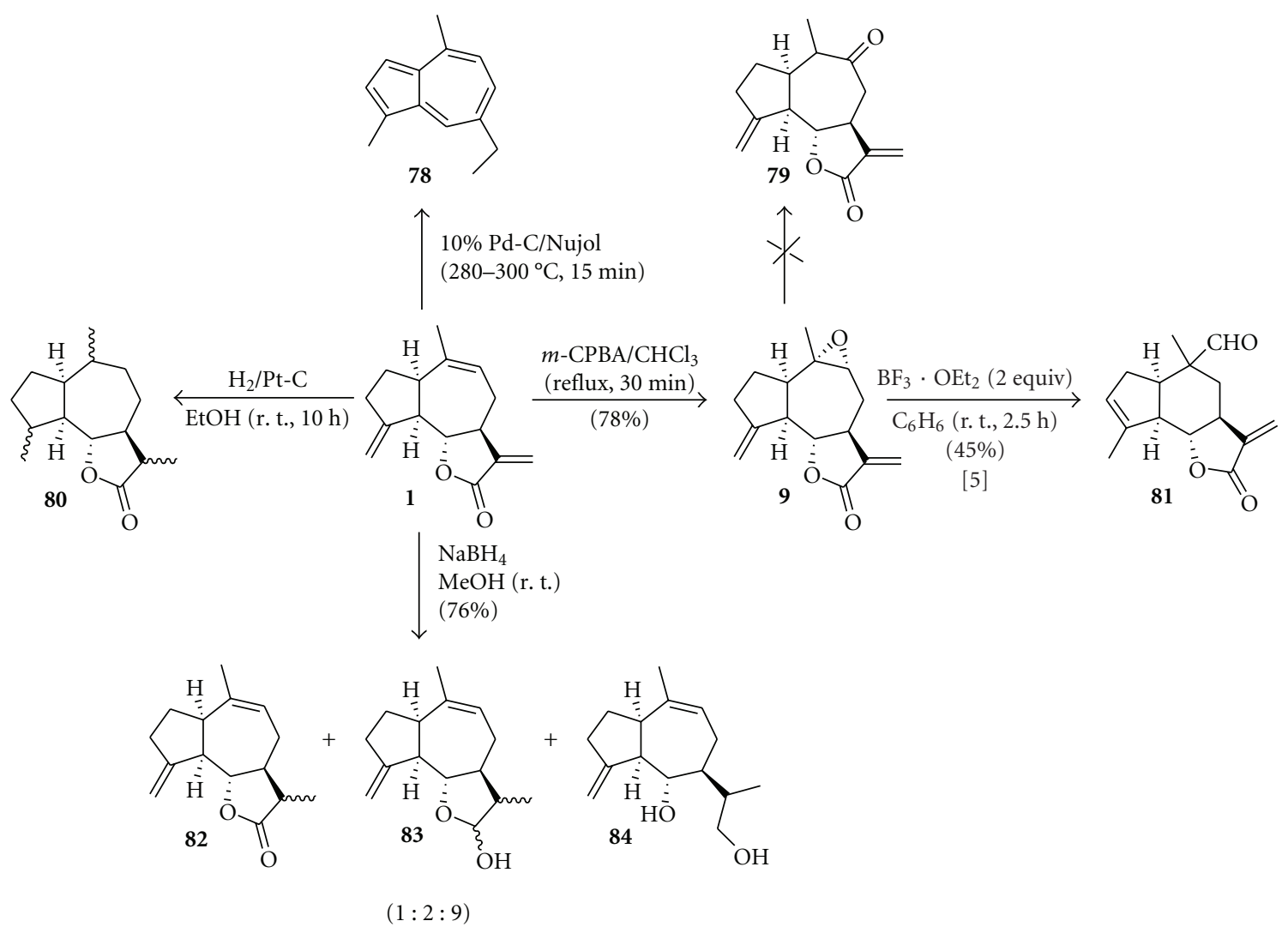

Scheme 19: The first chemical transformations of eremanthine (1).

\section{Synthesis of Eremanthine}

The synthesis of sesquiterpene lactones with their varied skeletons is composed by two crucial stages, which are the construction of the basic skeleton and the formation of the $\alpha$-methylene- $\gamma$-lactone. In the following subitems some considerations are done about the construction of the hydroazulene skeleton characteristic of the guaiane [131] and pseudoguaiane sesquiterpenoids, the formation of the $\alpha$-methylene- $\gamma$-lactone, besides the strategy and stages of the synthesis of eremanthine (1).

\subsection{Basic Strategies to Construction of the Hydroazule Skeleton.} The construction of the hydroazulene skeleton, reported by Heathcock et al. [132], involves four basic strategies which are shown in Scheme 16 with the respective substances that were synthesized.

The synthesis of confertin (60) [133] was accomplished by the strategy $\mathbf{A}$, in which the construction of the hydroazulene skeleton (55) was planned starting from a hydronaphthalene precursor (56) through a rearrangement reaction. The damsim (61) [134] could be obtained by the strategy $\mathbf{B}$, whose construction of the hydroazulene skeleton was planned starting from a cyclopentane precursor (57) on which the cycloheptane ring was inserted. In the synthesis of deoxydamsim (62) [135] the construction of the hydroazulene skeleton was planned by the strategy $\mathbf{C}$, using a precursor derived from the cyclodecane (58), through a transannular rearrangement reaction. Finally in strategy $\mathbf{D}$, used to the synthesis of dehydrocostus lactone (10) [136], the construction of the hydroazulene skeleton was planned starting from a cycloheptane derivative (59) on which the cyclopentane ring was inserted. The most recent literature on the synthesis of sesquiterpenoids reports the preparation of a chiron derived from cycloheptenone as a building block to the synthesis of guaiane sesquiterpene natural products [137] as well as the synthetic approaches to bicyclo[5.3.0]decane sesquiterpenes [138].

5.2. Synthesis of the $\alpha$-Methylene- $\gamma$-Lactone Moiety. The $\alpha$-methylene- $\gamma$-lactone is an important structural subunit found in several natural products with relevant biological activity. Due to the importance of this functional group, several researchers dedicated to the study of this structural moiety, with prominence to the various synthetic methods reported in literature [139-143].

5.3. Strategy to the Synthesis of Eremanthine. The enantioselective synthesis of eremanthine (1), developed by Yuuya et al. [12], employs the chiron approach strategy with the use of a chiral natural product as starting material on which chemical transformations are performed to reach the synthesis of the target molecule. There was used the strategy A shown in Scheme 16 to the construction of the hydroazulene skeleton of eremanthine (1), whose retrosynthetic analysis is presented in Scheme 17. In this strategy, the compound 1 


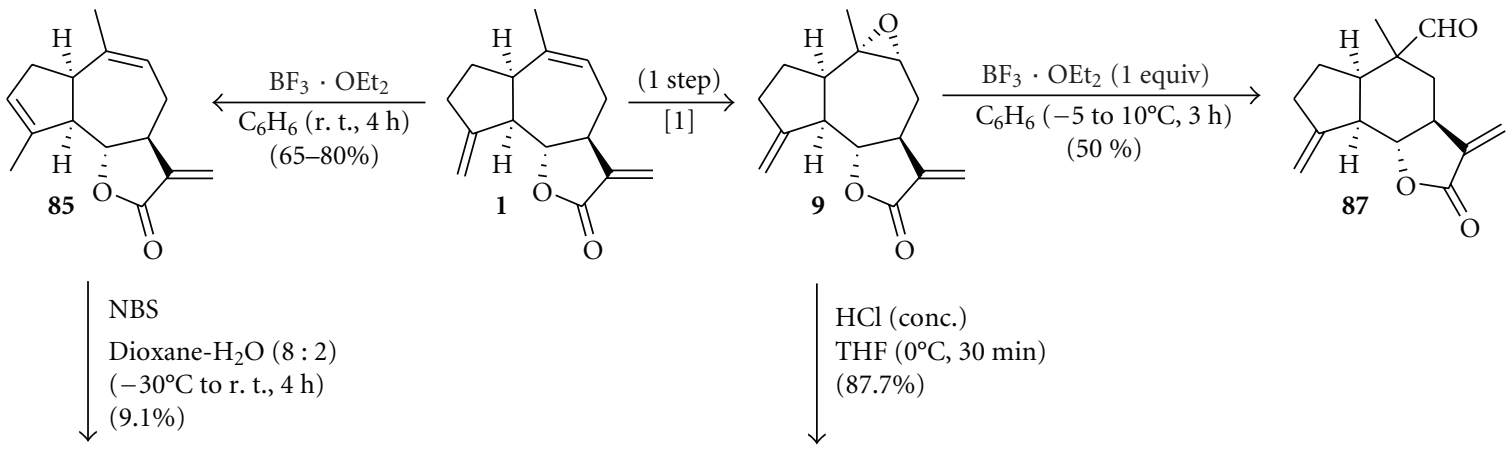

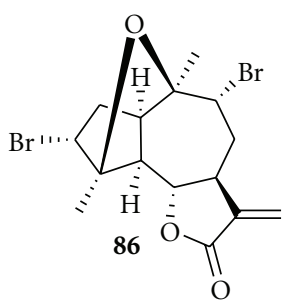

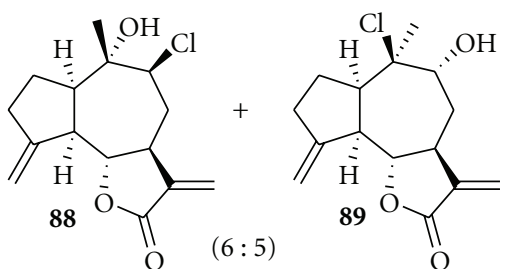

$$
\downarrow \begin{aligned}
& \mathrm{SOCl}_{2} / \mathrm{Py} \\
& \left(\sim 8^{\circ} \mathrm{C}, 5 \mathrm{~min}\right) \\
& (85 \%)
\end{aligned}
$$

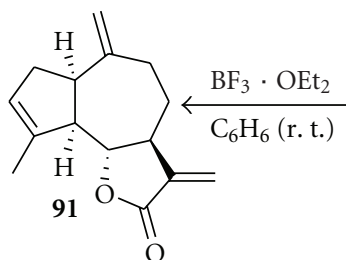<smiles>C=C1C(=O)O[C@H]2C1CCC(=C)[C@H]1CCCC(C)[C@H]12</smiles><smiles>C=C1C(=O)O[C@H]2[C@H]1CC(Cl)C(=C)[C@@H]1CCC(=C)[C@H]21</smiles>

Scheme 20: Synthesis of dehydrocostus lactone (10).

was planned to be synthesized via the cationic intermediate 63, that could be generated from the mesylate 64 through solvolytic rearrangement. The mesylate 64 could be obtained from $\alpha$-santonin $(65)$.

5.4. Stages of the Synthesis of Eremanthine. The steps that were employed by Yuuya et al. [12] to obtain eremanthine (1) starting from $\alpha$-santonin (65), by the strategy outlined in Scheme 17, are depicted in Scheme 18. The starting material used for the synthesis of key intermediate 64 was the $\alpha, \beta$ unsaturated ketone 66, which was prepared from $\alpha$-santonin (65) in six steps with an overall yield of 59\% (Scheme 18). Ketalization of $\mathbf{6 6}$ and subsequent isomerization of double bond at $\mathrm{C}-2$ by heating in ethylene glycol and $\mathrm{TsOH}$ gave the ketal 67 as the main product of that reaction. The acidic hydrolysis of compound $\mathbf{6 7}$ gave the ketone 68, which was submitted to subsequent step of dehydrogenation with DDQ and $\mathrm{TsOH}$ to furnish the exo-dienone 69 as the major product. Treatment of this compound with zinc amalgam in refluxing $\mathrm{AcOH}$ gave $\gamma, \delta$-unsaturated ketone 70. Selective reduction of the C-1 carbonyl group of 70 with
$\mathrm{LiAl}(t-\mathrm{BuO})_{3} \mathrm{H}$ furnished the desired $\beta$-alcohol 71 as the major product of that reaction. Mesylation of 71 with $\mathrm{MsCl}$ and pyridine gave the mesylate 64 . Solvolytic rearrangement of 64 with a solution of $\mathrm{KOAc}$ in $\mathrm{AcOH}$ provided a mixture of tetra-, tri-, and disubstituted olefins 72, 21, and 73 in a respective proportion of $(2: 1: 2.4)$. After separation of crude product from the reaction by preparative HPLC, a fraction with a mixture $(1: 1.6: 4)$ of 72,21 , and 73 was submitted to the following step of phenylselenylation with LDA and diphenyl diselenide to afford epimeric mixtures at C-11 of phenylseleno lactones $\mathbf{7 4}$ and $\mathbf{7 5}$ along with the lactone $\mathbf{7 6}$. After separation by HPLC, the epimeric mixture of 75 at C-11 was submitted to oxidative elimination with $\mathrm{H}_{2} \mathrm{O}_{2}$ to furnish eremanthine (1) and the corresponding endounsaturated $\gamma$-lactone 77.

\section{Chemical Transformations of Eremanthine}

As eremanthine (1) was abundantly isolated from the oil of Eremanthus elaeagnus and Vanillosmopsis erythropappa $[1,2]$, there was initiated a program of chemical transformations of 1 aiming at the syntheses of other biologically active 


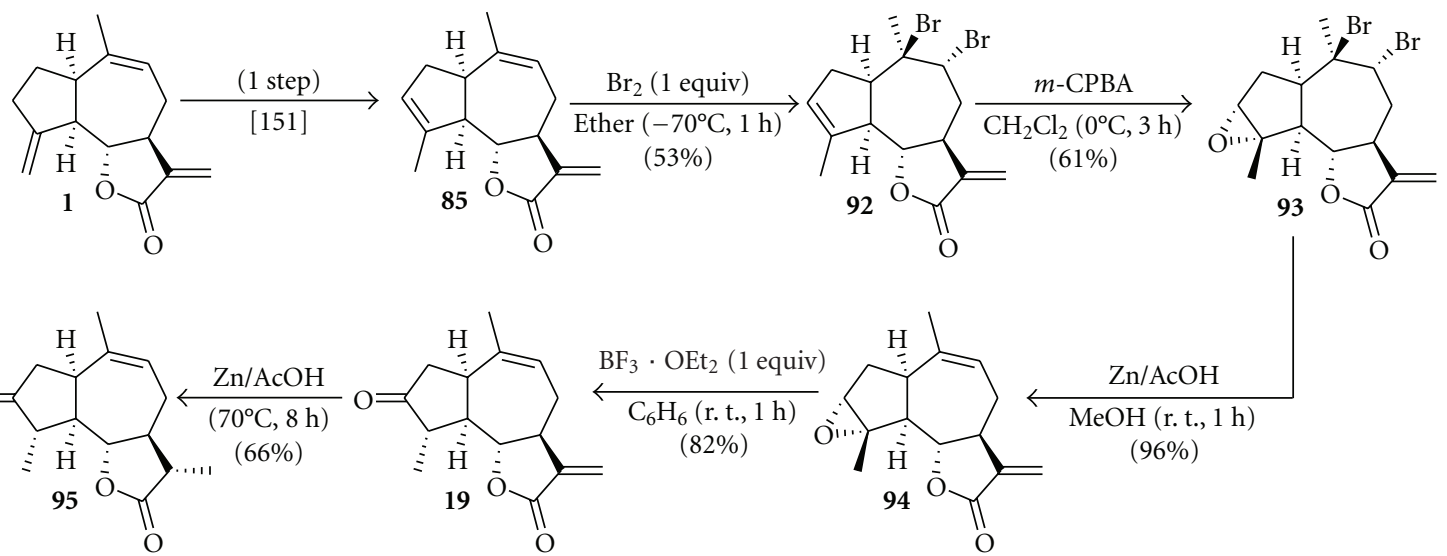

Scheme 21: Syntheses of eregoyazin (19) and eregoyazidin (95).
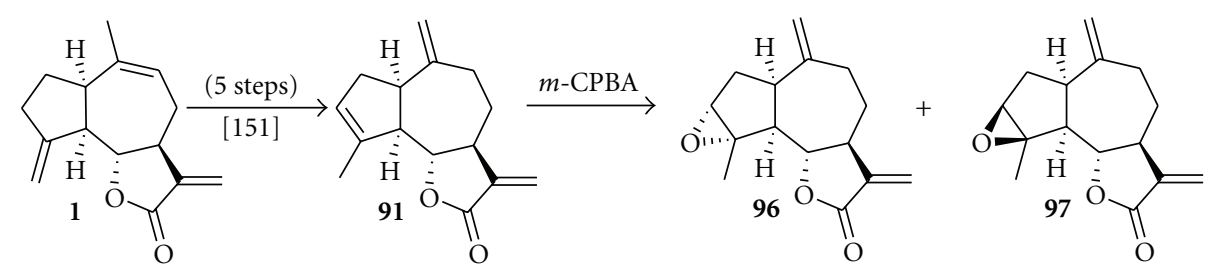

$(8: 2)$

SCHEme 22: Synthesis of (-)-estafiatin (96) in mixture with the isomer 97.

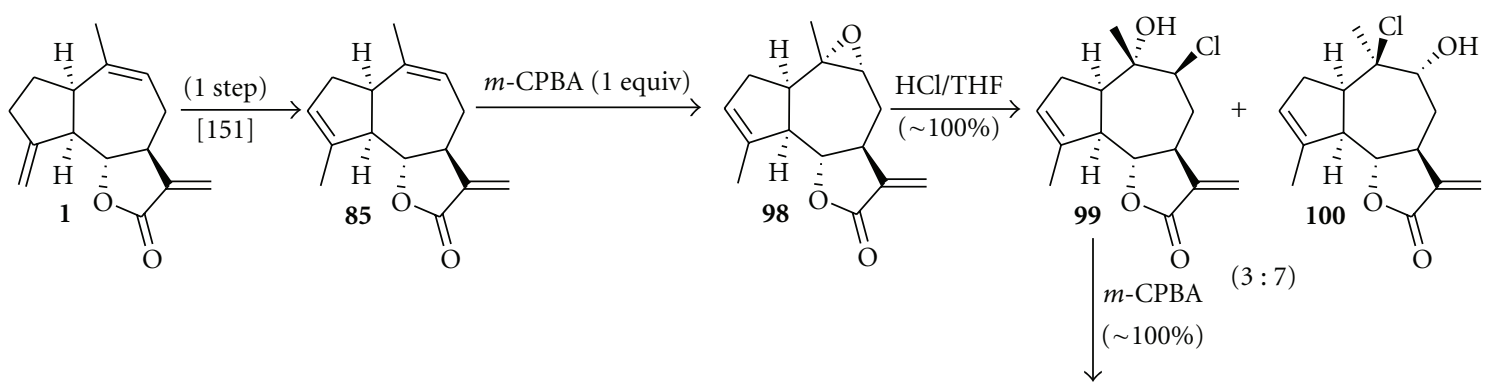

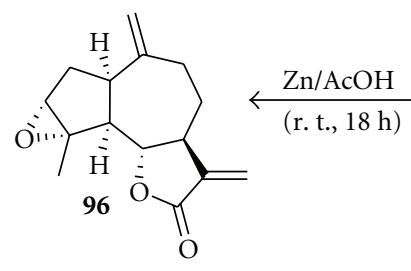

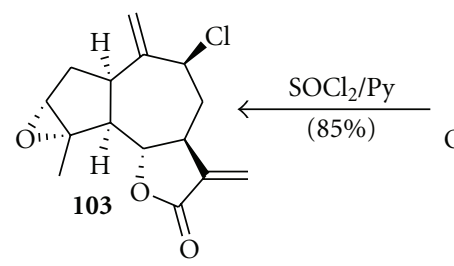<smiles>C=C1C(=O)O[C@H]2[C@H]1CC(Cl)[C@H](O)[C@@H]1CC3O[C@]3(C)[C@H]21</smiles><smiles>C=C1C(=O)O[C@H]2[C@@H]1CC(Cl)[C@H](O)[C@@H]1C[C@H]3OC3C21C</smiles>

$(55: 45)$

SCHEMe 23: Synthesis of (-)-estafiatin (96).
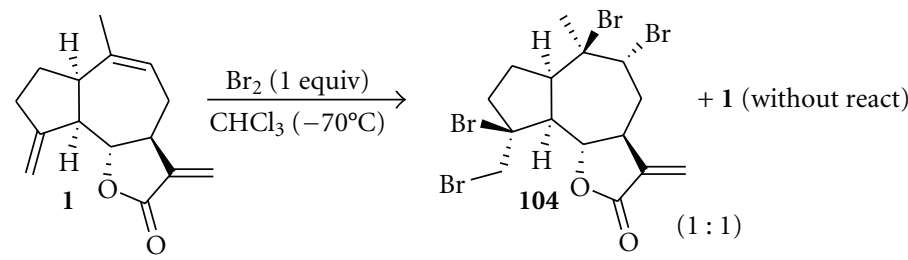

Scheme 24: Reaction of eremanthine (1) with equimolar amount of bromine. 


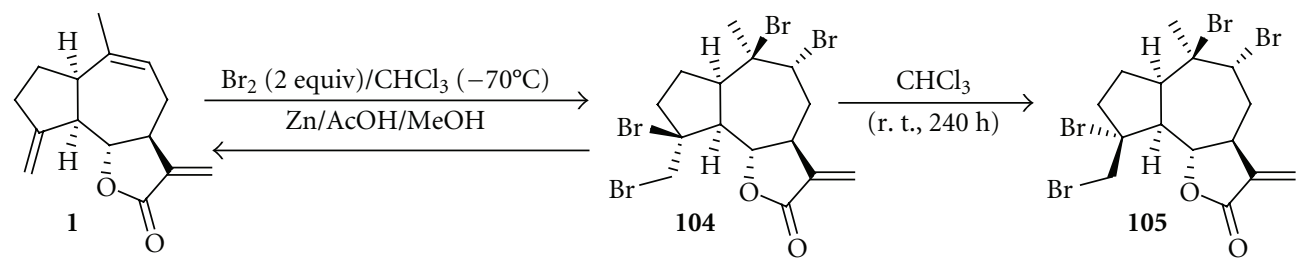

SCHEME 25: Reaction of eremanthine (1) with excess of bromine.
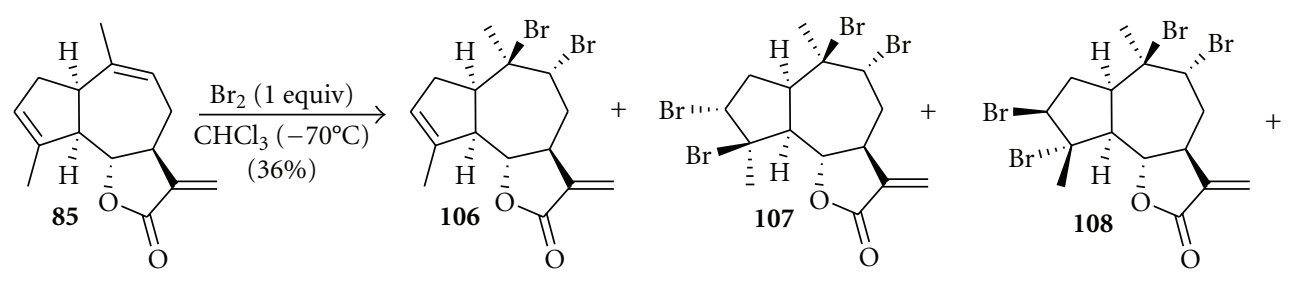

85

$(18: 15: 3: 26)$

SCHEME 26: Reaction of isoeremanthine (85) with bromine in chloroform.

derivatives as well as the preparation of less abundant naturally occurring lactones. As a result of this research program, several works of M.S. and Ph.D. degrees were accomplished using eremanthine (1) as object of study $[15,16,144-150]$. In the following subitems are described the syntheses of several eremanthine derivatives published in the period of 1972 to the current days.

6.1. The First Chemical Transformations of Eremanthine. The first chemical transformations performed with eremanthine (1) were published in 1972 by Vichnewski and Gilbert [1] and are depicted in Scheme 19.

Dehydrogenation of eremanthine (1) with palladium by heating in nujol gave chamazulene (78), and the selective epoxidation of $\mathbf{1}$ yielded the epoxide 9. Treatment of compound 9 with excess of $\mathrm{BF}_{3}$-etherate furnished a product that was initially characterized as the ketone 79 [1]. Reinvestigation of this reaction by Garcia et al. [5] showed this structural assignment to be incorrect and the structure of the aldehyde 81, resultant from a rearrangement, could be demonstrated by physical methods. Catalytic hydrogenation of eremanthine (1) resulted in the generation of a mixture of the isomers 80. Reduction of $\mathbf{1}$ with $\mathrm{NaBH}_{4}$ furnished a mixture of 3 products characterized as the compounds $\mathbf{8 2}$, 83 , and 84.

6.2. Chemical Transformations of Eremanthine for the Synthesis of Other Natural Guaianolides. In 1977 Maçaira et al. [151] published an article on the selective chemical modifications performed with eremanthine, aiming at the syntheses of other guaianolides of natural occurrence. As result of the chemical modifications performed with the substrate 1 , there were obtained the synthetic derivatives depicted in Scheme 20 besides the natural product dehydrocostus lactone (10), a guaianolide initially isolated from Saussurea lappa [152].
The isomerization of exocyclic double bond at fivemembered ring of eremanthine (1) was achieved treating this compound with excess of $\mathrm{BF}_{3} \cdot \mathrm{OEt}_{2}$. In these conditions isoeremanthine (85) could be obtained in yields ranging from 65 to $80 \%$, according to scale of the substrate, quantity of $\mathrm{BF}_{3} \cdot \mathrm{OEt}_{2}$, and reaction time. To ensure that the isomerization of $\mathbf{1}$ to $\mathbf{8 5}$ did not result in change of the configuration at $\mathrm{C}-1$ and $\mathrm{C}-5$, isoeremanthine (85) was treated with NBS in a mixture of dioxane- $\mathrm{H}_{2} \mathrm{O}$. The formation of the dibromoether $\mathbf{8 6}$ did confirm the cis fusion at the five- and seven-membered rings of isoeremanthine. The aldehyde 87 could be obtained selectively, without isomerization of exocyclic double bond at five-membered ring, by treating epoxide 9 with equimolar amount of $\mathrm{BF}_{3} \cdot \mathrm{OEt}_{2}$. When epoxide 9 was treated with concentrated $\mathrm{HCl}$ in THF, the chlorohydrins $\mathbf{8 8}$ and $\mathbf{8 9}$ were isolated in a respective proportion of $(6: 5)$. Treatment of compound 88 with a mixture of thionyl chloride and pyridine, at low temperature, gave allylic chloride 90. Dechlorination of 90 in acid medium with zinc and $\mathrm{MeOH}$ furnished a compound identified as dehydrocostus lactone (10). The isomerization of exocyclic double bond at five-membered ring of $\mathbf{1 0}$ was achieved through the reaction of this compound with $\mathrm{BF}_{3} \cdot \mathrm{OEt}_{2}$, at the same conditions used to convert eremanthine (1) into isoeremanthine (85). In those conditions isodehydrocostus lactone (91) was obtained.

6.3. Syntheses of Eregoyazin and Eregoyazidin. In order to confirm the structures of eregoyazin (19) and eregoyazidin (95), two guaianolides isolated from Eremanthus goyazensis by Vichnewski et al. [153], the syntheses of these compounds were accomplished according to the sequence of reactions depicted in Scheme $21[153,154]$. The reaction of isoeremanthine $(85)$ with one equivalent of bromine at $-70^{\circ} \mathrm{C}$ gave a mixture from which the compound $\mathbf{9 2}$ could be isolated. Peracid oxidation of $\mathbf{9 2}$ from the less hindered face 

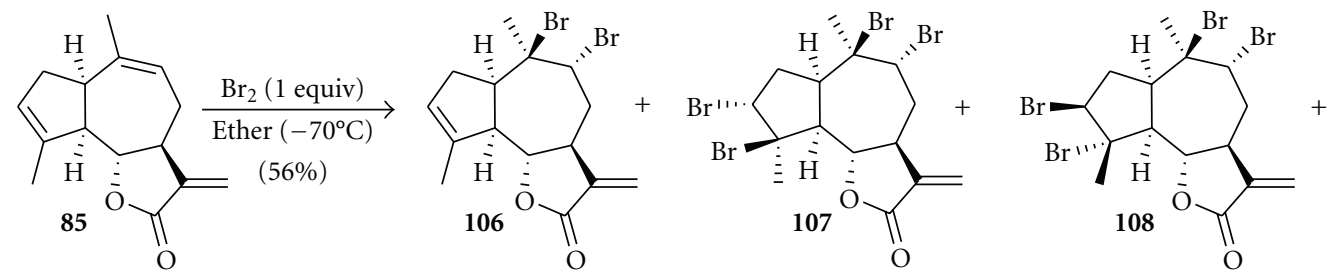

85

(without react)

$(53:$ traces $: 3: 16)$

Scheme 27: Reaction of isoeremanthine (85) with bromine in ether.
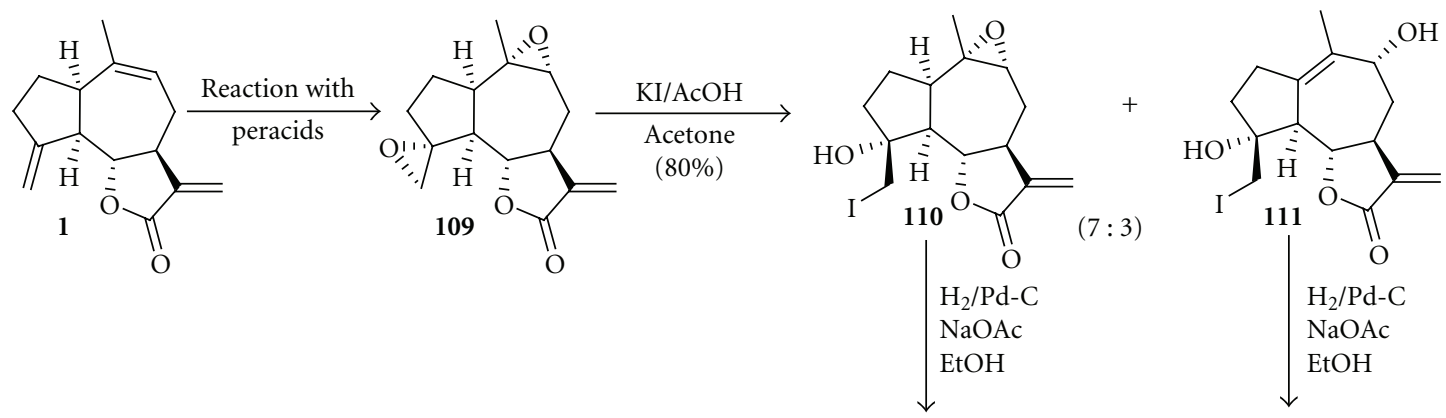

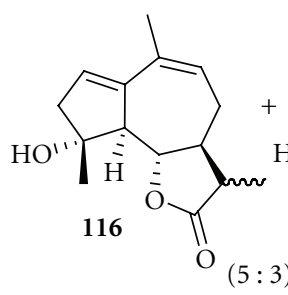<smiles>CC1=C2CC[C@@](C)(O)[C@H]2[C@@H]2OC(=O)C(C)[C@H]2C=C1</smiles>

$$
\underset{\substack{\mathrm{BF}_{3} \cdot \mathrm{OEt}_{2} \text { or } \\(80 \%)}}{\stackrel{\mathrm{TsOH} / \mathrm{Py}}{2}}
$$

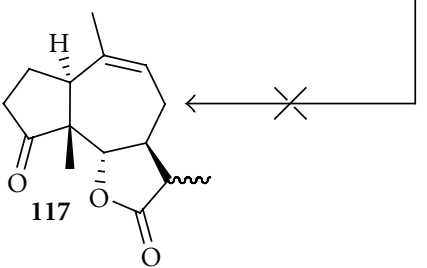
$\stackrel{\mathrm{HClO}_{4}}{\longleftarrow}$

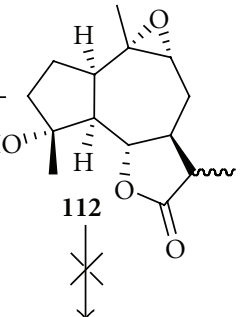<smiles>CC1=C2CC[C@@](C)(O)[C@H]2[C@@H]2OC(=O)[C@H](C)[C@H]2C[C@H]1O</smiles>

SCHeme 28: Biomimetic transformations of eremanthine (1).

afforded mainly the $\alpha$-epoxide 93 . Exposure of this epoxide to methanolic zinc resulted in debromination to furnish compound 94. Treatment of 94 with $\mathrm{BF}_{3} \cdot \mathrm{OEt}_{2}$ afforded a substance identical in all aspects with eregoyazin (19). Further reduction of 19 with zinc in hot glacial acetic acid yielded eregoyazidin (95).

6.4. Synthesis of (-)-Estafiatin. The stereoselective synthesis of the natural product (-)-estafiatin (96), a sesquiterpene lactone isolated from Artemisia mexicana [155], was developed by Rabi et al. $[154,156]$. The sequences of reactions used for the synthesis of this natural product are depicted in Schemes 22-23. Initially the triene 91, obtained from eremanthine
(1) for the sequence of reactions outlined in Scheme 20, was submitted to epoxidation with $m$-chloroperbenzoic acid to furnish a mixture characterized as the epoxides $\mathbf{9 6}$ and $97\left(8: 2,{ }^{1} \mathrm{H}\right.$ NMR). The major isomer showed identical properties with the naturally occurring (-)-estafiatin (96) (Scheme 22) [156].

The compound (-)-estafiatin (96) was also obtained by the sequence of reactions depicted in Scheme 23 [154, 156]. The reaction of isoeremanthine (85) with equimolar amount of $m$-chloroperbenzoic acid resulted in almost exclusive formation of epoxide $\mathbf{9 8}$ which upon reaction with $\mathrm{HCl}$ in THF gave a mixture of chlorohydrins 99 and 100 (3:7). Epoxidation of 99 led to a nearly equimolar 


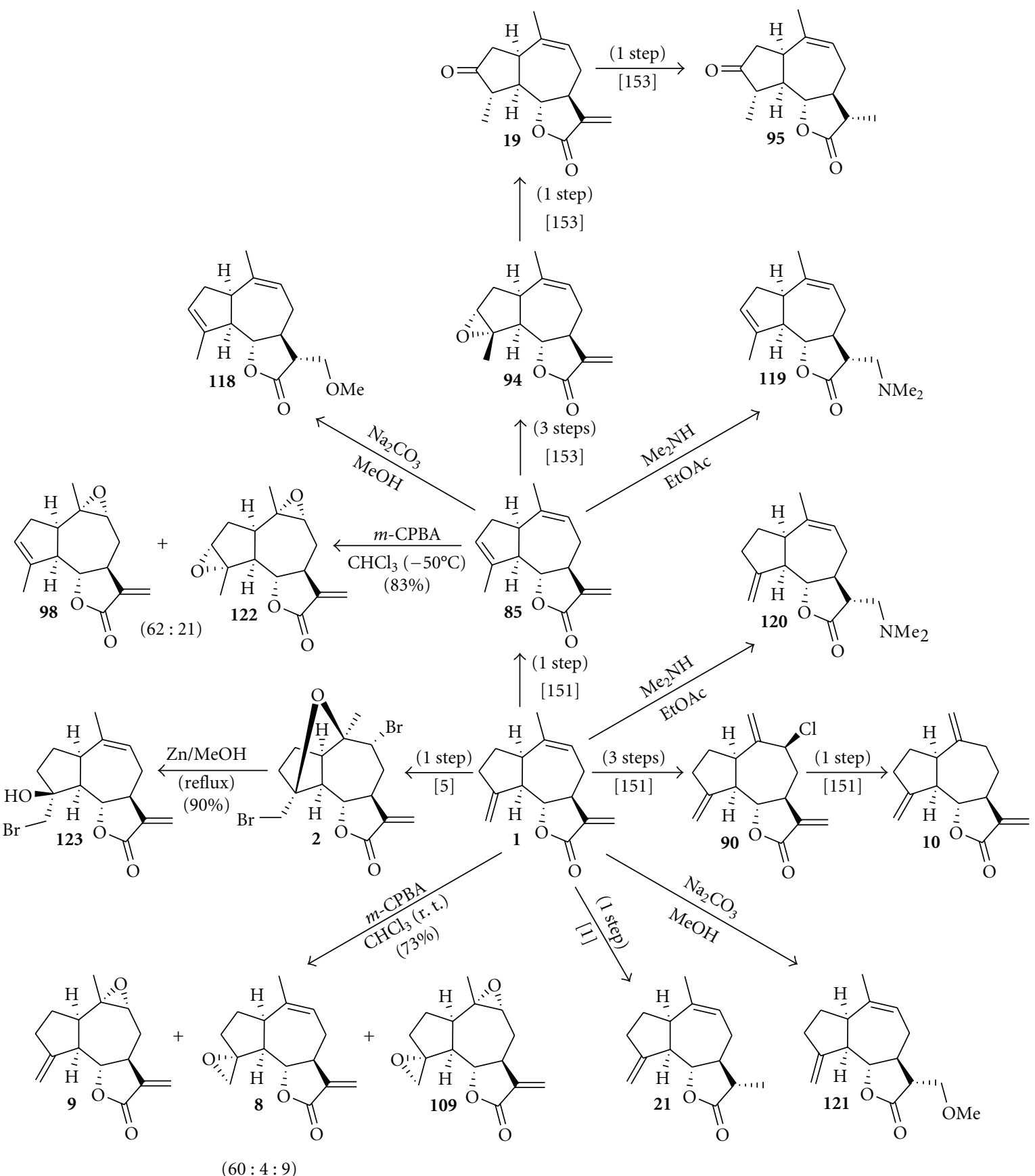

Scheme 29: Syntheses of eremanthine derivatives to the study of ${ }^{13} \mathrm{C}$ NMR spectroscopy.

mixture of epoxides 101 and 102 (55:45). Dehydration of 101 with a mixture of $\mathrm{SOCl}_{2}$ and pyridine furnished 103. Dechlorination of this compound with zinc yielded a substance identified as (-)-estafiatin (96).

6.5. Reaction of Eremanthine and Isoeremanthine with Bromine. The search for a selective method to protect the most nucleophilic 9,10-double bond of eremanthine (1) led to the investigation of eletrophilic addition of bromine to this compound and also to isoeremanthine $(\mathbf{8 5})$. The conditions that were employed by Garcia et al. [157] to study this addition reaction are described in Schemes 24-27. When eremanthine (1) was allowed to react with one equivalent of bromine at kinetic conditions, an equimolar mixture of tetrabromide 104 and 1 could be detected by ${ }^{1} \mathrm{H}$ NMR spectroscopy (Scheme 24).

Addition of two equivalents of bromine to eremanthine (1) resulted in the exclusive formation of tetrabromide 104. Reaction of this compound with zinc in methanol regenerated eremanthine (1) in quantitative yield. When 

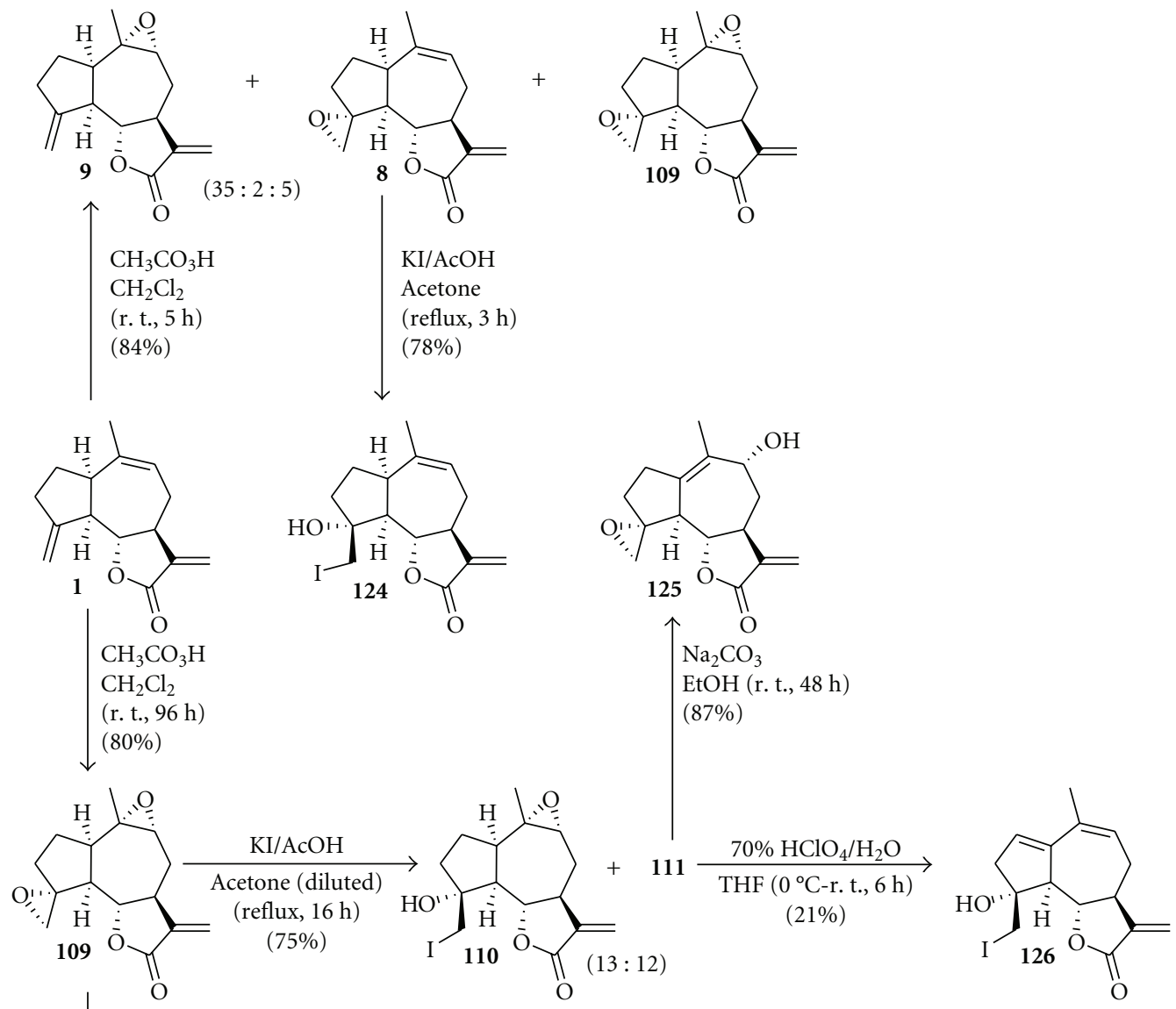
$\mathrm{KI} / \mathrm{AcOH}$
Acetone (conc.)
(reflux, 6 h)
$(75 \%)$

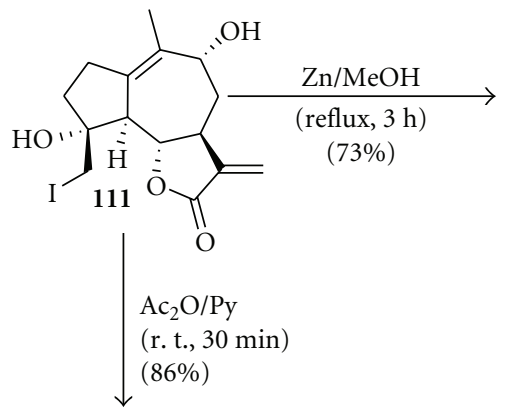

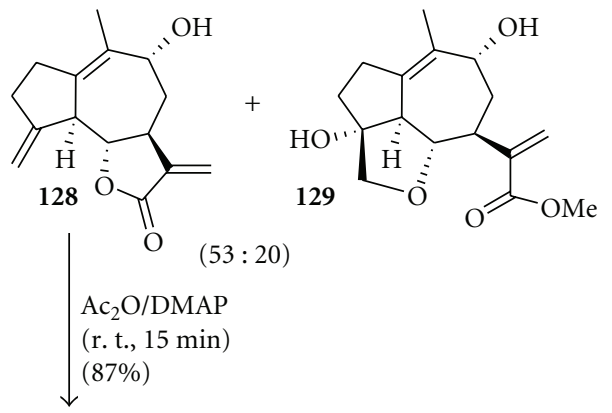<smiles>C=C1C(=O)O[C@H]2[C@H]1CC(OC(C)=O)C(C)=C1CC[C@H](O)[C@H]12</smiles><smiles>C=C1C(=O)O[C@@H]2C[C@H]1OC(=O)C2=C</smiles>

Scheme 30: Study on the chemical reactivity of epoxides derived from eremanthine (1).

a solution of compound 104 in $\mathrm{CHCl}_{3}$ was left at room temperature during 240 hours, the tetrabromide 105 was obtained (Scheme 25). The inversion of configuration at C-4 in this reaction was attributed to stereoelectronic repulsion between the $\beta$-oriented bromine atoms at C- 4 and $\mathrm{C}-10$ at the substrate 104 .

A complex mixture of products was obtained when isoeremanthine (85) was submitted to reaction with one 


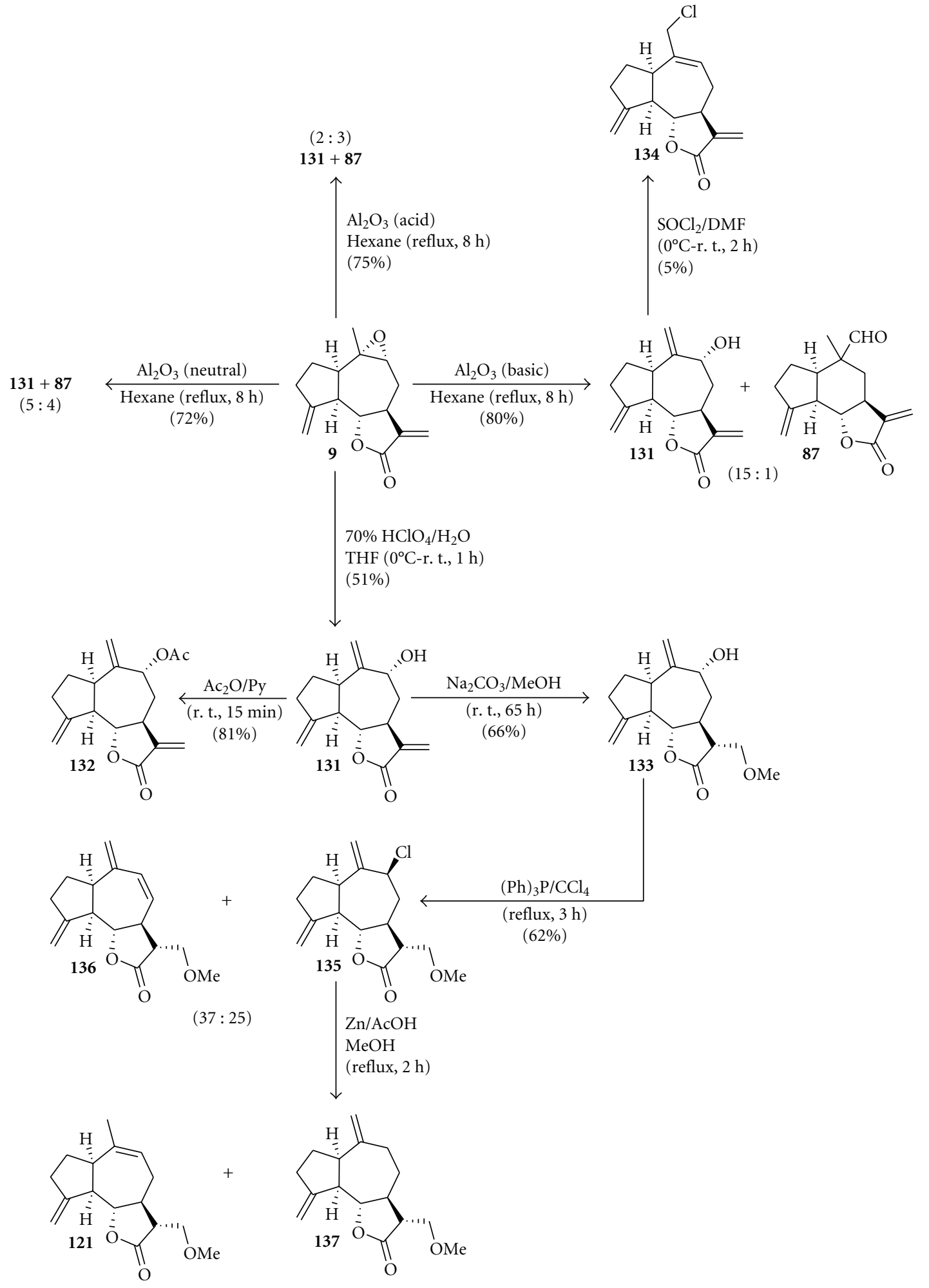

Scheme 31: Reaction conditions studied to the opening of epoxide 9.

equivalent of bromine at kinetic conditions (Schemes 2627). A detailed discussion on the probable mechanisms for these reactions of bromine addition is presented in the article published in 1980 [157]. 

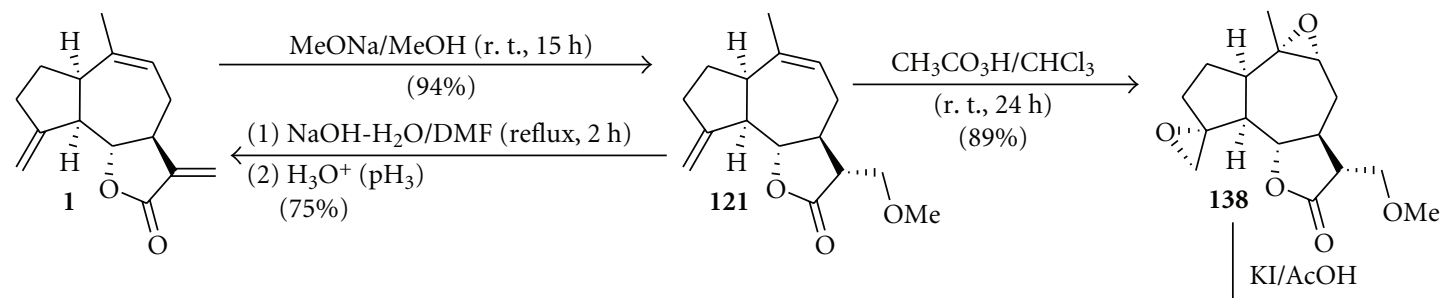

$\mathrm{KI} / \mathrm{AcOH}$

Acetone

(reflux, 10-12 h)<smiles>C=C1C(=O)O[C@H]2[C@H]1C[C@H](O)C(C)=C1CC[C@](C)(O)[C@H]12</smiles>

(1) $\mathrm{NaOH}-\mathrm{H}_{2} \mathrm{O} / \mathrm{DMF}$ (reflux, $2 \mathrm{~h}$ )
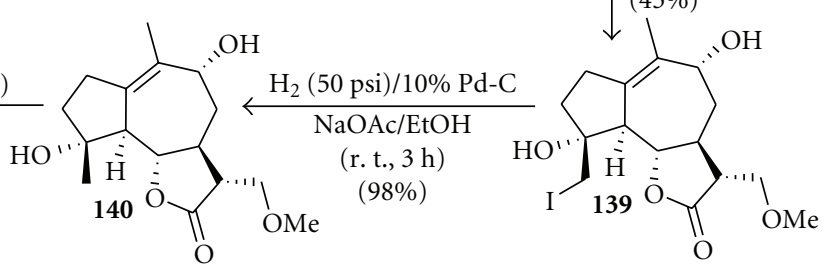

SCheme 32: Synthesis of the diol 141.

Route B

Route A

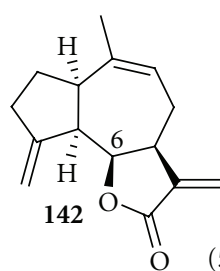

$(57: 43)$

(1) $\mathrm{KOH} / \mathrm{H}_{2} \mathrm{O}$ (reflux, $2 \mathrm{~h}$ )

$+1 \leftarrow \frac{(2) \text { Dryness }}{\text { (3) } \mathrm{MsCl} / \mathrm{Et}_{3} \mathrm{~N}\left(0^{\circ} \mathrm{C}, 1 \text { h; r. t., } 3 \mathrm{~h}\right)}$

(4) $\mathrm{NaOH} / \mathrm{H}_{2} \mathrm{O}\left(50^{\circ} \mathrm{C}, 1 \mathrm{~h}\right)$

(5) $\mathrm{H}_{3} \mathrm{O}^{+}(\mathrm{pH} 3)$

$(91 \%)$
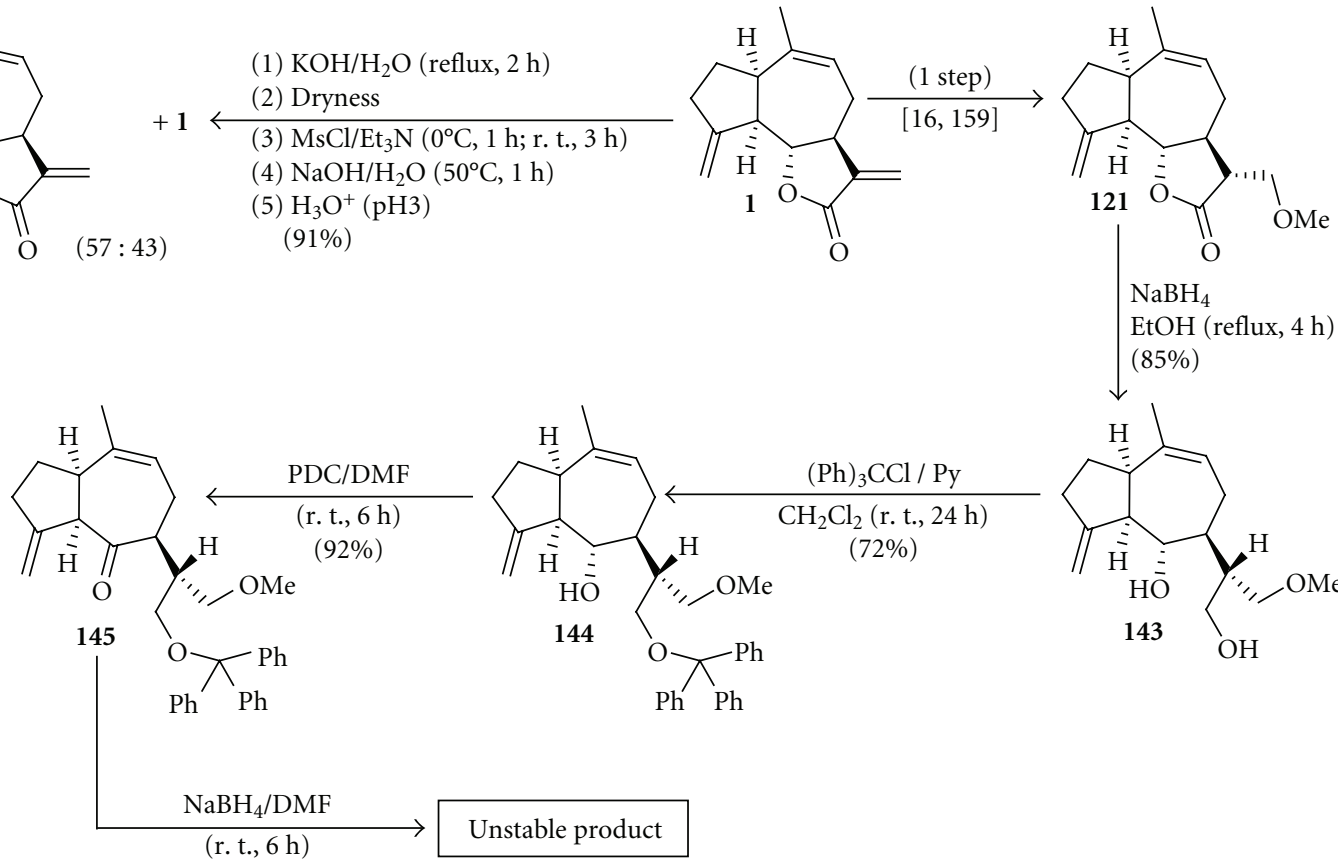

Scheme 33: Synthesis of 6-epi-eremanthine (142).

of reactions developed in that study is depicted in Scheme 28. Epoxidation of eremanthine (1) gave the diepoxide 109 which was submitted to reaction with KI and acetic acid to furnish a mixture of epoxide $\mathbf{1 1 0}$ and allylic alcohol 111. Catalytic hydrogenation of these compounds gave, respectively, the epoxide 112 and diol 113. Treatment of compound 112 with $\mathrm{HClO}_{4}$ resulted in the formation of diol 113 instead of the pseudoguaianolide 114. Reaction of diol
113 with the acids $\mathrm{BF}_{3} \cdot \mathrm{OEt}_{2}$ or $p$-TsOH furnished a mixture of dienes 115 and 116 instead of the desired compound 117 with pseudoguaianolide skeleton. The nonformation of the substances 114 and 117 with pseudoguaianolide skeleton reinforces, once again, the hypothesis that the formation of those compounds with lactonic fusion at the C-6 and C-7 positions need a $\beta$-oxygenated function at the C-6 position of the precursor guaianolide for the occurrence of 


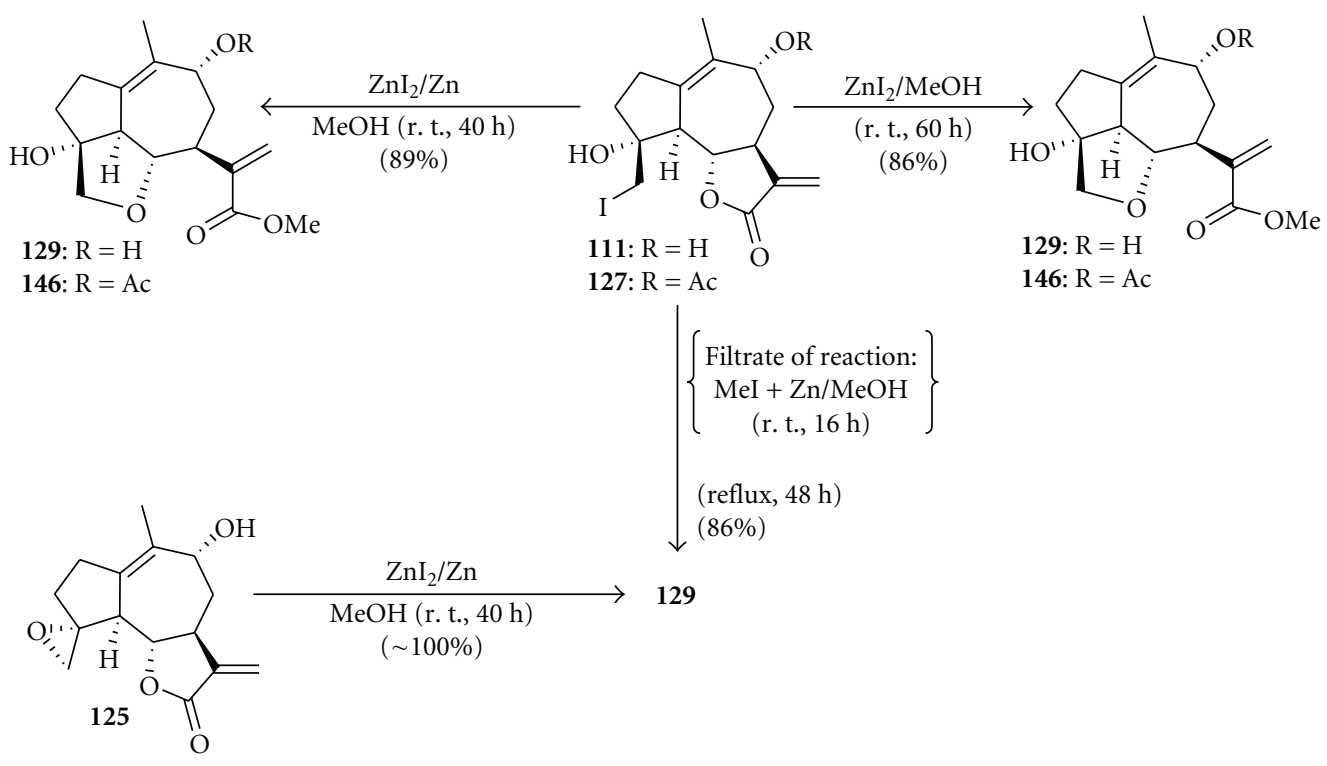

Scheme 34: Methanolysis of the iodohydrins 111 and 127 and epoxide 125.

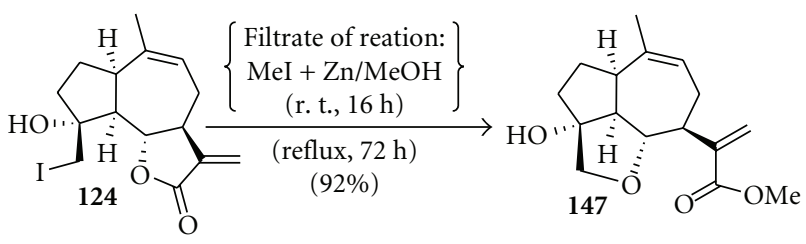

SCHeme 35: Methanolysis of the iodohydrin 124.

the rearrangements preconized by the biogenesis hypothesis of the ambrosanolides (Scheme 13).

6.7. Study of ${ }^{13} C$ NMR Spectroscopy on Eremanthine Derivatives. In 1981 da Silva et al. [158] published an article with the chemical shifts assigned to the carbons of naturally occurring guaianolides eremanthine (1), dehydrocostus lactone (10), eregoyazin (19), eregoyazidin (95), and other semisynthetic lactones derived from eremanthine (1). A detailed discussion correlating the data of ${ }^{13} \mathrm{C}$ NMR with the probable conformations at the seven-membered ring of the investigated guaianolides is presented in the article. The sequences of reactions employed to synthesize the eremanthine derivatives used in the experiments of ${ }^{13} \mathrm{C} \mathrm{NMR}$ spectroscopy of that article are depicted in Scheme 29. The lactones $2,9,10,19,21,85,90,94$, and 95 were obtained by the sequences of reactions outlined in Schemes 1 and 19-21. The others were prepared from known substances by standard simple procedures. The compounds 118, 119, 120, and 121 were prepared by reaction of eremanthine (1) or isoeremanthine (85) with $\mathrm{MeOH} / \mathrm{Na}_{2} \mathrm{CO}_{3}$ or $\mathrm{Me}_{2} \mathrm{NH} / \mathrm{EtOAc}$. The reaction of eremanthine (1) with $m$-chloroperbenzoic acid in $\mathrm{CHCl}_{3}$ at room temperature yielded a mixture of epoxides 9, 8, and 109. The compounds 98 and 122 were obtained by reaction of isoeremanthine $(85)$ with $\mathrm{m}$ chloroperbenzoic acid in $\mathrm{CHCl}_{3}$ at low temperature in a respective proportion of $(62: 21)$. The bromohydrin 123 was prepared by reaction of dibromoether 2 with zinc in refluxing $\mathrm{MeOH}$.

6.8. Studies on the Chemical Reactivity of Epoxides Derived from Eremanthine. The syntheses of guaianolides precursors of the series $\Delta^{1,10}$ and $\Delta^{10,14}$ starting from epoxides derived from eremanthine (1) were studied by Ferreira [15] (Schemes 30-31). The epoxidation of eremanthine (1) with peracetic acid during 5 hours gave a mixture of epoxides 9,8 , and 109 in a respective proportion of $(35: 2: 5)$ (Scheme 30). When this same reaction was performed during $96 \mathrm{~h}$, the diepoxide 109 was obtained as a single product. Treatment of a diluted solution of diepoxide 109 in acetone with $\mathrm{KI}$ and $\mathrm{AcOH}$ furnished a mixture of iodohydrin epoxide $\mathbf{1 1 0}$ and iodohydrin allylic alcohol 111 in a respective proportion of $(13: 12)$. When diepoxide 109 was submitted to this same reaction in a concentrated solution of acetone, the iodohydrin 111 could be isolated as a single product. The iodohydrin 124 was obtained by treatment of monoepoxide 8 with KI and $\mathrm{AcOH}$ in acetone. The transformation of iodohydrin 111 into epoxide $\mathbf{1 2 5}$ was achieved by an intramolecular reaction of nucleophilic substitution by using a solution of $\mathrm{Na}_{2} \mathrm{CO}_{3}$ in 


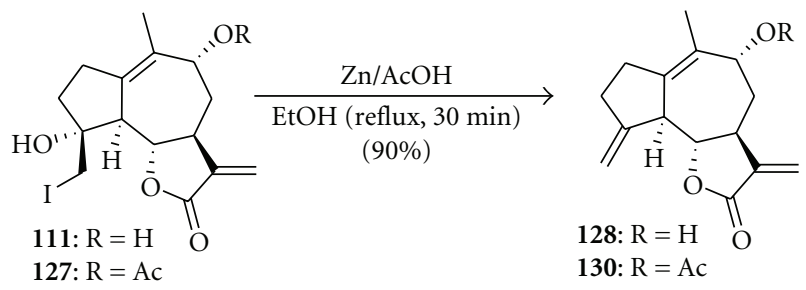

Scheme 36: Synthesis of the trienes $\mathbf{1 2 8}$ and $\mathbf{1 3 0 .}$<smiles>COC[C@H]1C(=O)O[C@H]2[C@H]1CC[C@@H](C)[C@@H]1CC[C@H](O)[C@H]1[C@@H]2COC</smiles>

$(10: 1: 1) \quad \uparrow \mathrm{H}_{2}(60 \mathrm{psi})$ $10 \%$ Pd-C, $\mathrm{NaOAc}$ EtOH (r. t., 48 h) (96\%) $[168,169]$

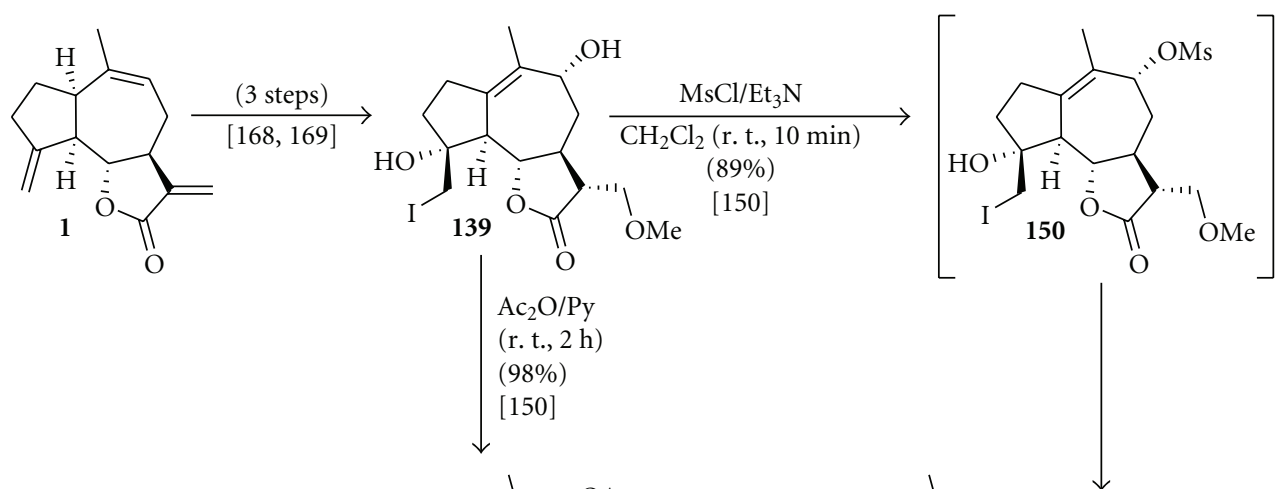

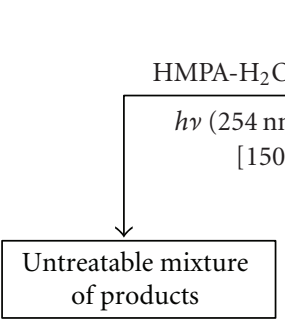<smiles>COC[C@H]1C(=O)O[C@H]2[C@@H]1CC=C(C)C1=CC[C@](O)(CI)[C@H]12</smiles>

$(1: 1)$

Scheme 37: Initial attempts to the synthesis of compound 149.

ethanol. Treatment of $\mathbf{1 1 1}$ in THF with an aqueous solution of $\mathrm{HClO}_{4}$ yielded the diene $\mathbf{1 2 6}$ and the acetylation of $\mathbf{1 1 1}$ with $\mathrm{Ac}_{2} \mathrm{O}$ and pyridine gave allylic acetate 127 . When the iodohydrin 111 was submitted to elimination reaction with zinc in refluxing $\mathrm{MeOH}$, the desired triene $\mathbf{1 2 8}$ was obtained along with another product identified as the oxacycloguaiane methyl ester 129. Acetylation of allylic alcohol 128 with acetic anhydride and DMAP yielded the allylic acetate 130. The opening of epoxide 9 was studied using different conditions (Scheme 31). The reaction of 9 in THF with an aqueous solution of $\mathrm{HClO}_{4}$ yielded allylic alcohol 131 and the opening of epoxide 9 with aluminum oxide (neutral, acid or basic) in refluxing hexane furnished the desired product 131 accompanied by another compound identified as the aldehyde 87. Acetylation of allylic alcohol 131 with $\mathrm{Ac}_{2} \mathrm{O}$ and pyridine gave the acetate 132. The protection of $\alpha$-methylene- $\gamma$-lactone of $\mathbf{1 3 1}$ was achieved by reaction of this compound with methanol and $\mathrm{Na}_{2} \mathrm{CO}_{3}$ to afford the adduct 133. Attempts to deoxygenate the C-9 position of compounds 131 and 133 were performed with limited success. The reaction of allylic alcohol 131 with thionyl chloride and DMF furnished a product identified by attempt 


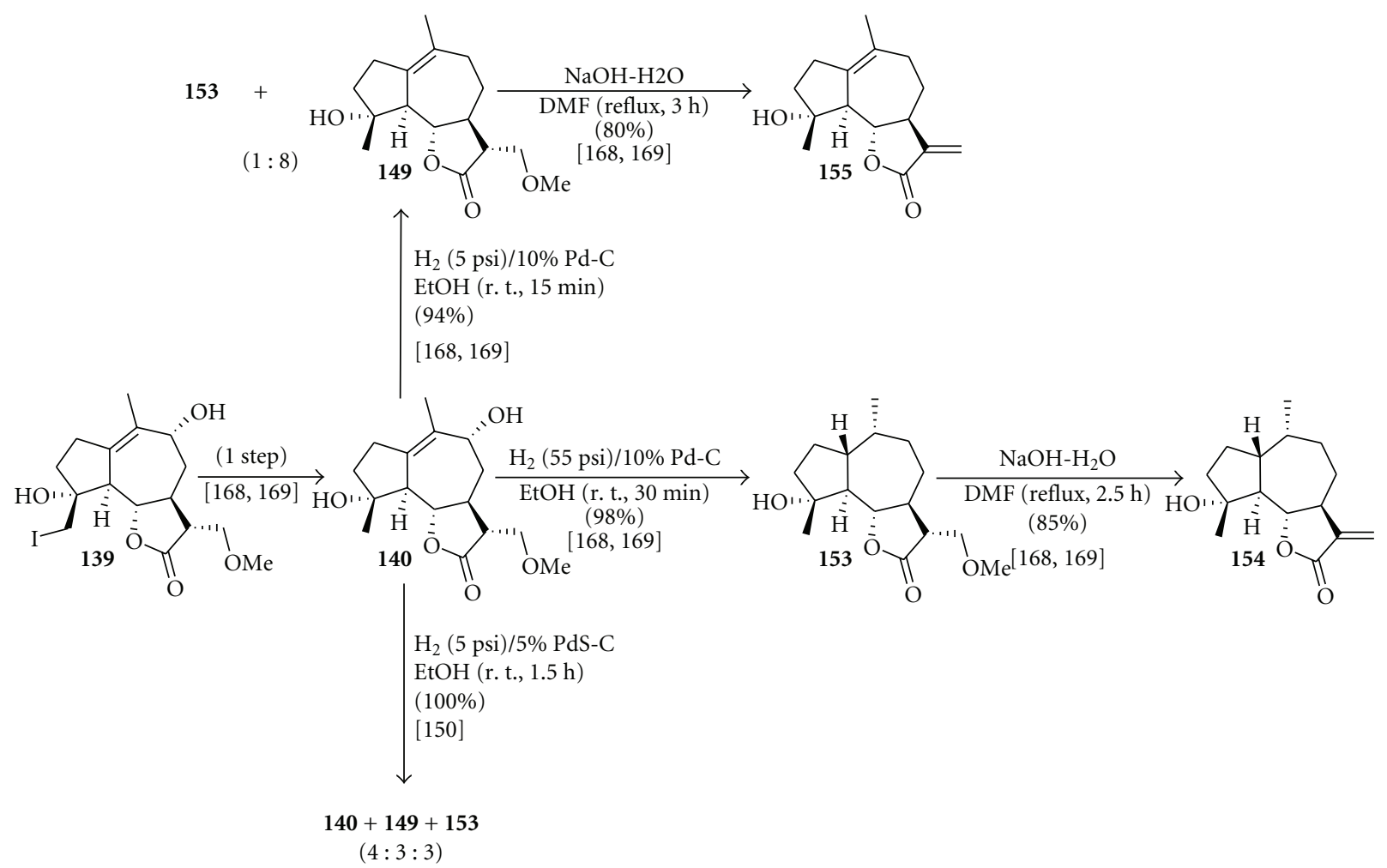

Scheme 38: Syntheses of micheliolide (155) and $1 R, 10 R$-dihydromicheliolide (154).

as allylic chloride 134 . On the other hand, the reaction of 133 with triphenylphosphine and $\mathrm{CCl}_{4}$ gave a mixture of desired product 135 accompanied by another compound identified as the conjugate diene 136. Dechlorination of 135 with zinc and $\mathrm{AcOH}$ in refluxing $\mathrm{MeOH}$ furnished a mixture of two products with the same $R_{f}$ of authentic samples of the methanol adducts of eremanthine (121) and dehydrocostus lactone (137).

6.9. Study on the Chemical Reactivity of Eremanthine: The $\alpha$ Methylene- $\gamma$-Lactone Moiety. With the objective of extending the study on the chemical transformations of eremanthine (1) to the lactonic ring, Fantini [16] developed her Ph.D. thesis focusing the $\alpha$-methylene- $\gamma$-lactone of that substance and of its synthetic derivatives. The syntheses of compounds used in that study are outlined in Schemes 32-35.

The search for a protective group of $\alpha$-methylene- $\gamma$ lactones resistant in certain reaction conditions, for example, catalytic hydrogenation, led to the synthesis of methanol adduct of eremanthine (121). It was verified that in basic conditions (aqueous $\mathrm{NaOH}, \mathrm{DMF}$, reflux), the $\alpha$-methylene$\gamma$-lactone could be regenerated in high yields [159]. The use of methoxyl as protective group for the $\alpha$-methylene- $\gamma$ lactone of eremanthine (1) was accomplished with success during the synthesis of diol 141 (Scheme 32) [16]. The reaction of eremanthine (1) with a solution of $\mathrm{MeONa}$ in methanol gave the adduct 121 . Treatment of this compound with a solution of peracetic acid in chloroform yielded diepoxide 138. The cleavage of oxiranic rings of 138 with
$\mathrm{KI}$ and acetic acid in refluxing acetone furnished iodohydrin 139. Catalytic hydrogenation of $\mathbf{1 3 9}$ with hydrogen, Pd-C, and sodium acetate in EtOH yielded diol 140. This substance was submitted to subsequent step of treatment with an aqueous solution of $\mathrm{NaOH}$ in refluxing DMF to give, after aqueous acid work up, the $\alpha$-methylene- $\gamma$-lactone 141 as the main product of this reaction.

The inversion of configuration at C-6 position of eremanthine (1), aiming at the synthesis of 6-epi-eremanthine (142), was studied by the two sequences of reactions depicted in Scheme $33[16,160]$. In the route $\mathbf{A}$, the inversion of configuration at C-6 position of 1 was planned by the method of oxidation-reduction of secondary hydroxy group in this position. The reduction of carboxy group of the lactonic ring at methanol adduct 121 with $\mathrm{NaBH}_{4}$ in ethanol gave diol 143. In the next step, this compound was submitted to protection of primary hydroxyl with $(\mathrm{Ph})_{3} \mathrm{CCl}$ and pyridine in $\mathrm{CH}_{2} \mathrm{Cl}_{2}$ to furnish compound 144. The oxidation of secondary hydroxyl at $\mathbf{1 4 4}$ was performed with pyridinium dichromate in DMF to afford the ketone 145. Treatment of 145 with sodium borohydride in DMF furnished an unstable product of difficult purification. With this unsatisfactory result, the synthesis of $\mathbf{1 4 2}$ was studied by the route $\mathrm{B}$. The inversion of configuration at C-6 of eremanthine (1) was achieved by displacement of intermediate mesylate generated in this position to afford a mixture of $\mathbf{1}$ and the unstable 6-epi-eremanthine (142) (43:57, $\left.{ }^{1} \mathrm{H} \mathrm{NMR}\right)$. The instability of 142 was attributed to steric effects at the hydroazule system. 


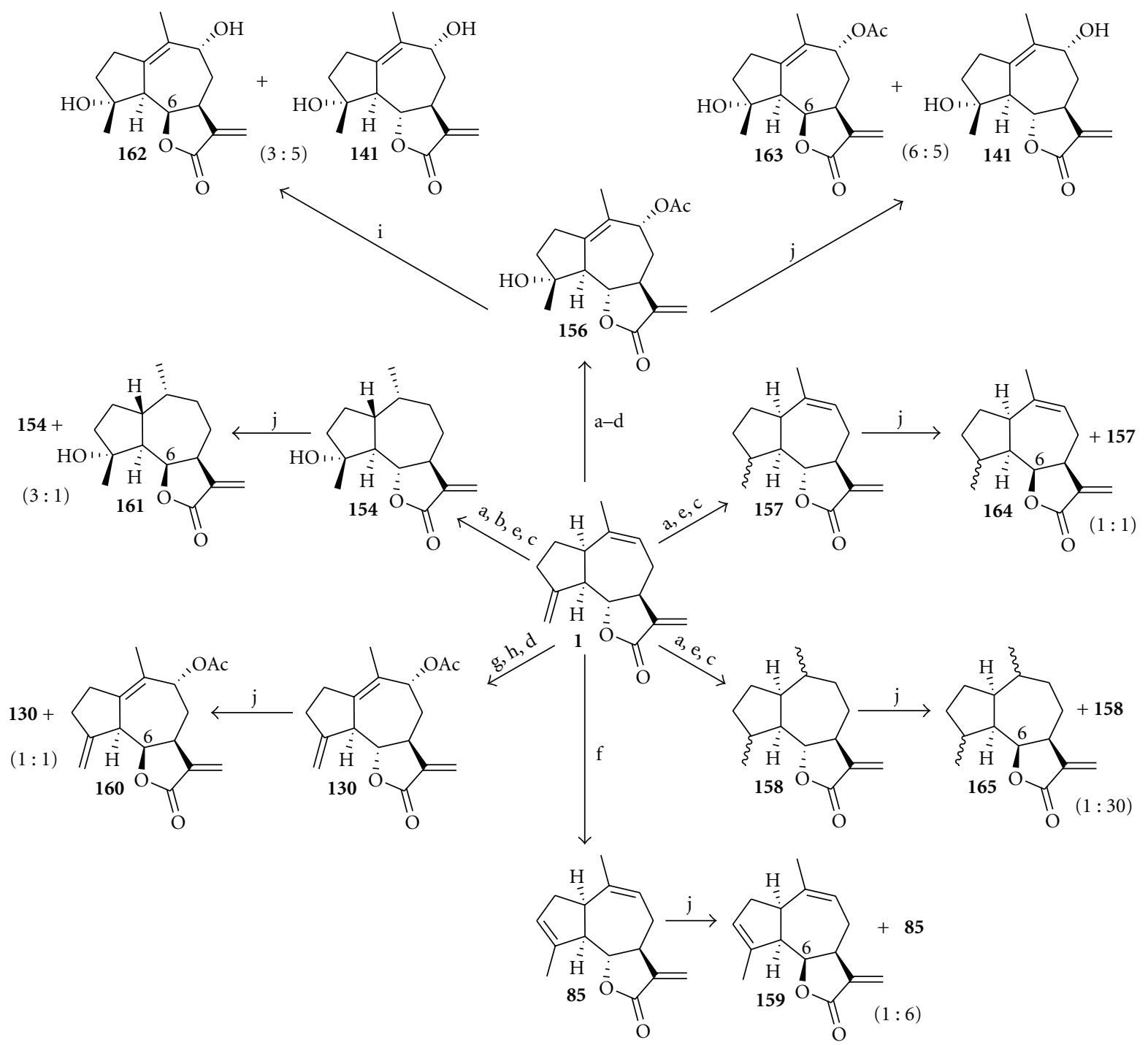

Scheme 39: Syntheses of the substrates 85, 130, 154, and 156-158 and their epimers at C-6 positions (159-165). (a) MeONa, MeOH; (b) (i) $\mathrm{AcO}_{2} \mathrm{H}, \mathrm{CH}_{2} \mathrm{Cl}_{2}$; (ii) $\mathrm{KI}, \mathrm{AcOH}$, acetone; (iii) $\mathrm{H}_{2}, \mathrm{Pd}-\mathrm{C}, \mathrm{NaOAc}, \mathrm{EtOH}$; (c) $\mathrm{NaOH}-\mathrm{H}_{2} \mathrm{O}$, DMF; (d) Ac $\mathrm{O}_{2} \mathrm{O}$, pyridine; (e) $\mathrm{H}_{2}$, Pd-C, EtOH; (f) $\mathrm{BF}_{3} . \mathrm{OEt}_{2}$, benzene; (g) (i) $\mathrm{AcO}_{2} \mathrm{H}, \mathrm{CHCl}_{3}$; (ii) $\mathrm{KI}, \mathrm{AcOH}$, acetone; (h) $\mathrm{Zn}, \mathrm{AcOH}, \mathrm{EtOH}$; (i) (i) $\mathrm{KOH}-\mathrm{H}_{2} \mathrm{O}$ (ii) $\mathrm{Dryness}_{\text {; }}$ (iii) $\mathrm{MsCl}_{3}$ Et ${ }_{3} \mathrm{~N}$, DMSO; (iv) $\mathrm{NaOH}-\mathrm{H}_{2} \mathrm{O}$; (v) $\mathrm{HCl}-\mathrm{H}_{2} \mathrm{O}$; (j) (i) $\mathrm{KOH}-\mathrm{H}_{2} \mathrm{O}$ (ii) Dryness; (iii) $\mathrm{MsCl}, \mathrm{Et}_{3} \mathrm{~N}$, THF; (iv) $\mathrm{NaOH}-\mathrm{H}_{2} \mathrm{O}$; (v) $\mathrm{HCl}-\mathrm{H}_{2} \mathrm{O}$.

After the synthesis of triene 128, obtained in mixture with oxacycloguaiane methyl ester 129 (Scheme 30), there was initiated a study aiming at to optimize the formation of compound $129[15,16,161,162]$. As a result of this study, the furanic derivatives 129, 146, and 147 were obtained (Schemes 34-35). There is a discussion evaluating the structures of reactive eremanthine derivatives $(111,124,125$, and 127) in comparison with other inert compounds obtained from eremanthine (1) as well as the reactive species responsible for the methanolysis of the lactonic ring in that reaction as reported in an article published in 1986 by Fantini et al. [163].

The reaction of iodohydrin 111 with zinc in refluxing methanol (Scheme 30) showed that furanic derivative $\mathbf{1 2 9}$ was formed after the triene 128. It was also verified that triene 128 did not generate the compound 129. Starting from these observations, it was presumed that the reactive species responsible for the formation of compound $\mathbf{1 2 9}$ was a by-product from the reaction of iodohydrin 111 with zinc $(\mathrm{IZnOH})$ [16]. As an attempt to simulate the reactional system of iodohydrin 111 with zinc in methanol, there was developed a reagent that in fact converted directly the substrate 111 into oxacycloguaiane 129. This reagent was the filtrate of a mixture containing MeI, zinc, and methanol left in contact for $16 \mathrm{~h}$ at room temperature [15]. When iodohydrin 111 was submitted to reaction with this reagent under reflux during $48 \mathrm{~h}$, the oxacycloguaiane $\mathbf{1 2 9}$ was obtained as a single product (Scheme 34). When iodohydrin 124 was submitted to similar conditions, the compound 147 was obtained after $72 \mathrm{~h}$ of reaction (Scheme 35) [15]. In the following stage this reaction was performed with $\mathrm{ZnI}_{2}$. When 


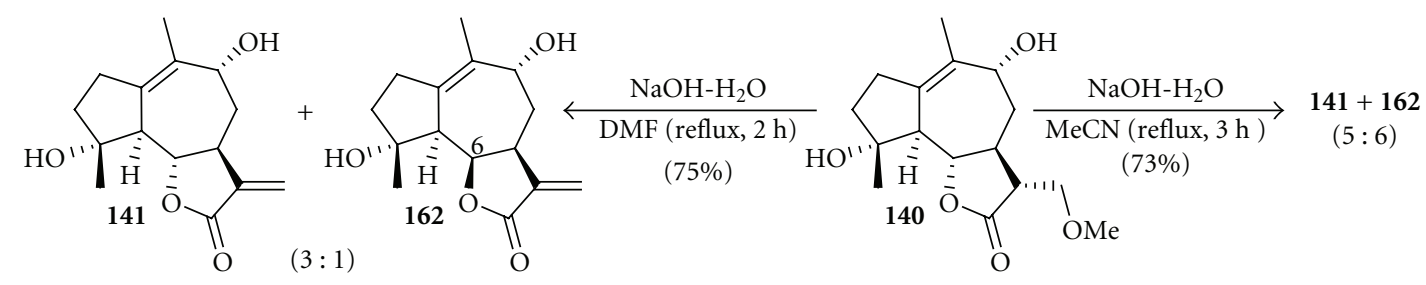

Scheme 40: Inversion of configuration at C-6 position of the diol 141 occurred at the step of methanol elimination on adduct 140.
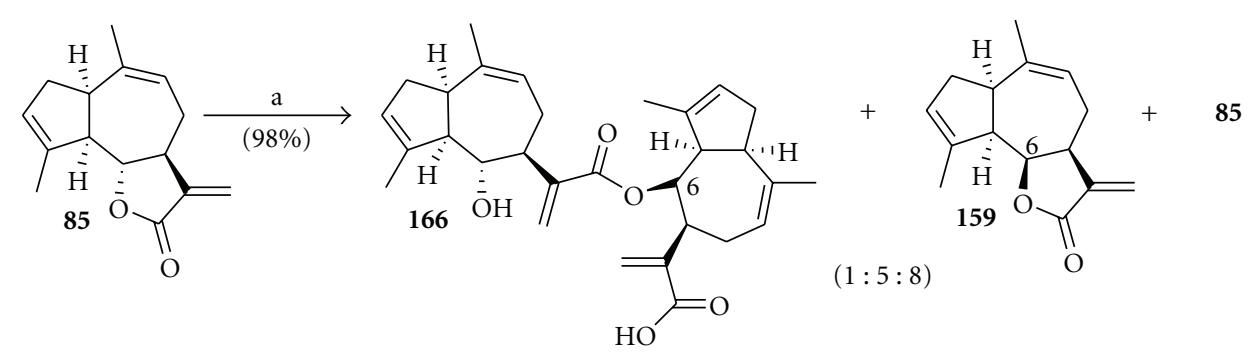

Scheme 41: Synthesis of the compound 166 in mixture with the lactone 159: (a) (i) $\mathrm{KOH}-\mathrm{H}_{2} \mathrm{O}$; (ii) Dryness; (iii) MsCl, Et 3 N, THF (conc.); (iv) $\mathrm{NaOH}-\mathrm{H}_{2} \mathrm{O}$; (v) $\mathrm{HCl}-\mathrm{H}_{2} \mathrm{O}$.

iodohydrins 111, and 127 were allowed to react with $\mathrm{ZnI}_{2}$ in methanol at room temperature, the respective furanic derivatives 129 and 146 were obtained (Scheme 34). It was also verified that the addition of zinc to reactional mixture accelerated the formation of these compounds. When the iodohydrins 111, 127 and epoxide 125 were allowed to react with a mixture of $\mathrm{ZnI}_{2}$, zinc, and methanol at room temperature for $40 \mathrm{~h}$, there was verified the total conversion of these substrates to respective products 129 and 146 (Scheme 34).

6.10. Synthesis of the Trienes 128 and 130. Besides the reactions of her Ph.D. thesis [16], described in the previous subitem (6.9), Fantini developed the synthesis of the trienes 128 and 130 starting from the respective iodohydrins 111 and 127 as a Researcher Professor of the Department of Chemistry at the Rural Federal University of Rio de Janeiro (UFRRJ). The optimized conditions of those reactions were reported in a congress abstract [164] and are depicted in Scheme 36.

6.11. Study of the Inversion Reaction of the Lactonic Fusion on Eremanthine Derivatives and Synthesis of Micheliolide. The last studies with eremanthine (1) were performed by Alves [150]. These studies were developed aiming at the syntheses of substrates derived from the lactone 1 with different structural features to be used in the next stage of inversion of the lactonic fusion employing the conditions depicted in Scheme 33 (route B), aiming to get epimers more stable than 6-epi-eremanthine (142) previously synthesized $[16,160]$. That study of inversion of the lactonic fusion was also planned to obtain a substance with the necessary structural requirements for an eventual investigation of the biomimetic transformation of guaianolide into pseudogua- ianolide, discussed in the text of this review at the subitems 3.1 (Scheme 13) and 6.6 (Scheme 28). There was also studied the synthesis of micheliolide, a naturally occurring substance initially isolated from Michelia compressa with relevant biological activity [165]. In the following subitems are described the sequences of reactions that were developed aiming to attain these objectives [150, 166-170] as well as the results of the study from the reactions of catalytic hydrogenation and methanol addition to $\alpha$-methylene- $\gamma$-lactone of eremanthine derivatives [171].

6.11.1. Study on the Synthesis of Micheliolide. The synthesis of micheliolide (155) was studied by the sequences of reactions depicted in Schemes 37 and 38. Initial attempts to deoxygenate the C-9 position of acetate 148 and iodohydrin 139 with concomitant hydrogenolysis of the bond C15-I in these compounds were unsuccessful [150]. When the allylic acetate 148 was submitted to photolysis conditions in a solution of HMPA and water, using the procedure reported by Deshayes et al. [172], an untreatable mixture of products was obtained instead of the desired compound 149 (Scheme 37). On the other hand, treatment of iodohydrin 139 with $\mathrm{MsCl}$ and $\mathrm{Et}_{3} \mathrm{~N}$ in dichloromethane, by the procedure of Crossland and Servis [173], generated a mixture of conjugate dienes 151 and 152 instead of the intermediate mesylate at C-9 position (150), which would be used in the next step of hydrogenolysis with $\mathrm{NaBH}_{3} \mathrm{CN}$ in HMPA by the procedure of Hutchins et al. [174], aiming to obtain the target molecule 149. The author is disregarding in this review the preliminary results reported before about this reaction [166]. On that occasion this reaction was described in the following way: treatment of 139 with $\mathrm{MsCl} / \mathrm{Et}_{3} \mathrm{~N} / \mathrm{CH}_{2} \mathrm{Cl}_{2}$ (r. t.) followed by 


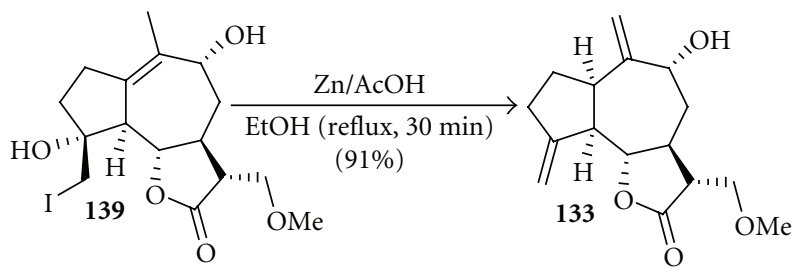

Scheme 42: Synthesis of the allylic alcohol 133.

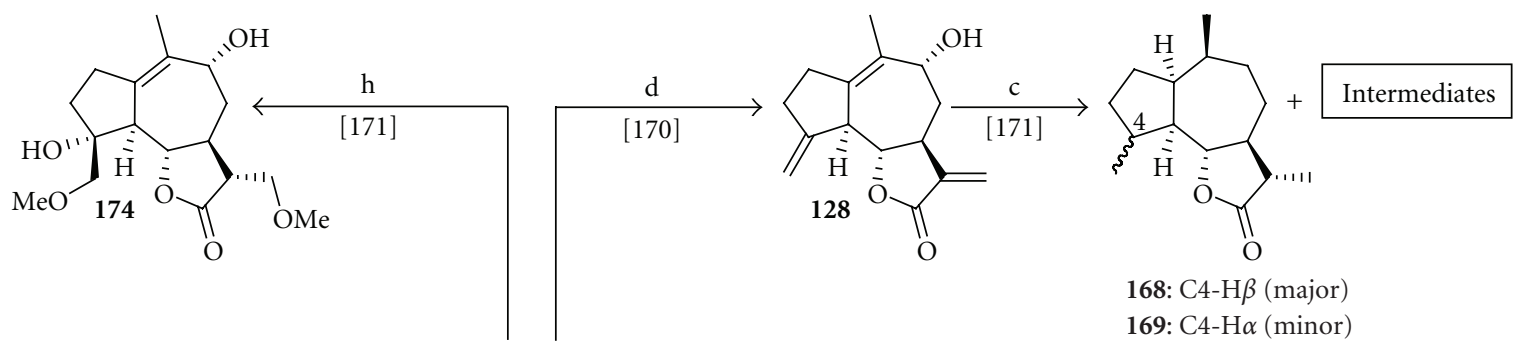

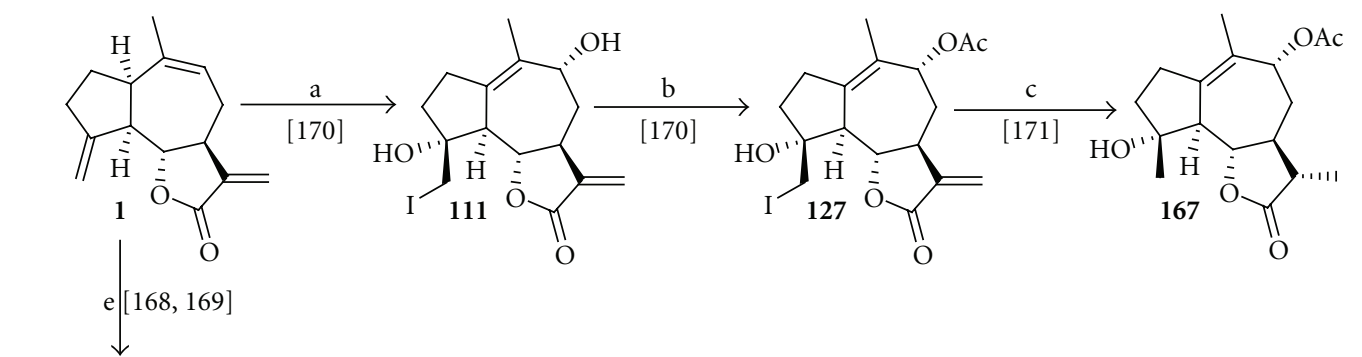

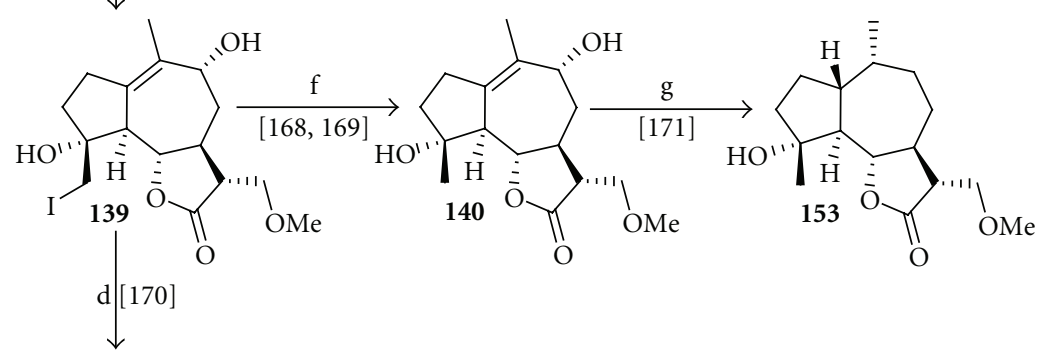

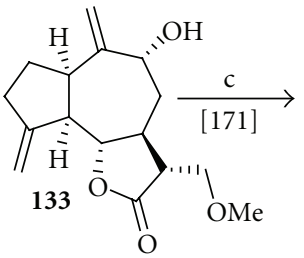<smiles>COC[C@H]1C(=O)O[C@H]2[C@H]1[C@H](C)CC[C@H]2CCC(C)C</smiles>

$(5: 1)$<smiles>COC[C@H]1C(=O)O[C@H]2[C@H]1[CH+]C[C@H](C)[C@H]1CCC(C)[C@@H]21</smiles><smiles>COC[C@H]1C(=O)O[C@H]2[C@H]1CCC(C)[C@H]1CC[C@H](C)[C@@H]21</smiles>

(traces)<smiles>CCC(C)[C@@H]1CC[C@@H](I)[C@@H]2[C@@H](COC)C(=O)O[C@H]12</smiles>

(traces)

Scheme 43: Preparation of the substrates 111, 127, 128, 133, and 140 and subsequent reactions of catalytic hydrogenation as well as methanol addition to $\alpha$-methylene- $\gamma$-lactone of the iodohydrin 111. (a) (i) $\mathrm{AcO}_{2} \mathrm{H}, \mathrm{CHCl}_{3}$; (ii) $\mathrm{KI}, \mathrm{AcOH}$, acetone; (b) $\mathrm{Ac} 2 \mathrm{O}$, pyridine; (c) $\mathrm{H}_{2}$, $\mathrm{Pd}-\mathrm{C}$, $\mathrm{EtOH}$; (d) $\mathrm{Zn}, \mathrm{AcOH}, \mathrm{EtOH}$; (e) (i) $\mathrm{MeONa}, \mathrm{MeOH}$; (ii) $\mathrm{AcO}_{2} \mathrm{H}, \mathrm{CH}_{2} \mathrm{Cl}_{2}$; (iii) $\mathrm{KI}, \mathrm{AcOH}$, acetone; (f) $\mathrm{H}_{2}, \mathrm{Pd}-\mathrm{C}, \mathrm{NaOAc}, \mathrm{EtOH}$; (g) $\mathrm{H}$, Pt-C, EtOH; (h) MeONa, MeOH.

$\mathrm{NaBH}_{3} \mathrm{CN} / \mathrm{HMPA}$ (r. t.) furnished dienes $\left(\Delta^{1,2}, \Delta^{9,10}\right)\left({ }^{1} \mathrm{H}\right.$ NMR $\left.200 \mathrm{MHz}, \mathrm{CDCl}_{3}, 5.85, \mathrm{~m}, 1 \mathrm{H}, \mathrm{C} 2-\mathrm{H}\right)$ [166]. On that time, in which that abstract was written with the results from scientific initiation of the author, his supervisor described the ${ }^{1} \mathrm{H}$ NMR data of only one elimination product (compound
151). For the occasion of the M.S., the author obtained the ${ }^{1} \mathrm{H}$ NMR spectrum of the crude product from the mesylation reaction described in Scheme 37 and he detected the presence of the conjugate dienes 151 and $152(1: 1)$ [150], concluding that the mesylate $\mathbf{1 5 0}$ is formed and it 


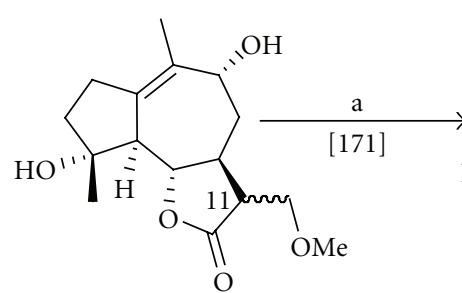

$140: \mathrm{C} 11-\mathrm{H} \beta$

$175: \mathrm{C} 11-\mathrm{H} \alpha$

$140: 175=1: 1$

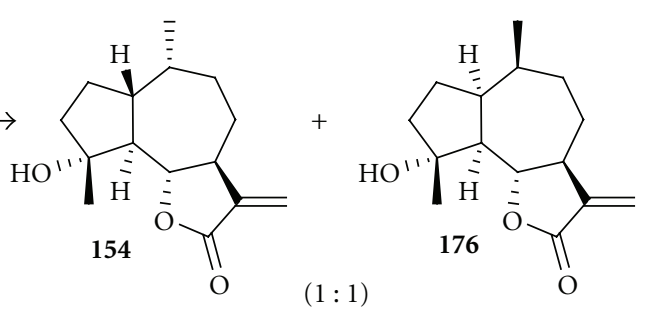

$(1: 1)$

Scheme 44: Synthesis of the compound 176 in mixture with the lactone 154: (a) (i) $\mathrm{H}_{2}$, Pd-C, EtOH; (ii) $\mathrm{NaOH}_{-} \mathrm{H}_{2} \mathrm{O}, \mathrm{DMF}$.

is instantly converted to the final products of elimination (151 and 152). Therefore, the subsequent and unnecessary step of reduction with $\mathrm{NaBH}_{3} \mathrm{CN}$ was not performed on that occasion of his academic formation (M.S.). It is important to emphasize in this point that the strategy aiming to deoxygenate the C-9 position of allylic acetate $\mathbf{1 4 8}$ and allylic mesylate 150 was unsuccessful due to the following reasons. In the case of the photolysis reaction, the method described by Deshayes et al. [172] is applied to nonactivated carboxylic esters. Evidently the allylic acetate at the substrate $\mathbf{1 4 8}$ is an activated moiety but the chemistry is an experimental science and the author, in that time, should test this reaction with the substance $\mathbf{1 4 8}$ to confirm experimentally the data of literature and know how to execute the reaction in a photochemical reactor. In the case of the attempt to isolate the allylic mesylate 150, this was impossible because electronwithdrawing groups such as $\mathrm{OSO}_{2} \mathrm{R}$ increase the acidity of the hydrogen that is lost in any elimination mechanism (E1, $\mathrm{E} 2$, and $\mathrm{E} 1 \mathrm{cB}$ ) when those groups are conjugated with double bond [175, page 893]. Once again in that time of scientific initiation in which this reaction was performed for the first time, the author had little knowledge of advanced organic chemistry and he should make that reaction to confirm the data described in literature on conjugate eliminations [175, page 900], in which allylic mesylate undergoes elimination reaction to furnish conjugate dienes. That result was also important to confirm the elimination reactions previously occurred with the allylic derivatives of eremanthine 113 (Scheme 28) and 111 (Scheme 30) yielding the respective conjugate dienes 115-116 [148] and 126 [15]. With those unsatisfactory results, the synthesis of compound 149 was attempted by catalytic hydrogenation of iodohydrin 139 with $\mathrm{NaOAc}$ in EtOH, using a longer reaction time and a higher hydrogen pressure than those commonly used to get diol 140 (Scheme 32). In those reaction conditions (60 psi of hydrogen, r. t., $48 \mathrm{~h}$ ), the desired compound 149 was obtained as the minor product in mixture with diol 140 and compound 153 (Scheme 37) [168, 169].

In the next stage, the hydrogenolysis reaction aiming at the synthesis of compound 149 was performed with the substrate 140 (Scheme 38), using the hydrogenolysis conditions of allylic alcohols reported by House [176, page 23]. When diol 140 in EtOH was submitted to hydrogenation (55 psi of hydrogen) with Pd-C, a compound identified as $\mathbf{1 5 3}$ was obtained as a result of hydrogenolysis of the bond $\mathrm{C} 9-\mathrm{OH}$ and hydrogenation of tetrasubstituted double bond C1-C10. Attempt to perform only hydrogenolysis of the bond C9$\mathrm{OH}$ on diol 140 without reduction of double bond C1-C10 was carried out using a less reactive catalyst (PdS-C) than $\mathrm{Pd}-\mathrm{C}$ in EtOH under low hydrogen pressure (5 psi). After the reaction time $(1.5 \mathrm{~h}, \mathrm{r} . \mathrm{t}$.), the substrate $\mathbf{1 4 0}$ was recovered in mixture with 149 and 153 in a respective proportion of $(4: 3: 3)$ [150]. Hydrogenation of allylic alcohol 140 using a low hydrogen pressure $(5 \mathrm{psi})$ during a short reaction time (15 $\mathrm{min})$ generated the target compound $\mathbf{1 4 9}$ as the main product of this reaction in mixture with the lactone $\mathbf{1 5 3}$ in a respective proportion of $(8: 1)$, according to ${ }^{1} \mathrm{H} N M R$ spectrum of crude product from that reaction. The probable causes from the low reactivity of allylic alcohol 139 in catalytic hydrogenation reaction with $\mathrm{NaOAc}$, in opposition to the high reactivity of the similar allylic alcohol 140 without the use of $\mathrm{NaOAc}$, were reported in a recently published work [171]. Elimination of methanol on the compounds 149 and 153 generated the respective $\alpha$-methylene- $\gamma$-lactones micheliolide (155) and 1R,10R-dihydromicheliolide (154) (Scheme 38).

\subsubsection{Study of the Inversion Reaction of the Lactonic Fusion on} Eremanthine Derivatives. The inversion of configuration at C-6 position on eremanthine derivatives was studied with the substrates 85, 130, 154, and 156-158 shown in Scheme 39. These substances were prepared from eremanthine (1) by simple standard procedures and were described in recent articles [168-170]. After exposure of these substrates to reaction conditions of inversion of the lactonic fusion, epimeric mixtures at C-6 were obtained in different proportions (Scheme 39). The variations in the proportions of products with cis lactonic fusion obtained in that work were attributed to steric effects at the hydroazulene system. A detailed discussion on the probable causes of variation in the proportions of products with cis lactonic fusion displayed in Scheme 39 was reported in a recent article and in its supplementary information [170]. The author would like to make a correction on the major product of the inversion reaction of lactonic fusion of the allylic acetate $\mathbf{1 5 6}$ (Scheme 39) previsously described in a congress abstract [167]. The major product obtained in that reaction is the allylic acetate 163 and not the allylic alcohol 162 
as it was written in an equivocal way in that abstract [167].

An intriguing result was obtained in the reaction of diol 140 with aqueous $\mathrm{NaOH}$ in refluxing DMF (Scheme 40). The product of this reaction was identified by ${ }^{1} \mathrm{H} N M R$ as a mixture of epimers 141 and $162(3: 1)$. After acetylation of this mixture with $\mathrm{Ac}_{2} \mathrm{O}$ and pyridine, the major product 156 was separated and then used in reaction of inversion of the lactonic fusion (Scheme 39) [170]. The author would like to explain that the allylic acetate $\mathbf{1 5 6}$ was obtained for the first time in his works of scientific initiation [166] and M.S. [150] and not as it was previously described in an equivocal way [167]. It was reported in the congress abstract [167] that the substance 156 had been obtained in a work of Ph.D. [16], but the compound obtained in that thesis [16] was the diol 141 (Scheme 32). Reinvestigation of the methanol elimination on diol 140 using $\mathrm{MeCN}$ as the solvent of reaction resulted in generation of the epimeric mixture 141 and 162. The major product of that reaction was the epimer 162 with cis lactonic fusion obtained in a proportion of $(6: 5)\left({ }^{1} \mathrm{H}\right.$ NMR) in relation to compound 141 (Scheme 40) [170]. The allylic alcohol 162 and its correspondent allylic acetate 163 possess the necessary structural requirements to unchain the rearrangements preconized by the hypothesis of the biotransformation of guaianolide into pseudoguaianolide (ambrosanolide) reported by Fischer et al. [14].

It was verified at the step of inversion of the lactonic fusion on isoeremanthine (85) that the use of concentrated solutions of that substrate in THF generated 6-epiisoeremanthine (159) in mixture with a minor product identified by ${ }^{1} \mathrm{H}$ NMR as the compound 166 (5:1) (Scheme 41) [170]. The allylic alcohol 133, was obtained when iodohydrin 139 was treated with zinc and acetic acid in refluxing EtOH (Scheme 42). The speculative mechanism of this reaction was published in a recent article [170].

6.12. Study of Catalytic Hydrogenation and Methanol Addition to $\alpha$-Methylene- $\gamma$-Lactone of Eremanthine Derivatives. Besides the sequences of reactions described in the previous subitem (6.11), Alves [171] also studied the reactivity of allylic derivatives 127, 128, 133, and 140 in catalytic hydrogenation reactions as well as the methanol addition to $\alpha$-methylene- $\gamma$-lactone of iodohydrin 111 (Scheme 43). Catalytic hydrogenation of iodohydrin acetate $\mathbf{1 2 7}$ in EtOH with hydrogen and Pd-C yielded a single product identified by ${ }^{1} \mathrm{H}$ NMR as the allylic acetate $\mathbf{1 6 7}$. On the other hand, catalytic hydrogenation of allylic alcohol 128 in EtOH with hydrogen and $\mathrm{Pd}-\mathrm{C}$ furnished a complex mixture of substances. After a meticulous analysis of the ${ }^{1} \mathrm{H}$ NMR and ${ }^{13} \mathrm{C}$ NMR spectra, in combination with the calculations of molecular modeling, it was verified that the mixture obtained in the reaction was composed by intermediates that did not totally react and two products were resultant from hydrogenation of the reactive functions of the substrate 128, characterized as the isomers 168 (major) and $\mathbf{1 6 9}$ (minor). Hydrogenation of allylic alcohol 133 afforded a mixture of products characterized by ${ }^{1} \mathrm{H}$ NMR as the compounds 170 and $171(5: 1)$ in mixture with traces of the lactones 172 and 173 . The stereochemistry of methyl groups C-14 and $\mathrm{C}-15$ at the major product $\mathbf{1 7 0}$ was determined by NOE experiment. The catalytic hydrogenation reaction of allylic alcohol 140 using the catalyst $\mathrm{Pt}-\mathrm{C}$ and low hydrogen pressure generated the compound $\mathbf{1 5 3}$ in quantitative yield. The treatment of iodohydrin 111 with a solution of $\mathrm{NaOMe}$ in methanol at room temperature furnished a single product characterized by ${ }^{1} \mathrm{H}$ NMR as the dimethoxylated compound 174 , as result of methanol addition to $\alpha$-methylene- $\gamma$-lactone and nucleophilic substitution at C-15.

The catalytic hydrogenation of allylic alcohol $\mathbf{1 4 0}$ in mixture with its epimer at C-11 position (175), followed by the step of methanol elimination, generated a mixture of compounds 154 and 176 (Scheme 44). This result suggests that the addition of hydrogen to double bond $\mathrm{C} 1-\mathrm{C} 10$ on this mixture of allylic alcohols is induced by the group $\mathrm{CH}_{2} \mathrm{OMe}$ at $\mathrm{C}-11$ position. A detailed discussion on the reactivity of allylic derivatives from eremanthine shown in Schemes 4344 , in catalytic hydrogenation reaction, was presented in a recently published work including analysis of molecular modeling with the use of molecular mechanic tools (MM2 calculation) [171].

\section{Conclusions}

This review about the chemistry of eremanthine (1) has demonstrated the usefulness of the chiron approach to the syntheses of other sesquiterpene lactones derived from $\mathbf{1}$, by the use of a building block with well-established stereocenters as starting material. From the described synthetic studies it was possible to know the reactivity of several functional groups at the compound $\mathbf{1}$ as well as in other derivatives obtained from 1 . Although the chemistry of eremanthine and its derivatives has been quite explored, there is still opportunity for new discoveries and syntheses of new substances by using this natural sesquiterpenoid as starting material.

\section{Acknowledgments}

J. C. F. Alves thanks FAPERJ and CNPq for the fellowships to develop the project "Chemical transformations of natural substances. I-Studies with eremanthine" [177], Professor Dr. Edna C. Fantini (in memoriam) for the supervision of the research project, and the Rural Federal University of Rio de Janeiro (UFRRJ) for the reception during the period in which the project was developed.

\section{References}

[1] W. Vichnewski and B. Gilbert, "Schistosomicidal sesquiterpene lactone from Eremanthus elaeagnus," Phytochemistry, vol. 11, no. 8, pp. 2563-2566, 1972.

[2] P. M. Baker, C. C. Fortes, E. G. Fortes et al., "Chemoprophylactic agents in schistosomiasis: eremanthine, costunolide, $\alpha$-cyclocostunolide and bisabolol," Journal of Pharmacy and Pharmacology, vol. 24, no. 11, pp. 853-857, 1972.

[3] M. S. Silvério, O. V. Sousa, G. Del-Vechio-Vieira, M. A. Miranda, F. C. Matheus, and M. A. C. Kaplan, "Pharmacological properties of the ethanol extract from Eremanthus erythropappus (DC.) McLeisch (Asteraceae)," Brazilian Journal of Pharmacognosy, vol. 18, no. 3, pp. 430-435, 2008. 
[4] A. Corbella, P. Gariboldi, G. Jommi, F. Orsini, and G. Ferrari, "Structure and absolute stereochemistry of vanillosmin, a guaianolide from Vanillosmopsis erythropappa," Phytochemistry, vol. 13, no. 2, pp. 459-465, 1974.

[5] M. Garcia, A. J. R. da Silva, P. M. Baker, B. Gilbert, and J. A. Rabi, "Absolute stereochemistry of eremanthine, a schistosomicidal sesquiterpene lactone from Eremanthus elaeagnus," Phytochemistry, vol. 15, no. 2, pp. 331-332, 1976.

[6] P. D. D. B. Lima, M. Garcia, and J. A. Rabi, "Selective extraction of $\alpha$-methylene- $\gamma$-lactones. Reinvestigation of Vanillosmopsis erythropappa," Journal of Natural Products, vol. 48, no. 6, pp. 986-988, 1985.

[7] J. F. M. Pérez, J. R. S. Scolforo, A. D. de Oliveira, J. M. de Mello, L. F. R. Borges, and J. F. Camolesi, "Management system for native candeia forest (Eremanthus erythropappus (DC.) MacLeish) - the option for selective cutting," Cerne, vol. 10, no. 2, pp. 257-273, 2004.

[8] A. D. de Oliveira, I. S. A. Ribeiro, J. R. S. Scolforo, J. M. de Mello, F. W. Acerbi Jr., and J. F. Camolesi, "Market chain analysis of candeia timber (Eremanthus erythropappus)," Cerne, vol. 15, no. 3, pp. 257-264, 2009.

[9] One of the industries of essential oils that extract the oil from Eremanthus erythropappus is Citróleo Indústria e Comércio de Óleos Essenciais Ltda, http://www.citroleo.com.br/.

[10] G. P. P. Kamatou and A. M. Viljoen, "A review of the application and pharmacological properties of $\alpha$-bisabolol and $\alpha$-bisabolol-rich oils," Journal of the American Oil Chemists' Society, vol. 87, no. 1, pp. 1-7, 2010.

[11] A. T. de Souza, T. L. Benazzi, M. B. Grings et al., "Supercritical extraction process and phase equilibrium of Candeia (Eremanthus erythropappus) oil using supercritical carbon dioxide," The Journal of Supercritical Fluids, vol. 47, no. 2, pp. 182-187, 2008.

[12] S. Yuuya, H. Hagiwara, T. Suzuki et al., "Guaianolides as immunomodulators. Synthesis and biological activities of dehydrocostus lactone, mokko lactone, eremanthin, and their derivatives," Journal of Natural Products, vol. 62, no. 1, pp. 22-30, 1999.

[13] J. W. de Kraker, M. C. R. Franssen, M. Joerink, A. de Groot, and H. J. Bouwmeester, "Biosynthesis of costunolide, dihydrocostunolide, and leucodin. Demonstration of cytochrome P450-catalyzed formation of the lactone ring present in sesquiterpene lactones of chicory," Plant Physiology, vol. 129, no. 1, pp. 257-268, 2002.

[14] N. H. Fischer, E. J. Olivier, and H. D. Fischer, "The biogenesis and chemistry of sesquiterpene lactones," in Progess in the Chemistry of Organic Natural Products, W. Herz, H. Grisebach, and G. W. Kirby, Eds., vol. 38, pp. 47-390, Springer, New York, NY, USA, 1979.

[15] J. L. P. Ferreira, Studies on the chemical reactivity of epoxides derived from eremanthine, M.Sc. dissertation, NPPN, Universidade Federal do Rio de Janeiro, Rio de Janeiro, Brazil, 1985.

[16] E. C. Fantini, Study on the chemical reactivity of eremanthine. The $\alpha$-methylene- $\gamma$-lactone moiety, Ph.D. thesis, Universidade Federal do Rio de Janeiro, Rio de Janeiro, Brazil, 1985.

[17] N. H. Fischer, Y. F. Wu-Shih, G. Chiari, F. R. Fronczek, and S. F. Watkins, "Molecular structure of a cis-decalin-type eudesmanolide and its formation from a guaianolide-1(10)epoxide," Journal of Natural Products, vol. 44, no. 1, pp. 104110, 1981.

[18] J. E. Barquera-Lozada and G. Cuevas, "Biogenesis of sesquiterpene lactones pseudoguaianolides from germacranolides: theoretical study on the reaction mechanism of terminal biogenesis of 8-epiconfertin," The Journal of Organic Chemistry, vol. 74, no. 2, pp. 874-883, 2009.

[19] A. Ortega and E. Maldonado, "A one step transformation of $4 \alpha, 5 \beta$-epoxygermacranolide into pseudoguaianolide," Heterocycles, vol. 29, no. 4, pp. 635-638, 1989.

[20] M. J. Bordoloi, R. P. Sharma, and J. C. Sarma, "Biomimetic transformation of a guaianolide to a pseudoguaianolide," Tetrahedron Letters, vol. 27, no. 38, pp. 4633-4634, 1986.

[21] B. M. Fraga, "Natural sesquiterpenoids," Natural Product Reports, vol. 27, no. 11, pp. 1681-1708, 2010.

[22] D. N. Cavalcanti, M. A. V. Gomes, A. C. Pinto, C. M. de Rezende, R. C. Pereira, and V. L. Teixeira, "Effects of storage and solvent type in a lipophylic chemical profile of the seaweed Dictyota menstrualis," Brazilian Journal of Oceanography, vol. 56, no. 1, pp. 51-57, 2008.

[23] J. C. De-Paula, L. B. Bueno, D. N. Cavalcanti, Y. YoneshigueValentin, and V. L. Teixeira, "Diterpenes from the brown alga Dictyota crenulata," Molecules, vol. 13, no. 6, pp. 1253-1262, 2008.

[24] M. A. Vallim, V. L. Teixeira, and R. C. Pereira, "Feedingdeterrent properties of diterpenes of Dictyota mertensii (phaeophyceae, dictyotales)," Brazilian Journal of Oceanography, vol. 55, no. 3, pp. 223-229, 2007.

[25] X. Zhang, H. Wang, J. Sheng, and X. Luo, "A new guaiane diterpenoid from Euphorbia wallichii," Natural Product Research, vol. 20, no. 1, pp. 89-92, 2006.

[26] S. A. Kolesnikova, A. I. Kalinovsky, S. N. Fedorov, L. K. Shubina, and V. A. Stonik, "Diterpenes from the far-eastern brown alga Dictyota dichotoma," Phytochemistry, vol. 67, no. 19, pp. 2115-2119, 2006.

[27] J. W. Blunt, B. R. Copp, M. H. G. Munro, P. T. Northcote, and M. R. Prinsep, "Marine natural products," Natural Product Reports, vol. 23, no. 1, pp. 26-78, 2006.

[28] J. W. Blunt, B. R. Copp, M. H. G. Munro, P. T. Northcote, and M. R. Prinsep, "Marine natural products," Natural Product Reports, vol. 22, no. 1, pp. 15-61, 2005.

[29] M. A. Vallim, J. C. de Paula, R. C. Pereira, and V. L. Teixeira, "The diterpenes from Dictyotacean marine brown algae in the tropical Atlantic American region," Biochemical Systematics and Ecology, vol. 33, no. 1, pp. 1-16, 2005.

[30] P. Siamopoulou, A. Bimplakis, D. Iliopoulou et al., "Diterpenes from the brown algae Dictyota dichotoma and Dictyota linearis," Phytochemistry, vol. 65, no. 14, pp. 2025-2030, 2004.

[31] S. R. Gedara, O. B. Abdel-Halim, S. H. El-Sharkawy, O. M. Salama, T. W. Shier, and A. F. Halim, "Cytotoxic hydroazulene diterpenes from the brown alga Dictyota dichotoma," Zeitschrift für Naturforschung Section C, vol. 58, no. 1-2, pp. 17-22, 2003.

[32] S. E. N. Ayyad, O. B. Abdel-Halim, W. T. Shier, and T. R. Hoye, "Cytotoxic hydroazulene diterpenes from the brown alga Cystoseira myrica," Zeitschrift für Naturforschung Section C, vol. 58, no. 1-2, pp. 33-38, 2003.

[33] V. L. Teixeira, D. N. Cavalcanti, and R. C. Pereira, "Chemotaxonomic study of the diterpenes from the brown alga Dictyota menstrualis," Biochemical Systematics and Ecology, vol. 29, no. 3, pp. 313-316, 2001.

[34] R. C. Pereira, D. N. Cavalcanti, and V. L. Teixeira, "Effects of secondary metabolites from the tropical Brazilian brown alga Dictyota menstrualis on the amphipod Parhyale hawaiensis," Marine Ecology Progress Series, vol. 205, pp. 95-100, 2000.

[35] M. Gavagnin and A. Fontana, "Diterpenes from marine opisthobranch molluscs," Current Organic Chemistry, vol. 4, no. 12, pp. 1201-1248, 2000. 
[36] D. J. Faulkner, "Marine natural products," Natural Product Reports, vol. 15, no. 2, pp. 113-158, 1998.

[37] R. Durán, E. Zubía, M. J. Ortega, and J. Salvá, "New diterpenoids from the alga Dictyota dichotoma," Tetrahedron, vol. 53, no. 25, pp. 8675-8688, 1997.

[38] G. M. König, A. D. Wright, O. Sticher, and H. Ruegger, "Four new hydroazulenoid diterpenes from the tropical marine brown alga Dictyota volubilis," Planta Medica, vol. 59, no. 2, pp. 174-178, 1993.

[39] V. L. Teixeira, S. A. D. S. Almeida, and A. Kelecom, "Chemosystematic and biogeographic studies of the diterpenes from the marine brown alga Dictyota dichotoma," Biochemical Systematics and Ecology, vol. 18, no. 2-3, pp. 8792, 1990.

[40] V. L. Teixeira and A. Kelecom, "A chemotaxonomic study of diterpenes from marine brown algae of the genus Dictyota," Science of the Total Environment, vol. 75, no. 2-3, pp. 271-283, 1988.

[41] J. T. Vázquez, M. Chang, K. Nakanishi, E. Manta, C. Pérez, and J. D. Martín, "Structure of hydroazulenoid diterpenes from a marine alga and their absolute configuration based on circular dichroism," The Journal of Organic Chemistry, vol. 53, no. 20, pp. 4797-4800, 1988.

[42] S. de Rosa, S. de Stefano, and N. Zavodnik, "Hydroazulenoid diterpenes from the brown alga Dictyota dichotoma var. Implexa," Phytochemistry, vol. 25, no. 9, pp. 2179-2181, 1986.

[43] A. Kelecom and V. L. Teixeira, "Diterpenes of marine brown algae of the family dictyotaceae: their possible role as defense compounds and their use in chemotaxonomy," The Science of the Total Environment, vol. 58, no. 1-2, pp. 109-115, 1986.

[44] H. H. Sun, F. J. McEnroe, and W. Fenical, "Acetoxycrenulide, a new bicyclic cyclopropane-containing diterpenoid from the brown seaweed Dictyota crenulata," The Journal of Organic Chemistry, vol. 48, no. 11, pp. 1903-1906, 1983.

[45] J. Finer, J. Clardy, W. Fenical et al., "Structures of dictyodial and dictyolactone, unusual marine diterpenoids," The Journal of Organic Chemistry, vol. 44, no. 12, pp. 2044-2047, 1979.

[46] A. E. Greene, "Synthesis of (+)-pachydictyol-A," Tetrahedron Letters, vol. 19, no. 9, pp. 851-854, 1978.

[47] B. Danise, L. Minale, R. Riccio et al., "Further perhydroazulene diterpenes from marine organisms," Experientia, vol. 33, no. 4, pp. 413-415, 1977.

[48] D. J. Faulkner, B. N. Ravi, J. Finer, and J. Clardy, "Diterpenes from Dictyota dichotoma," Phytochemistry, vol. 16, no. 7, pp. 991-993, 1977.

[49] L. Minale and R. Riccio, "Constituents of the digestive gland of the molluscs of the genus Aplysia. I. Novel diterpenes from Aplysia depilans," Tetrahedron Letters, vol. 17, no. 31, pp. 2711-2714, 1976.

[50] E. Fattorusso, S. Magno, L. Mayol et al., "Dictyol A and B, two novel diterpene alcohols from the brown alga Dictyota dichotoma," Journal of the Chemical Society, Chemical Communications, no. 14, pp. 575-576, 1976.

[51] D. R. Hirschfeld, W. Fenical, G. H. Y. Lin, R. M. Wing, P. Radlick, and J. J. Sims, "Marine natural products. VIII. Pachydictyol A, an exceptional diterpene alcohol from the brown alga, Pachydictyon coriaceum," Journal of the American Chemical Society, vol. 95, no. 12, pp. 4049-4050, 1973.

[52] Y. Ye, X. Q. Li, and C. P. Tang, "Natural products chemistry research 2006's progress in China," Chinese Journal of Natural Medicines, vol. 6, no. 1, pp. 70-78, 2008.

[53] Q. L. Dang, Y. H. Choi, G. J. Choi et al., "Pesticidal activity of ingenane diterpenes isolated from Euphorbia kansui against
Nilaparvata lugens and Tetranychus urticae," Journal of AsiaPacific Entomology, vol. 13, no. 1, pp. 51-54, 2010.

[54] Q. C. Wu, Y. P. Tang, A. W. Ding, F. Q. You, L. Zhang, and J. A. Duan, " ${ }^{13} \mathrm{C}-\mathrm{NMR}$ data of three important diterpenes isolated from Euphorbia species," Molecules, vol. 14, no. 11, pp. 4454-4475, 2009.

[55] E. Sulyok, A. Vasas, D. Rédei, G. Dombi, and J. Hohmann, "Isolation and structure determination of new 4,12dideoxyphorbol esters from Euphorbia pannonica Host," Tetrahedron, vol. 65, no. 20, pp. 4013-4016, 2009.

[56] Z. Q. Lu, M. Yang, J. Q. Zhang et al., "Ingenane diterpenoids from Euphorbia esula," Phytochemistry, vol. 69, no. 3, pp. 812-819, 2008.

[57] A. R. Jassbi, "Chemistry and biological activity of secondary metabolites in Euphorbia from Iran," Phytochemistry, vol. 67, no. 18, pp. 1977-1984, 2006.

[58] J. K. Cha and O. L. Epstein, "Synthetic approaches to ingenol,” Tetrahedron, vol. 62, no. 7, pp. 1329-1343, 2006.

[59] M. E. Krafft, Y. Y. Cheung, S. A. Kerrigan, and K. A. Abboud, "Synthesis of 'inside-outside' medium-sized rings via ringclosing metathesis," Tetrahedron Letters, vol. 44, no. 4, pp. 839-843, 2003.

[60] J. H. Rigby and M. Fleming, "Construction of the ingenane core using an $\mathrm{Fe}(\mathrm{III})$ or $\mathrm{Ti}(\mathrm{IV})$ Lewis acid-catalyzed intramolecular [6+4] cycloaddition," Tetrahedron Letters, vol. 43, no. 48, pp. 8643-8646, 2002.

[61] M. Blanco-Molina, G. C. Tron, A. Macho et al., "Ingenol esters induce apoptosis in Jurkat cells through an AP-1 and NF- $\kappa \mathrm{B}$ independent pathway," Chemistry and Biology, vol. 8, no. 8, pp. 767-778, 2001.

[62] J. H. Rigby, H. Jingdan, and M. J. Heeg, "Synthetic studies on the ingenane diterpenes. Construction of an $\mathrm{ABC}$ tricycle exhibiting trans-intrabridgehead stereochemistry," Tetrahedron Letters, vol. 39, no. 16, pp. 2265-2268, 1998.

[63] J. A. Marco, J. F. Sanz-Cervera, F. J. Ropero, J. Checa, and B. M. Fraga, "Ingenane and lathyrane diterpenes from the latex of Euphorbia acrurensis," Phytochemistry, vol. 49, no. 4, pp. 1095-1099, 1998.

[64] J. A. Marco, J. F. Sanz-Cervera, and A. Yuste, "Ingenane and lathyrane diterpenes from the latex of Euphorbia canariensis," Phytochemistry, vol. 45, no. 3, pp. 563-570, 1997.

[65] J. D. Winkler, B. C. Hong, A. Bahador, M. G. Kazanietz, and P. M. Blumberg, "Synthesis of ingenol analogs with affinity for protein kinase C," Bioorganic \& Medicinal Chemistry Letters, vol. 3, no. 4, pp. 577-580, 1993.

[66] G. Brooks, A. T. Evans, D. P. Markby, M. E. Harrison, M. A. Baldwin, and F. J. Evans, "An ingenane diterpene from belizian Mabea excelsa," Phytochemistry, vol. 29, no. 5, pp. 1615-1617, 1990.

[67] P. A. Wender, C. L. Hillemann, and M. J. Szymonifka, "An approach to the tiglianes, daphnanes, and ingenanes via the divinylcyclopropane rearrangement," Tetrahedron Letters, vol. 21, no. 23, pp. 2205-2208, 1980.

[68] J. Y. Hong, J. W. Nam, E. K. Seo, and S. K. Lee, "Daphnane diterpene esters with anti-proliferative activities against human lung cancer cells from Daphne genkwa," Chemical \& Pharmaceutical Bulletin, vol. 58, no. 2, pp. 234-237, 2010.

[69] L. Pan, X. F. Zhang, Y. Deng, Y. Zhou, H. Wang, and L. S. Ding, "Chemical constituents investigation of Daphne tangutica," Fitoterapia, vol. 81, no. 1, pp. 38-41, 2010.

[70] S. A. Ayatollahi, A. Shojaii, F. Kobarfard, M. Nori, M. Fathi, and M. I. Choudhari, "Terpens from aerial parts of Euphorbia splendida," Journal of Medicinal Plant Research, vol. 3, no. 9, pp. 660-665, 2009. 
[71] P. Y. Hayes, S. Chow, M. J. Somerville, J. J. de Voss, and M. T. Fletcher, "Pimelotides A and B, diterpenoid ketal-lactone orthoesters with an unprecedented skeleton from Pimelea elongata," Journal of Natural Products, vol. 72, no. 12, pp. 2081-2083, 2009.

[72] R. Yazdanparast and A. Meshkini, "3-hydrogenkwadaphnine, a novel diterpene ester from Dendrostellera lessertii, its role in differentiation and apoptosis of KG1 cells," Phytomedicine, vol. 16, no. 2-3, pp. 206-214, 2009.

[73] C. V. Diogo, L. Félix, S. Vilela et al., "Mitochondrial toxicity of the phyotochemicals daphnetoxin and daphnoretinrelevance for possible anti-cancer application," Toxicology in Vitro, vol. 23, no. 5, pp. 772-779, 2009.

[74] B. Y. Park, B. S. Min, K. S. Ahn et al., "Daphnane diterpene esters isolated from flower buds of Daphne genkwa induce apoptosis in human myelocytic HL-60 cells and suppress tumor growth in Lewis lung carcinoma (LLC)-inoculated mouse model," Journal of Ethnopharmacology, vol. 111, no. 3, pp. 496-503, 2007.

[75] L. Pan, X. F. Zhang, H. F. Wu, and L. S. Ding, "A new daphnane diterpene from Daphne tangutica," Chinese Chemical Letters, vol. 17, no. 1, pp. 38-40, 2006.

[76] R. Yazdanparast and M. A. Moosavi, "Daphnane-type diterpene esters as powerful agents for the treatment of leukemia," Medical Hypotheses, vol. 67, no. 6, pp. 1472-1473, 2006.

[77] A. Tempeam, N. Thasana, C. Pavaro, W. Chuakul, P. Siripong, and S. Ruchirawat, "A new cytotoxic daphnane diterpenoid, rediocide G, from Trigonostemon reidioides," Chemical \& Pharmaceutical Bulletin, vol. 53, no. 10, pp. 1321-1323, 2005.

[78] Z. J. Zhan, C. Q. Fan, J. Ding, and J. M. Yue, "Novel diterpenoids with potent inhibitory activity against endothelium cell HMEC and cytotoxic activities from a well-known TCM plant Daphne genkwa," Bioorganic and Medicinal Chemistry, vol. 13, no. 3, pp. 645-655, 2005.

[79] A. T. Tchinda, A. Tsopmo, M. Tene et al., "Diterpenoids from Neoboutonia glabrescens (Euphorbiaceae)," Phytochemistry, vol. 64, no. 2, pp. 575-581, 2003.

[80] W. He, M. Cik, L. van Puyvelde et al., "Neurotrophic and antileukemic daphnane diterpenoids from Synaptolepis kirkii," Bioorganic and Medicinal Chemistry, vol. 10, no. 10, pp. 3245-3255, 2002.

[81] J. R. Carney, J. M. Krenisky, R. T. Williamson et al., "Maprouneacin, a new daphnane diterpenoid with potent antihyperglycemic activity from Maprounea africana," Journal of Natural Products, vol. 62, no. 2, pp. 345-347, 1999.

[82] F. Abe, Y. Iwase, T. Yamauchi et al., "Minor daphnane-type diterpenoids from Wikstroemia retusa," Phytochemistry, vol. 47, no. 5, pp. 833-837, 1998.

[83] F. Abe, Y. Iwase, T. Yamauchi, K. Kinjo, and S. Yaga, "Daphnane diterpenoids from the bark of Wikstroemia retusa," Phytochemistry, vol. 44, no. 4, pp. 643-647, 1997.

[84] P. C. B. Page, D. C. Jennens, and H. McFarland, "An IMDA approach to tigliane and daphnane diterpenoids: generation of the tetracyclic ring system of the tiglianes," Tetrahedron Letters, vol. 38, no. 39, pp. 6913-6916, 1997.

[85] P. C. B. Page, D. C. Jennens, and H. McFarland, "An IMDA approach to tigliane and daphnane diterpenoids: introduction of the C-12, C-13 C ring oxygenation of phorbol," Tetrahedron Letters, vol. 38, no. 30, pp. 5395-5398, 1997.

[86] Y. Shiryo, K. Kazuhiko, H. Hiroya, M. Naochika, A. Fumiko, and Y. Tatsuo, "Diterpenoids with the daphnane skeleton from Wikstroemia retusa," Phytochemistry, vol. 32, no. 1, pp. 141-143, 1992.
[87] T. Terai, K. Osakabe, M. Katai et al., "Preparation of 9hydroxy grayanotoxin derivatives and their acute toxicity in mice," Chemical \& Pharmaceutical Bulletin, vol. 51, no. 3, pp. 351-353, 2003.

[88] M. Shimizu, Y. Nakagawa, Y. Sato et al., "Studies on endophytic actinomycetes (I) Streptomyces sp. isolated from rhododendron and its antifungal activity," Journal of General Plant Pathology, vol. 66, no. 4, pp. 360-366, 2000.

[89] L. Q. Wang, B. Y. Ding, G. W. Qin, G. Lin, and K. F. Cheng, "Grayanoids from Pieris formosa," Phytochemistry, vol. 49, no. 7, pp. 2045-2048, 1998.

[90] M. Sato, Y. Katsube, M. Katai, J. Katakawa, and T. Tetsumi, "Crystal and molecular structure of asebotoxin IV," Bulletin of the Chemical Society of Japan, vol. 67, no. 3, pp. 866-868, 1994.

[91] N. Harada, "Pharmacological studies on the mechanisms of asebotoxin III-induced centrogenic pulmonary hemorrhagic edema in guinea pigs," Nippon Yakurigaku Zasshi, vol. 81, no. 2, pp. 105-113, 1983.

[92] K. Takeya, Y. Hotta, N. Harada, G. Itoh, and J. Sakakibara, "Asebotoxin-induced centrogenic pulmonary hemorrhage in guinea pigs," The Japanese Journal of Pharmacology, vol. 31, no. 1, pp. 137-140, 1981.

[93] H. Hikino, M. Ogura, S. Fushiya, C. Konno, and T. Takemoto, "Stereostructure of asebotoxin VI, VIII, and IX, toxins of Pieris japonica," Chemical \& Pharmaceutical Bulletin, vol. 25, no. 3, pp. 523-524, 1971.

[94] H. Hikino, T. Ohta, M. Ogura, Y. Ohizumi, C. Konno, and T. Takemoto, "Structure activity relationship of ericaceous toxins on acute toxicity in mice," Toxicology and Applied Pharmacology, vol. 35, no. 2, pp. 303-310, 1976.

[95] H. Hikino, M. Ogura, and T. Takemoto, "Stereostructure of asebotoxin VII, toxin of Pieris japonica," Chemical \& Pharmaceutical Bulletin, vol. 19, no. 9, pp. 1980-1981, 1971.

[96] R. J. Peters, "Two rings in them all: the labdane-related diterpenoids," Natural Product Reports, vol. 27, no. 11, pp. 1521-1530, 2010.

[97] F. Berrue and R. G. Kerr, "Diterpenes from gorgonian corals," Natural Product Reports, vol. 26, no. 5, pp. 681-710, 2009.

[98] T. Busch and A. Kirschning, "Recent advances in the total synthesis of pharmaceutically relevant diterpenes," Natural Product Reports, vol. 25, no. 2, pp. 318-341, 2008.

[99] J. R. Hanson, “Diterpenoids," Natural Product Reports, vol. 24, no. 6, pp. 1332-1341, 2007.

[100] R. A. Keyzers, P. T. Northcote, and M. T. Davies-Coleman, "Spongian diterpenoids from marine sponges," Natural Product Reports, vol. 23, no. 2, pp. 321-334, 2006.

[101] J. R. Hanson, "Diterpenoids," Natural Product Reports, vol. 22, no. 5, pp. 594-602, 2005.

[102] J. B. Hendrickson, "Molecular geometry. I. Machine computation of the common rings," Journal of the American Chemical Society, vol. 83, no. 22, pp. 4537-4547, 1961.

[103] J. B. Hendrickson, "Molecular geometry. II. Methylcyclohexanes and cycloheptanes," Journal of the American Chemical Society, vol. 84, no. 17, pp. 3355-3359, 1962.

[104] J. B. Hendrickson, "Sesquiterpenes-IV. Conformational analysis in the perhydroazulenic sesquiterpenes," Tetrahedron, vol. 19, no. 9, pp. 1387-1396, 1963.

[105] J. B. Hendrickson, "Molecular geometry. IV. The medium rings," Journal of the American Chemical Society, vol. 86, no. 22, pp. 4854-4866, 1964. 
[106] J. B. Hendrickson, "Molecular geometry. V. Evaluation of functions and conformations of medium rings," Journal of the American Chemical Society, vol. 89, no. 26, pp. 7036-7043, 1967.

[107] J. B. Hendrickson, "Molecular geometry. VI. Methyl-substituted cycloalkanes," Journal of the American Chemical Society, vol. 89, no. 26, pp. 7043-7046, 1967.

[108] J. B. Hendrickson, "Molecular geometry. VII. Modes of interconversion in the medium rings," Journal of the American Chemical Society, vol. 89, no. 26, pp. 7047-7061, 1967.

[109] J. B. Hendrickson, R. K. Boeckman, J. D. Glickson, and E. Grunwald, "Molecular geometry. VIII. Proton magnetic resonance studies of cycloheptane conformations," Journal of the American Chemical Society, vol. 95, no. 2, pp. 494-505, 1973.

[110] P. J. de Clercq, "Systematic conformational analysis. General method for rapid conformational evaluation. Its application to the hydroazulene system," The Journal of Organic Chemistry, vol. 46, no. 4, pp. 667-675, 1981.

[111] P. J. de Clercq, "Systematic conformational analysis. Torsion constraint evaluation in cyclic systems," Tetrahedron, vol. 37, no. 24, pp. 4277-4286, 1981.

[112] P. J. de Clercq, "Systematic conformational analysis. A microcomputer method for the semiquantitative evaluation of polycyclic systems containing five-, six- and seven-membered rings. 1. Program characteristics," Tetrahedron, vol. 40, no. 19, pp. 3717-3727, 1984.

[113] P. J. de Clercq, "Systematic conformational analysis. A microcomputer method for the semiquantitative evaluation of polycyclic systems containing five-, six- and seven-membered rings. 2. Scope and limitations," Tetrahedron, vol. 40, no. 19, pp. 3729-3738, 1984.

[114] J. Hoflack and P. J. de Clercq, "The sca program: an easy way for the conformational evaluation of polycyclic molecules," Tetrahedron, vol. 44, no. 21, pp. 6667-6676, 1988.

[115] P. J. de Clercq, "Systematic conformational analysis. General method for rapid conformational evaluation. Its application to the hydroazulene system," The Journal of Organic Chemistry, vol. 46, no. 4, pp. 667-675, 1981, Supplementary material and references cited therein.

[116] Z. Hassan, H. Hussain, V. U. Ahmad et al., "Absolute configuration of $1 \beta, 10 \beta$-epoxydesacetoxymatricarin isolated from Carthamus oxycantha by means of TDDFT CD calculations," Tetrahedron Asymmetry, vol. 18, no. 24, pp. 2905-2909, 2007.

[117] S. Bercion, T. Buffeteau, L. Lespade, and M. A. C. D. Martin, "IR, VCD, ${ }^{1} \mathrm{H}$ and ${ }^{13} \mathrm{C}$ NMR experimental and theoretical studies of a natural guaianolide: unambiguous determination of its absolute configuration," Journal of Molecular Structure, vol. 791, no. 1-3, pp. 186-192, 2006.

[118] F. A. Macías, V. M. I. Viñolo, F. R. Fronczek, G. M. Massanet, and J. M. G. Molinillo, "11,16 Oxetane lactones. Spectroscopic evidences and conformational analysis," Tetrahedron, vol. 62, no. 33, pp. 7747-7755, 2006.

[119] S. Milosavljevic, I. Juranic, V. Bulatovic et al., "Conformational analysis of guaianolide-type sesquiterpene lactones by low-temperature NMR spectroscopy and semiempirical calculations," Structural Chemistry, vol. 15, no. 3, pp. 237245, 2004.

[120] K. Schorr, A. J. García-Piñeres, B. Siedle, I. Merfort, and F. B. da Costa, "Guaianolides from Viguiera gardneri inhibit the transcription factor NF- $\kappa \mathrm{B}$," Phytochemistry, vol. 60 , no. 7, pp. 733-740, 2002.

[121] T. J. Schmidt, "Helenanolide type sesquiterpene lactones. Part 1. Conformations and molecular dynamics of helenalin, its esters and 11,13-dihydro derivatives," Journal of Molecular Structure, vol. 385, no. 2, pp. 99-112, 1996.

[122] T. J. Schmidt, F. R. Fronczek, and Y.-H. Liu, "Helenanolidetype sesquiterpene lactones. Part 2. The molecular conformations of arnifolin and some related helenanolides as determined by X-ray crystallographic and NMR spectroscopic analyses," Journal of Molecular Structure, vol. 385, no. 2, pp. 113-121, 1996.

[123] M. de Bernardi, L. Garlaschelli, L. Toma, G. Vidari, and P. Vita-Finzi, "The chemical basis of hot-tasting and yellowing of the mushrooms Lactarius chrysorrheus and L. scrobiculatus," Tetrahedron, vol. 49, no. 7, pp. 1489-1504, 1993.

[124] M. T. Scotti, M. B. Fernandes, M. J. P. Ferreira, and V. P. Emerenciano, "Quantitative structure-activity relationship of sesquiterpene lactones with cytotoxic activity," Bioorganic \& Medicinal Chemistry, vol. 15, no. 8, pp. 2927-2934, 2007.

[125] H. Matsuda, T. Kagerura, I. Toguchida, H. Ueda, T. Morikawa, and M. Yoshikawa, "Inhibitory effects of sesquiterpenes from bay leaf on nitric oxide production in lipopolysaccharide-activated macrophages: structure requirement and, role of heat shock protein induction," Life Sciences, vol. 66, no. 22, pp. 2151-2157, 2000.

[126] T. J. Schmidt, "Toxic activities of sesquiterpene lactones: structural and biochemical aspects," Current Organic Chemistry, vol. 3, no. 6, pp. 577-608, 1999.

[127] E. Rodriguez, G. H. N. Towers, and J. C. Mitchell, "Biological activities of sesquiterpene lactones," Phytochemistry, vol. 15, no. 11, pp. 1573-1580, 1976.

[128] S. M. Kupchan, M. A. Eakin, and A. M. Thomas, "Tumor inhibitors. 69. Structure-cytotoxicity relationships among the sesquiterpene lactones," Journal of Medicinal Chemistry, vol. 14, no. 12, pp. 1147-1152, 1971.

[129] R. L. Hanson, H. A. Lardy, and S. M. Kupchan, "Inhibition of phosphofructokinase by quinone methide and $\alpha$-methylene lactone tumor inhibitors," Science, vol. 168, no. 3929, pp. 378-380, 1970.

[130] S. M. Kupchan, D. C. Fessler, M. A. Eakin, and T. J. Giacobbe, "Reactions of alpha methylene lactone tumor inhibitors with model biological nucleophiles," Science, vol. 168, no. 3929, pp. 376-378, 1970.

[131] B. T. Zhuzbaev, S. M. Adekenov, and V. V. Veselovsky, "Approaches to the total synthesis of sesquiterpenoids of the guaiane series," Russian Chemical Reviews, vol. 64, no. 2, pp. 187-200, 1995

[132] C. H. Heathcock, C. M. Tice, and T. C. Germroth, "Synthesis of sesquiterpene antitumor lactones. 10. Total synthesis of ( \pm )-parthenin," Journal of the American Chemical Society, vol. 104, no. 22, pp. 6081-6091, 1982.

[133] C. H. Heathcock, E. G. DelMar, and S. L. Graham, "Synthesis of sesquiterpene antitumor lactones. 9. The hydronaphthalene route to pseudoguaianes. Total synthesis of $( \pm)$ confertin," Journal of the American Chemical Society, vol. 104, no. 7, pp. 1907-1917, 1982.

[134] P. de Clercq and M. Vandewalle, "Total synthesis of ( \pm )damsin," The Journal of Organic Chemistry, vol. 42, no. 21, pp. 3447-3450, 1977.

[135] J. A. Marshall and W. R. Snyder, "Total synthesis of ( \pm )4-deoxydamsin. Structure correlation of pseudoguaianolide sesquiterpenes," The Journal of Organic Chemistry, vol. 40, no. 11, pp. 1656-1659, 1975.

[136] J. H. Rigby and J. Z. Wilson, "Total synthesis of guaianolides: ( \pm )-dehydrocostus lactone and $( \pm)$-estafiatin," Journal of the American Chemical Society, vol. 106, no. 26, pp. 8217-8224, 1984. 
[137] T. J. Brocksom, U. Brocksom, and F. P. Barbosa, "The enantioselective synthesis of (R)-(+)-6-isopropenyl-3-methyl-2cycloheptenone," Journal of the Brazilian Chemical Society, vol. 17, no. 4, pp. 792-796, 2006.

[138] D. A. Foley and A. R. Maguire, "Synthetic approaches to bicyclo[5.3.0]decane sesquiterpenes," Tetrahedron, vol. 66, no. 6, pp. 1131-1175, 2010.

[139] J. Méndez-Andino and L. A. Paquette, "Tandem development of aqueous indium chemistry and ring-closing metathesis as a general route to fused-ring $\alpha$-methylene- $\gamma$-butyrolactones," Advanced Synthesis and Catalysis, vol. 344, no. 3-4, pp. 303$311,2002$.

[140] N. Petragnani, H. M. C. Ferraz, and G. V. J. Silva, "Advances in the synthesis of $\alpha$-methylenelactones," Synthesis, no. 3, pp. 157-183, 1986.

[141] H. M. R. Hoffmann and J. Rabe, "Synthesis and biological activity of $\alpha$-methylene- $\gamma$-butyrolactones," Angewandte Chemie International Edition in English, vol. 24, no. 2, pp. 94110, 1985.

[142] P. A. Grieco, "Methods for the synthesis of $\alpha$-methylene lactones," Synthesis, no. 2, pp. 67-82, 1975.

[143] R. B. Gammill, C. A. Wilson, and T. A. Bryson, "Synthesis of $\alpha$-methylene- $\gamma$-butyrolactones," Synthetic Communications, vol. 5, no. 4, pp. 245-268, 1975.

[144] M. Garcia, Study on the chemical reactivity of eremanthine, M.Sc. dissertation, NPPN, Universidade Federal do Rio de Janeiro, Rio de Janeiro, Brazil, 1975.

[145] A. J. R. da Silva, Techniques of nuclear magnetic resonance applied to the study of some sesquiterpenes, M.Sc. dissertation, NPPN, Universidade Federal do Rio de Janeiro, Rio de Janeiro, Brazil, 1976.

[146] F. W. L. Machado, Structural modifications of isoeremanthine. Synthesis of eregoyazin and eregoyazidin, M.Sc. dissertation, NPPN, Universidade Federal do Rio de Janeiro, Rio de Janeiro, Brazil, 1977.

[147] L. A. Maçaira, Structural modifications of eremanthine. Synthesis of dehydrocostus lactone and estafiatin, M.Sc. dissertation, NPPN, Universidade Federal do Rio de Janeiro, Rio de Janeiro, Brazil, 1978.

[148] A. A. S. Rodrigues, Biomimetic transformations of costunolide and eremanthine, M.Sc. dissertation, NPPN, Universidade Federal do Rio de Janeiro, Rio de Janeiro, Brazil, 1979.

[149] P. D. D. B. Lima, Development of a new specific method for the isolation of $\alpha$-methylene lactones. Reinvestigation of Vanillosmopsis erythropappa Sch. Bip., M.Sc. dissertation, NPPN, Universidade Federal do Rio de Janeiro, Rio de Janeiro, Brazil, 1983.

[150] J. C. F. Alves, Inversion of the lactonic fusion on eremanthine derivatives and synthesis of micheliolide, M.Sc. dissertation, Universidade Federal Rural do Rio de Janeiro, Rio de Janeiro, Brazil, 1993.

[151] L. A. Maçaira, M. Garcia, and J. A. Rabi, "Chemical transformations of abundant natural products. 3. Modifications of eremanthin leading to other naturally occurring guaianolides," The Journal of Organic Chemistry, vol. 42, no. 26, pp. 4207-4209, 1977.

[152] S. B. Mathur, S. V. Hiremath, G. H. Kulkarni et al., "Terpenoids-LXX. Structure of dehydrocostus lactone," Tetrahedron, vol. 21, no. 12, pp. 3575-3590, 1965.

[153] W. Vichnewski, F. W. L. Machado, J. A. Rabi, R. Murari, and W. Herz, "Eregoyazin and eregoyazidin, two new guaianolides from Eremanthus goyazensis," The Journal of Organic Chemistry, vol. 42, no. 24, pp. 3910-3913, 1977.
[154] J. A. Rabi, M. Garcia, L. A. Maçaira, and F. W. L. Machado, "Chemical transformations of eremanthine: a way for the synthesis of cercareacide agents," Anais da Academia Brasileira de Ciências, vol. 49, no. 4, pp. 563-565, 1977.

[155] F. Sánchez-Viesca and J. Romo, "Estafiatin, a new sesquiterpene lactone isolated from Artemisia mexicana (Willd)," Tetrahedron, vol. 19, no. 8, pp. 1285-1291, 1963.

[156] L. A. Maçaira, F. W. L. Machado, M. Garcia, and J. A. Rabi, "Unambiguous transformation of eremanthin into (-)-estafiatin," Tetrahedron Letters, vol. 21, no. 9, pp. 773-776, 1980.

[157] M. Garcia, F. W. L. Machado, L. A. Maçaira, and J. A. Rabi, "The reaction of eremanthin and isoeremanthin with bromine. Unprecedented simultaneous addition of $\mathrm{Br}_{2}$ to two isolated but topographically related double bonds," Tetrahedron Letters, vol. 21, no. 9, pp. 777-780, 1980.

[158] A. J. R. da Silva, M. Garcia, P. M. Baker, and J. A. Rabi, " ${ }^{13} \mathrm{C}$ NMR spectra of natural products. 1-guaianolides," Organic Magnetic Resonance, vol. 16, no. 3, pp. 230-233, 1981.

[159] E. C. Fantini and J. A. Rabi, "Methoxyl group as protector of $\alpha$-methylene- $\gamma$-lactones," Ciência e Cultura, vol. 35, no. 7, suplemento, p. 403 (49-D.2.3), 1983.

[160] E. C. Fantini and J. A. Rabi, "Synthesis of 6-epi-eremanthine," Ciência e Cultura, vol. 37, no. 7, suplemento, p. 417 (27D.2.3), 1985.

[161] J. L. P. Ferreira, E. C. Fantini, and J. A. Rabi, "Participation of neighboring-group on the methanolysis of $\alpha$-methylene$\gamma$-lactones derived from eremanthine," Ciência e Cultura, vol. 35, no. 7, suplemento, p. 403 (48-D.2.3), 1983.

[162] E. C. Fantini, J. L. P. Ferreira, and J. A. Rabi, "Participation of neighboring-groups on the methanolysis of $\alpha$-methylene$\gamma$-lactones derived from eremanthine. II-Reaction conditions and structural requirements," Ciência e Cultura, vol. 36, no. 7, suplemento, p. 487 (73-D.2.3), 1984.

[163] E. C. Fantini, J. L. P. Ferreira, and J. A. Rabi, "Metal ion promoted methanolysis of sesquiterpene lactones leading to $O^{6,15}$-cycloguaiane methyl esters," Journal of Chemical Research (Synopses), no. 8, pp. 298-299, 1986.

[164] E. C. Fantini and J. A. Rabi, "Elimination versus formation of 15,6- $\alpha$-oxidos on 4 - $\alpha$-hydroxy-15-iodine derived from eremanthine," Ciência e Cultura, vol. 38, no. 7, suplemento, p. 521 (55-D.2.3), 1986.

[165] M. Ogura, G. A. Cordell, and N. R. Farnsworth, "Anticancer sesquiterpene lactones of Michelia compressa (magnoliaceae)," Phytochemistry, vol. 17, no. 5, pp. 957-961, 1978.

[166] J. C. F. Alves, J. A. Rabi, and E. C. Fantini, "Trans-cis inversion of the lactonic fusion on eremanthine derivatives. I-preliminary studies," in Abstracts of the 14a Reunião Anual da Sociedade Brasileira de Química, (IC-32), Caxambu, Brazil, 1991.

[167] J. C. F. Alves and E. C. Fantini, "Trans-cis inversion of the lactonic fusion on eremanthine derivatives. II-study with substrates bearing double bonds at the positions 1,10;3,4 and 9,10; 1,10 and 4,15," in Abstracts of the 16a Reunião Anual da Sociedade Brasileira de Química, (QO-24), Caxambu, Brazil, 1993.

[168] J. C. F. Alves and E. C. Fantini, "Chemical transformations of eremanthine. Synthesis of micheliolide and 1(R),10(R)dihydromicheliolide," Journal of the Brazilian Chemical Society, vol. 16, no. 4, pp. 749-755, 2005.

[169] J. C. F. Alves and E. C. Fantini, "Erratum: Chemical transformations of eremanthine: Synthesis of micheliolide and 1(R),10(R)-dihydromicheliolide," Journal of the Brazilian Chemical Society, vol. 21, no. 5, p. 946, 2010. 
[170] J. C. F. Alves and E. C. Fantini, "Study of the inversion reaction of the lactonic fusion on eremanthine derivatives," Journal of the Brazilian Chemical Society, vol. 18, no. 3, pp. 643-664, 2007.

[171] J. C. F. Alves, "Study of catalytic hydrogenation and methanol addition to $\alpha$-methylene- $\gamma$-lactone of eremanthine derivatives," Organic Chemistry International, vol. 2010, Article ID 603436, 11 pages, 2010.

[172] H. Deshayes, J. P. Pete, C. Portella, and D. Scholler, "Photolysis of carboxylic esters: conversion of alcohols into alkanes," Journal of the Chemical Society, Chemical Communications, no. 11, pp. 439-440, 1975.

[173] R. K. Crossland and K. L. Servis, "A facile synthesis of methanesulfonate esters," The Journal of Organic Chemistry, vol. 35, no. 9, pp. 3195-3196, 1970.

[174] R. O. Hutchins, D. Kandasamy, C. A. Maryanoff, D. Masilamani, and B. E. Maryanoff, "Selective reductive displacement of alkyl halides and sulfonate esters with cyanoborohydride reagents in hexamethylphosphoramide," The Journal of Organic Chemistry, vol. 42, no. 1, pp. 82-91, 1977.

[175] J. March, Advanced Organic Chemistry, John Wiley \& Sons, New York, NY, USA, 3rd edition, 1985.

[176] H. O. House, Modern Synthetic Reactions, W. A. Benjamin, Menlo Park, California, USA, 2nd edition, 1972.

[177] J. C. F. Alves would like to explain that the incorrectness previously committed in the writing of works about chemical transformations of eremanthine [150, 166-167] were, whenever possible, corrected and revised in works published on this decade [168-170]. 


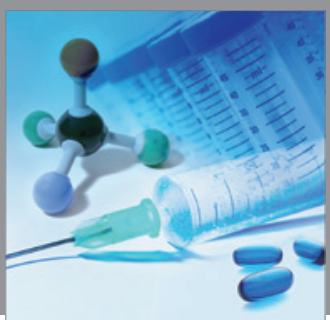

International Journal of

Medicinal Chemistry

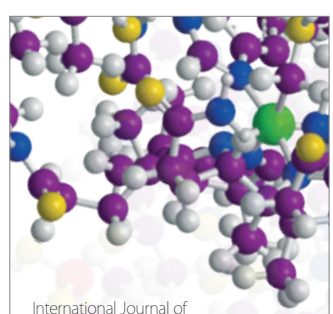

Carbohydrate Chemistry

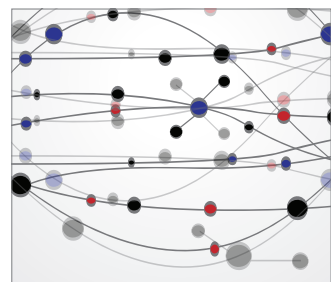

The Scientific World Journal
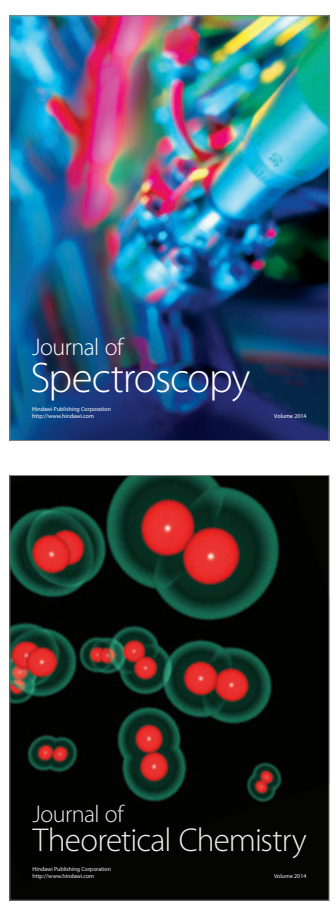
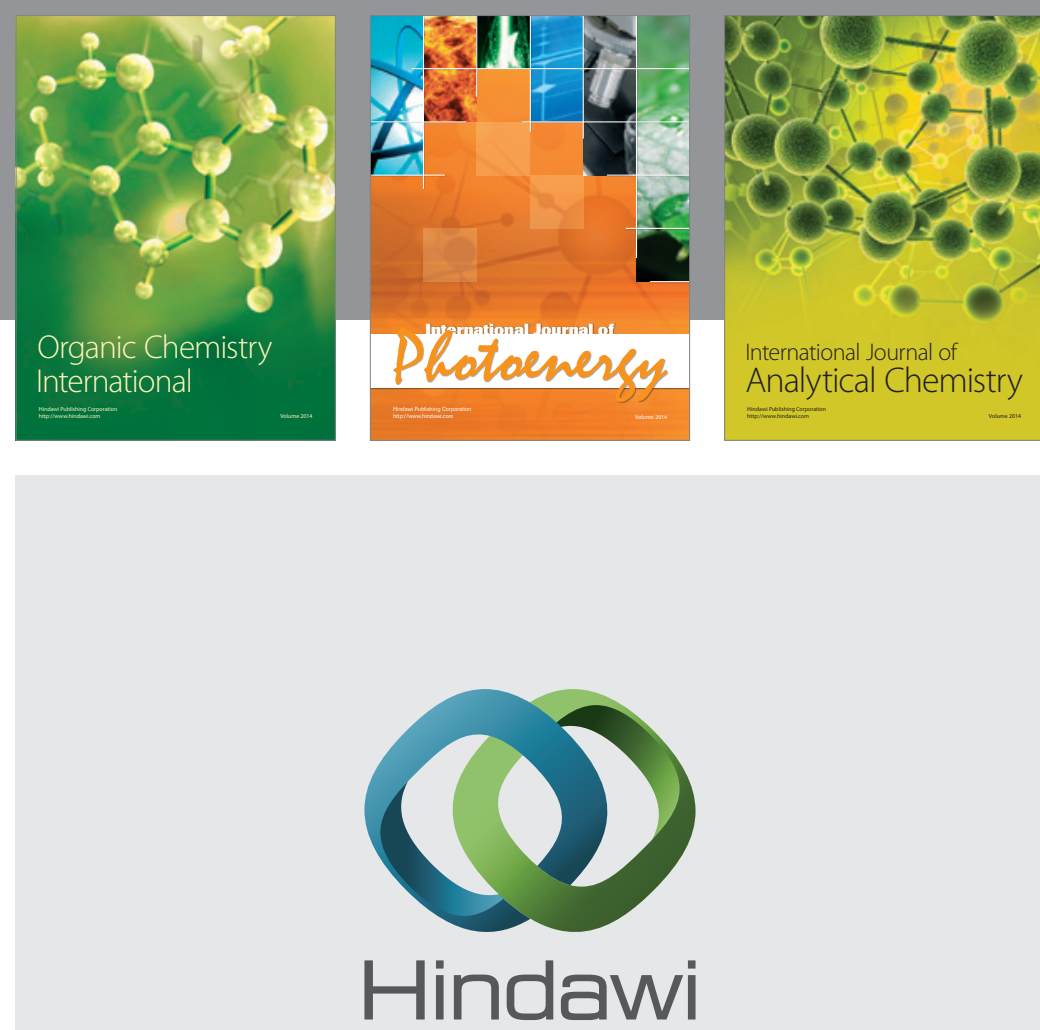

Submit your manuscripts at

http://www.hindawi.com
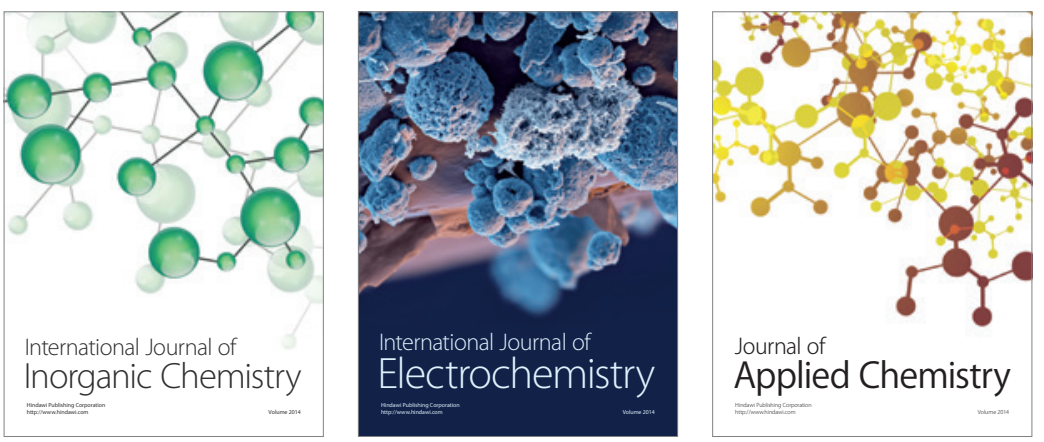

Journal of

Applied Chemistry
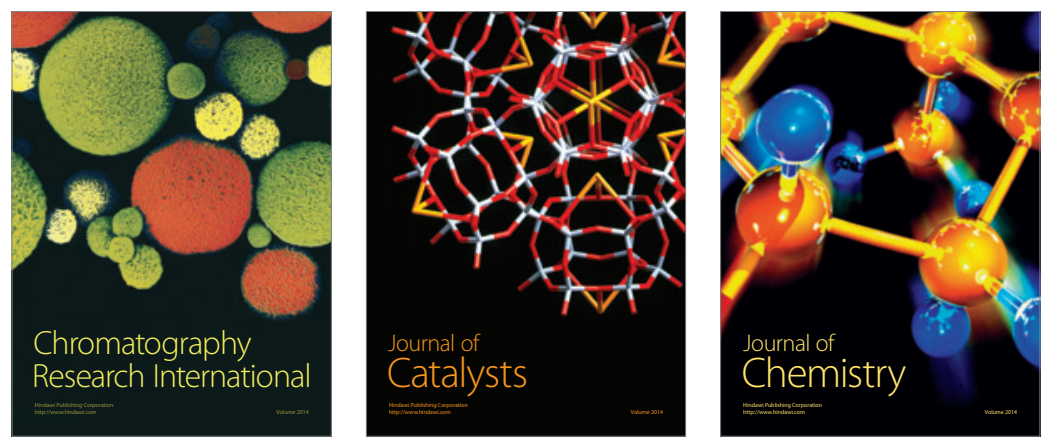
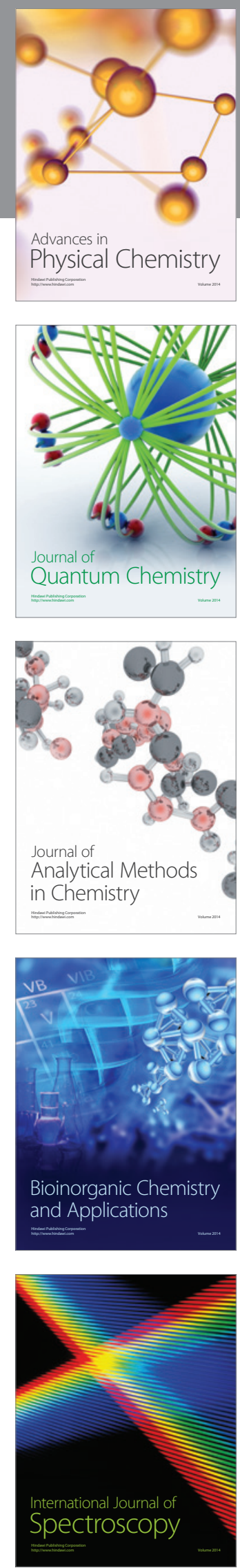